\title{
CHEMICAL STOCKPILE DISPOSAL PROGRAM RAPID ACCIDENT ASSESSMENT
}

\author{
C. V. Chester \\ Date Published: August 1990 \\ Prepared for \\ Program Manager for \\ Chemical Demilitarization \\ Aberdeen Proving Ground, Maryland 21010 \\ Interagency Agreement No. 1769-1354-A-1
}

\author{
prepared by \\ Oak Ridge National Laboratory \\ Oak Ridge, Tennessee 37831 \\ MARTIN MARIETTA ENERGY SYSTEMS, INC. \\ for the \\ U.S. DEPARTMENT OF ENERGY \\ under \\ Contract No. DE-AC05-84OR21400
}


TABLE OF CONTENTS

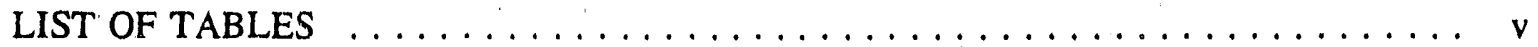

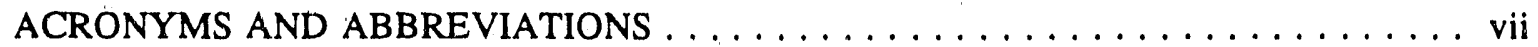
ABSTRACT $\ldots \ldots \ldots \ldots \ldots \ldots \ldots \ldots \ldots \ldots \ldots \ldots \ldots \ldots$ ix

1. INTRODUCTION AND SUMMARY $\ldots \ldots \ldots \ldots \ldots \ldots \ldots \ldots \ldots \ldots$

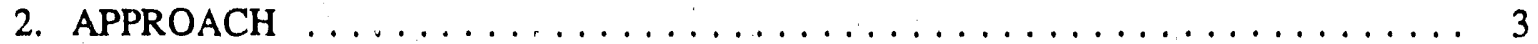

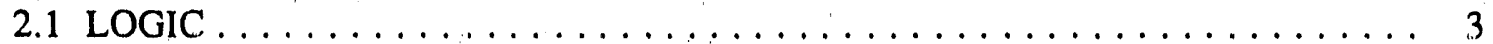

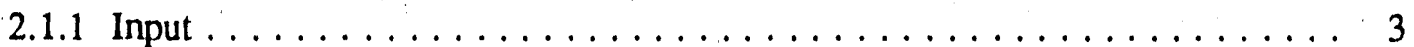

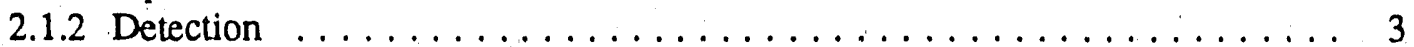

2.1 .3 Identification $\ldots \ldots \ldots \ldots \ldots \ldots \ldots \ldots \ldots \ldots \ldots \ldots \ldots \ldots$

2.1 .4 Estimated Release $\ldots \ldots \ldots \ldots \ldots \ldots \ldots \ldots \ldots \ldots \ldots \ldots \ldots$

2.1.5 Estimated Consequences . . . . . . . . . . . . . . . . . . . 4

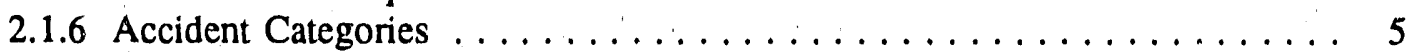

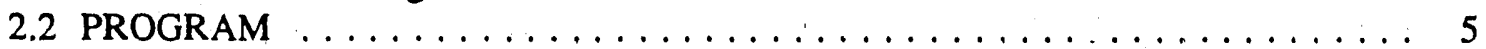

3. USE OF RISK-ANALYSIS DATA $\ldots \ldots \ldots \ldots \ldots \ldots \ldots \ldots \ldots \ldots \ldots \ldots$

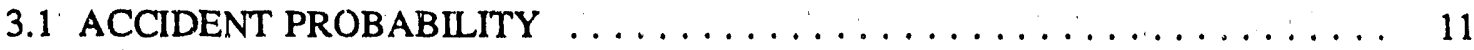

3.2 ACCIDENT LOCATION TABLES $\ldots \ldots \ldots \ldots \ldots \ldots \ldots \ldots \ldots \ldots \ldots$

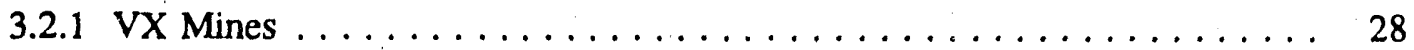

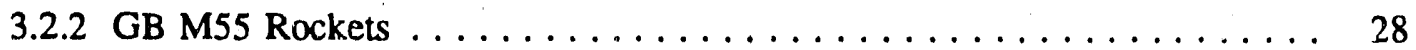

3.2 .3 VX M55 Rockets . . . . . . . . . . . . . . . . . . . . 29

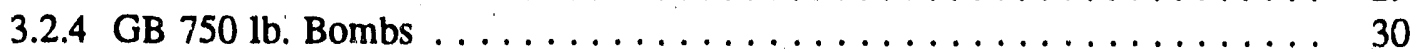

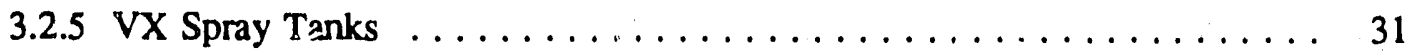

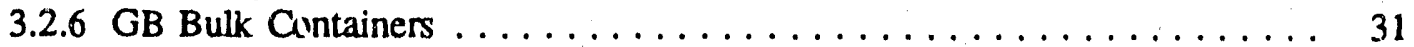

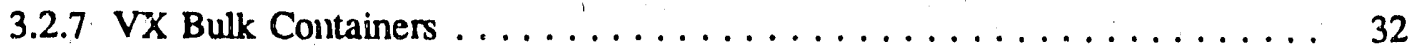

$3.2 .8 \mathrm{H}, \mathrm{HD}$, and HT Bulk Containers $\ldots \ldots \ldots \ldots \ldots \ldots \ldots \ldots \ldots \ldots$

3.2.9 H, HD, and HT 4.2-in. Mortar Projectiles . . . . . . . . . . . . . 33

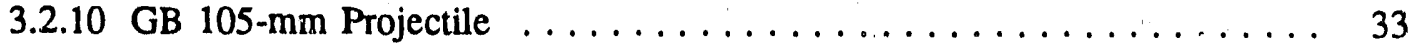

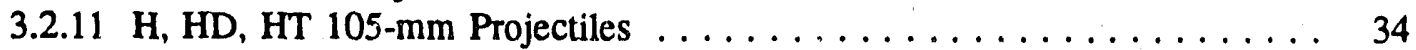

3.2 .12 GB $155-\mathrm{mm}$ Projectiles ..................... 34

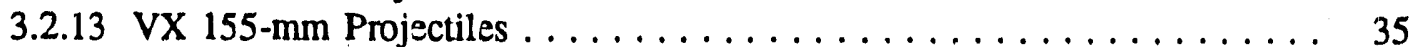

3.2.14 H, HD, HT 155-mm Projectiles ................. 35

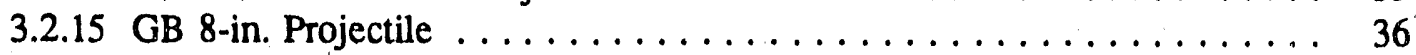

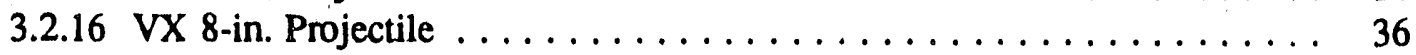

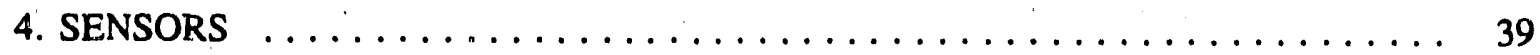

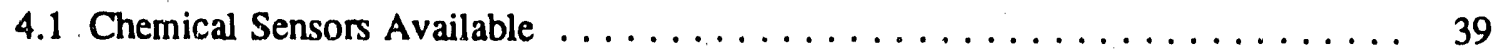

4.2 Remote Sensing Systems . . . . . . . . . . . . . . . . . . . 39

5. CONCLUSIONS $\ldots \ldots \ldots \ldots \ldots \ldots \ldots \ldots \ldots \ldots \ldots \ldots \ldots \ldots \ldots$

REFERENCES $\ldots \ldots \ldots \ldots \ldots \ldots \ldots \ldots \ldots \ldots \ldots \ldots \ldots \ldots \ldots \ldots \ldots \ldots$

APPENDICES $\ldots \ldots \ldots \ldots \ldots \ldots \ldots \ldots \ldots \ldots \ldots \ldots \ldots \ldots \ldots \ldots$ 


\section{LIST OF TABLES}

2.2.1. Examples of chemical occurrence . . . . . . . . . . . . . 8

2.2.2. Example of accidents evoking an advisory $\ldots \ldots \ldots \ldots \ldots \ldots \ldots \ldots \ldots$

2.2.3. Example of accidents evoking on-post emergency $\ldots \ldots \ldots \ldots \ldots \ldots \ldots$

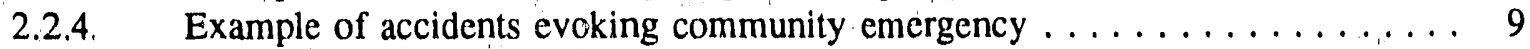

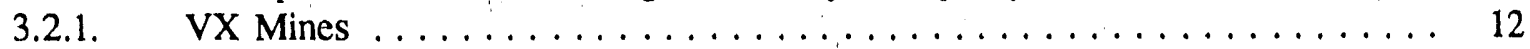

3.2.2. GB M55 Rockets ........................ 13

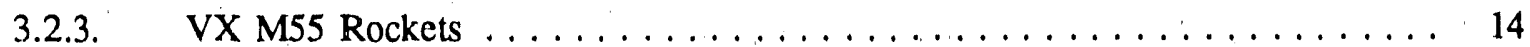

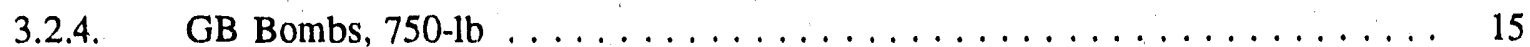

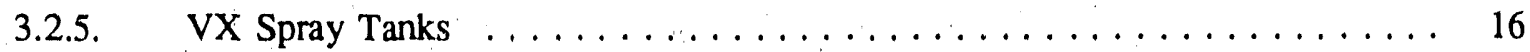

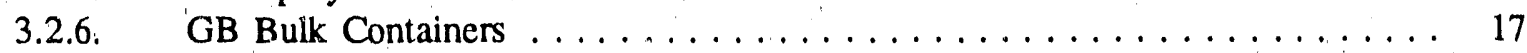

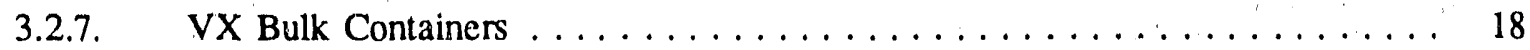

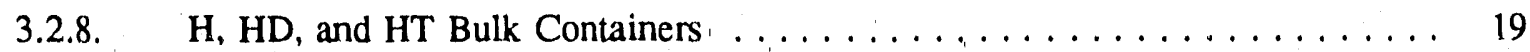

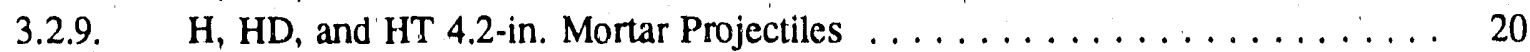

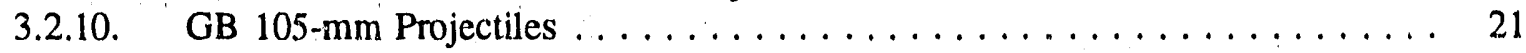

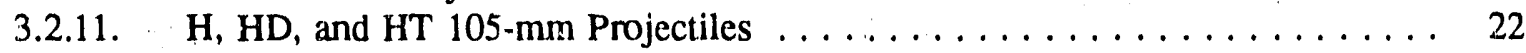

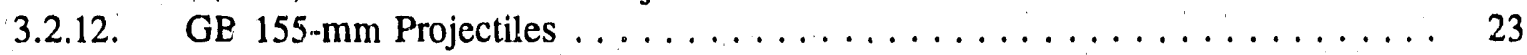

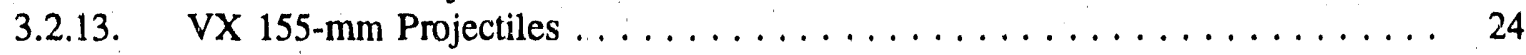

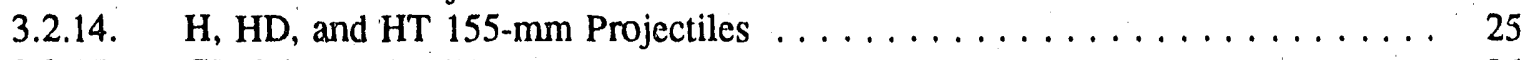

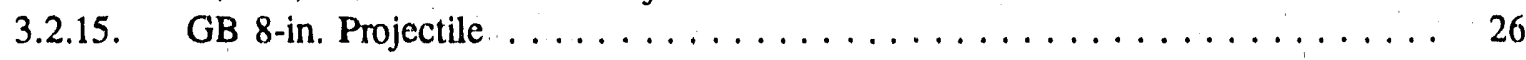

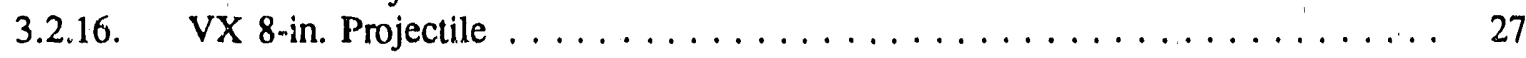




\section{ACRONYMS AND ABBREVIATIONS}

$\begin{array}{ll}\text { AAS } & \text { accident assessment system } \\ \text { ACAMS } & \text { automatic continuous air monitoring system } \\ \text { ANAD } & \text { Anniston Amy Depot } \\ \text { APG } & \text { Aberdeen Proving Ground } \\ \text { A/C Crash } & \text { aircraft crash } \\ \text { CHB } & \text { container-handling building } \\ \text { CONUS } & \text { Continental United States } \\ \text { CSDP } & \text { Chemical Stockpile Disposal Program } \\ \text { DAAMS } & \text { depot area air monitoring system } \\ \text { DFS } & \text { deactivation fumace system } \\ \text { Dropped } & \text { dropped munition } \\ \text { DUN } & \text { dunnage incinerator } \\ \text { EQK } & \text { earthquake } \\ \text { ECV } & \text { explosion containment vestibule } \\ \text { ECR } & \text { explosion containment room } \\ \text { EIS } & \text { environmental impact statement } \\ \text { EOC } & \text { Emergency Operations Center } \\ \text { FEMA } & \text { Federal Emergency Management Agency } \\ \text { FKl } & \text { forklift } \\ \text { AP } & \text { differential pressure } \\ \text { HF } & \text { handling operation at the facility } \\ \text { HO } & \text { handling operation related to on-site transportation } \\ \text { JACADS } & \text { Johnston Atoll Chemical Agent Disposal System } \\ \text { LBAD } & \text { Lexington-Bluegrass Amy Depot } \\ \text { LIC } & \text { liquid incinerator } \\ \text { MDB } & \text { Munitions Demilitarization Building } \\ \text { MHI } & \text { munitions holding igloo } \\ \text { MPF } & \text { metal parts furmace } \\ \text { NA } & \text { not applicable } \\ \text { ONC } & \text { on-site transport container } \\ \text { ORNL } & \text { Oak Ridge Natiunal Laboratory } \\ \text { PAS } & \text { Pollution abatement system } \\ \text { PBA } & \text { Pine Bluff Arsenal } \\ \text { PRA } & \text { probabilistic risk assessment } \\ \text { PUDA } & \text { Pueblo Depot Activity } \\ \text { TEAD } & \text { Tooele Amy Depot } \\ \text { TMI } & \text { Three Mile Island } \\ \text { TOX } & \text { toxic cubicle } \\ \text { UMDA } & \text { Umatilla Depot Activity } \\ \text { UPA } & \text { unpack area } \\ \text { WC } & \text { worst case } \\ & \end{array}$




\begin{abstract}
This report develops a scheme for the rapid assessment of a release of toxic chemicals resulting from an accident in one of the chemical weapon demilitarization plants or storage areas. The system uses such inputs as chemical and pressure sensors monitoring the plant and reports of accidents radioed to the Emergency Operations Center by work parties or monitoring personnel. A size of release can be estimated from previous calculations done in the risk analysis, from back calculation from an open-air chemical sensor measurement, or from an estimated percentage of the inventory of agent at the location of the release. Potential consequences of the estimated release are calculated from real-time meteorological data, surrounding population data, and properties of the agent. In addition to the estimated casualties, area coverage and no-death contours vs time would be calculated. Accidents are assigned to one of four categories: community emergencies, which involve a threat to off-site personnel; on-post emergencies, which involve a threat only to on-site personnel; advisory, which involves a potential for threat to on-site personnel; and chemical occurrence, which can produce an abnormal operating condition for the plant but no immediate threat to on-site personnel.
\end{abstract}




\section{INTRODUCTION AND SUMMARY}

This work is a continuation of work begun in 1984 when the Oak Ridge National Laboratory undertook to develop the final Project Environmental Impact Statement for the Chemical Stockpile Disposal Program (CSDP) (PEO-PMCD 1988). This is one of the technical support studies done in conjunction with and as an input to the emergency planning program being undertaken under the U.S. Federal Emergency Management Agency (FEMA)-U.S. Department of the Army Memorandum of Understanding.

At several of the disposal-plant sites, civilians live or work within a few kilometers of the proposed locations and existing storage areas. Under some meteorological conditions, credible accidental releases could disperse dangerous concentrations of agent aerosol or vapor off post within a few minutes. If people in the area are to respond effectively to potential emergencies, a waming system and accident-assessment system (AAS) with a very fast response time must be installed. This study is concemed primarily with accident assessment and consequence evaluation. Warning is the subject of another study (Sorensen 1988), as is protective action (Rogers et al. 1990). The design goal for response time of the AAS phase is $5 \mathrm{~min}$.

1. theory, all possible accidents were considered in the risk analysis (PEO-PMCD 1987), but many small accidents were omitted because they would not produce dangerous concentrations of agent off-site under worst-case meteorological conditions or because the probability of the accident was less than $10^{-8}$ per year. One of the tasks confronting any AAS is correctly identifying these high-probability, low-consequence accidents as low-consequence accidents not requiring an off-site emergency response. Likewise, some skepticism is warranted on the low probability calculated for some accidents. For example, the catastrophes at Bhopal, Three-Mile Island (TMI), and Chemobyl were not predicted but were the result of concatenations of highly improbable human errors, exacerbated at TMI by equipment failures and at Bhopal by deliberate sabotage (Kalelkar 1988).

The objective of this study is to devise a scheme for the rapid assessment of an accident that would release chemical agent during chemical-weapons-stockpile-disposal operations at any of the eight sites planned in the continental United States (CONUS). Inputs to the assessment would include

- the type of agent and munition being processed;

- the output and location of chemical, pressure, and temperature sensors both outside and inside the Munition Demilitarization Building (MDB), including process instrumentation and fire detectors;

- periodically (5-15 min) updated meteorological measurements, including stability asse'ssments; and

- prompt radio or telephone reports of any accidents/incidents and their locations from work, surveillance, or escort parties in the field.

The magnitude of a release would be estimated by one of three methods:

- back calculating plume size from a concentration-time measurement by an open-air chemical sensor, measured meteorological conditions, and the relative location of the sensor and point of release; 
- using the release estimated in the risk analysis if it can be determined that the accident is one of those analyzed in the risk analysis;

- estimating the inventory of agent involved from the location and nature of the accident and by estimating the fraction airbome from experiments with similar agents in similar accident scenarios.

The no-deaths contours would be calculated from the estimated amount of release and from meteorological conditions. Potential casualties would be calculated from populationdistribution data.

On the basis of the inputs and calculations, the accident/incident would be assigned to one of four categories:

- Community emergency: involves a release for which the "timated no-deaths contours include off-post personnel.

- On-post emiergency: occurs if the no-deaths contour covers normally unmasked personnel on post but the release does not travel off post.

- Advisory condition: occurs if there is no release but if an abnonnal condition exists that substantially increases the potential for a release that can threaten personnel.

- Chemical occurrence: involves an unplanned occurrence of abnormal operation or an abnormal condition at the post that does not immediately threaten the lives or safety of personnel.

A 5-min assessment time appears to be achievable if

- the Emergency Operations Center (EOC) or other assessment facility is manned and operating when the incident orcurs,

- personnel at the accident site are able to communicate directly with the EOC,

- meteorological data are being collected and stability conditions are being calculated,

- a computer program that supports the assessment is operating. 


\section{APPROACH}

The philosophy was to emphasize simplicity in the scheme. Rather than attempting to apply an expert system or some other more general artificial-intelligence software, a simple decision tree tailored to the problem was developed. Where possible, inputs and outputs were grouped to reduce the number of logic steps in the analysis. Emphasis is on the accidents identified in the risk analysis, although the proposed system recognized the potential for occurrences not identified in the Probabilistic Risk Analysis.

\subsection{LOGIC}

The steps in the assessment are to (1) detect the accident from sensors or field reports, (2) identify the accident from the munitions being processed and the location of the accident. (3) estimate the release size by ore of three methods, (4) calculate the consequences of the accident in terms of population exposed, and (5) decide which of the four categories the accident falls in for emergency response.

\subsubsection{Input}

Real-time inputs consist of radio reports of abnormal situations from monitoring and work parties, sensor readings of abnormal circumstances and their locations, and frequently updated measurements of wind speed, direction, and atmospheric stability. Data that change more slowly include the population distribution and density around the site, the flow sheets of the demilitarization process, the planned inventories for each agent, and the munitic and identity of the agent and munition currently being processed. To meet the requirement of a 5-min response time for accident assessment, chemical sensors must respond in 1 or 2 min and be connected to an alarm and readout in the EOC. The improved automatic continuous air monitoring system (ACAMS) would be suitable, but depot area air monitoring system (DAAMS) would not. Field personrel, such as escort or monitoring personnel in a position to report releases or accidents, must have direct communication with the EOC.

\subsubsection{Detection}

An accident outside the MDB is most likely to be detected by field personnel reporting by radio or by sensors with readouts and alanns in the on-post EOC. People or monitors reporting an accident occurrence would report its location. Exceptions would include the detection of an airbome agent by an outside sensor. Location of the point of release would have to be determined by back-calculating the trajectory of the cloud from meteorological information.

\subsubsection{Identification}

In general, the nature of an accident can be identified from its location in the demilitarization process, as specified in the process flow sheet (see Appendix A) for the munitions being processed (Sect. 3). The munitions and the agent under process are known from the operations plan. In some cases differentiation between two or more possible 
accidents at a given location would have to be made by referring to sensor reports or reports by personnel at the scene.

\subsubsection{Estimated Release}

Three different methods (depending on avallable information) are used to estimate the quantity of agent released for any given accident. If the accident is one of those listed in the risk analysis, the amount released by that accident is estimated in the analysis and can be used in subsequent calculations. The amount released can subsequently be revised as more information regarding the accident becomes available.

Potentially, the most accurate estimation of release can be made from a real-time concentration-time reading by one or more outdoor chemical sensors; from the known distance and direction from a known site of a release, as determined by the locations of each sensor, and from the site of the release and meteorology. The size of the release can then be backcalculated from meteorological information. This method is only as accurate as the plume models used to predict downwind concentrations. A program to do this has been developed by the DuPont Company and is incorporated in its SAFERC ${ }^{*}$ system (Whiteside 1989). However, estimating by this technique would be the exception iather than the rule because of the scarcity of sensors measuring coricentration vs time.

The third and prubably the most likely method of estimating the release is by estimating the inventory of the agent involved in the accident. This could be a single munition, a pallet, an on-site container, a truckload or room inventory in the MDB, or a building or bunker inventory, depending on the nature of the accident. Information on the extent of the accident would be radioed from on-site personnel to the EOC. With the inventory, the fraction airborne can be estimated by percentages, which are estimated in the risk analysis for the nature of the accident (explosion, fire, spill, etc.).

Detection of an accident by an outside point sensor would be unusual, because most of the sensors currently deployed outside do not provide real-time concentration readings; they are generally for historical record. Real-time sensors are available but are expensive to purchase and maintain. If located close to the sites of all potential accidents, the sensors still have a good chance of being missed by the plume from an accident because the plume may be narrow at its source or may be carried over the sensors by heat from an associated explosion or fire.

\subsubsection{Estimated Consequences}

Given the results of one of the three methods of estimating the release and meteorological data exposure as a function of time can be calculated for any downwind distance providing contours of exposure at varying levels. If the estimated no-deaths contours extend heyond the site boundary and into civilian population, then an off-post emergency would be declared. A variety of computer programs will do the meteorological calculations, plume contours, and casualty estimates, given the location and data on surrounding populations; D2PC is such a program. The location and extent of expected casualties would provide the basis of recommended emergency response.

\footnotetext{
"Copyright 1989 by EI DuPont de Nemours Co.
} 


\subsubsection{Accident Categories}

In similarity with nuclear accidents, four categories are proposed: community emergency, on-post emergency, advisory, and chemical occurrence (Schneider 1989).

A chemical occurrence is an unplanned, unscheduled occurrence of abnormal operation or abnormal condition of the plant that does not pose any immediate threat to the safety of the personnel. An advisory is an unusual condition or occurrence; it does hold a potential threat to the safety of personnel or the plant. On notification of an advisory, plant personnel would be expected to locate their gas masks. An on-post emergency would be declared in the event of the release of an agent out of controlled spaces in a quantity that can threaten the safety of plant personnel or a condition posing an imminent threat of such release. A community emergency is one in which the safety of off-site personnel is threatened by the release of an agent in quantities that can produce agent exposures off-site greater than the no-deaths criterion or that have the potential to do so.

\subsection{PROGRAM}

A program to classify accidents and provide an early estimate of their consequences is shown in Fig. 1. The required data inputs of the program are shown at the top of the page. They have been briefly discussed previously. The individual operations in the program are shown in the boxes, also discussed previously. Branch points or decision points in the program are shown in the diamonds.

The program would be initiated by an abnormal sensor reading or a radioed report of an accident or abnormal condition from field personnel. Sensor readings could indicate loss of negative pressure in the toxic handling areas of the MDB; reading of a stationary chemical sensor, installed to send its output back to the EOC; or smoke detectors or fire detectors designed to alarm the EOC. Radio reports could include those of a fire and its location, an explosion and its location, or a spill or leak and its location. Radio reports could also include damage from an aircraft crash, a vehicle collision, a drop of a munition pallet or on-site container, or other mechanical accidents. In general, the detection of the accident also will identify its location. Exceptions to this might be (1) the explosion in one storage igloo in a storage area at night or (2) the detection of an agent cloud by a chemical sensor.

The identity of the agent and munition would be known for accidents occurring at the demilitarization plant site; the munition being processed would be identified by the operations plan. Identification of the munitions involved in the explosion of one munitions igloo in a remote area of the storage area could, in general, not be done until the igloo is identified.

If real-time chemical sensors are part of the suite of monitoring instruments, they would be interrogated early in the analysis of an accident. Positive readings on one or more sensors would initiate a subroutine to back-calculate, using current meteorological data and possible trajectories of the material affecting the sensor. This hopefully will identify the accident's source. If the source can be determined and concentration-time information is obtained from the sensor(s), the size of the release can be back-calculated from the sensor and source positions and meteorological data, which are tracked and recorded in real time by the meteorological instrumentation system. The release thus calculated would be used as input to the module which would calculate the dose contours and potential population exposed.

If there is not an external chemical sensor reading or if the source of the reading cannot be determined, then the program would default to trying to identify the accident, as described in the risk analysis. With knowiedge of the munition and agent, reference should be made to 1 of the 16 "flow sheets" prepared for each of the agent-munition combinations which list the 
RAPID ACCIDENT ASSESSMENT

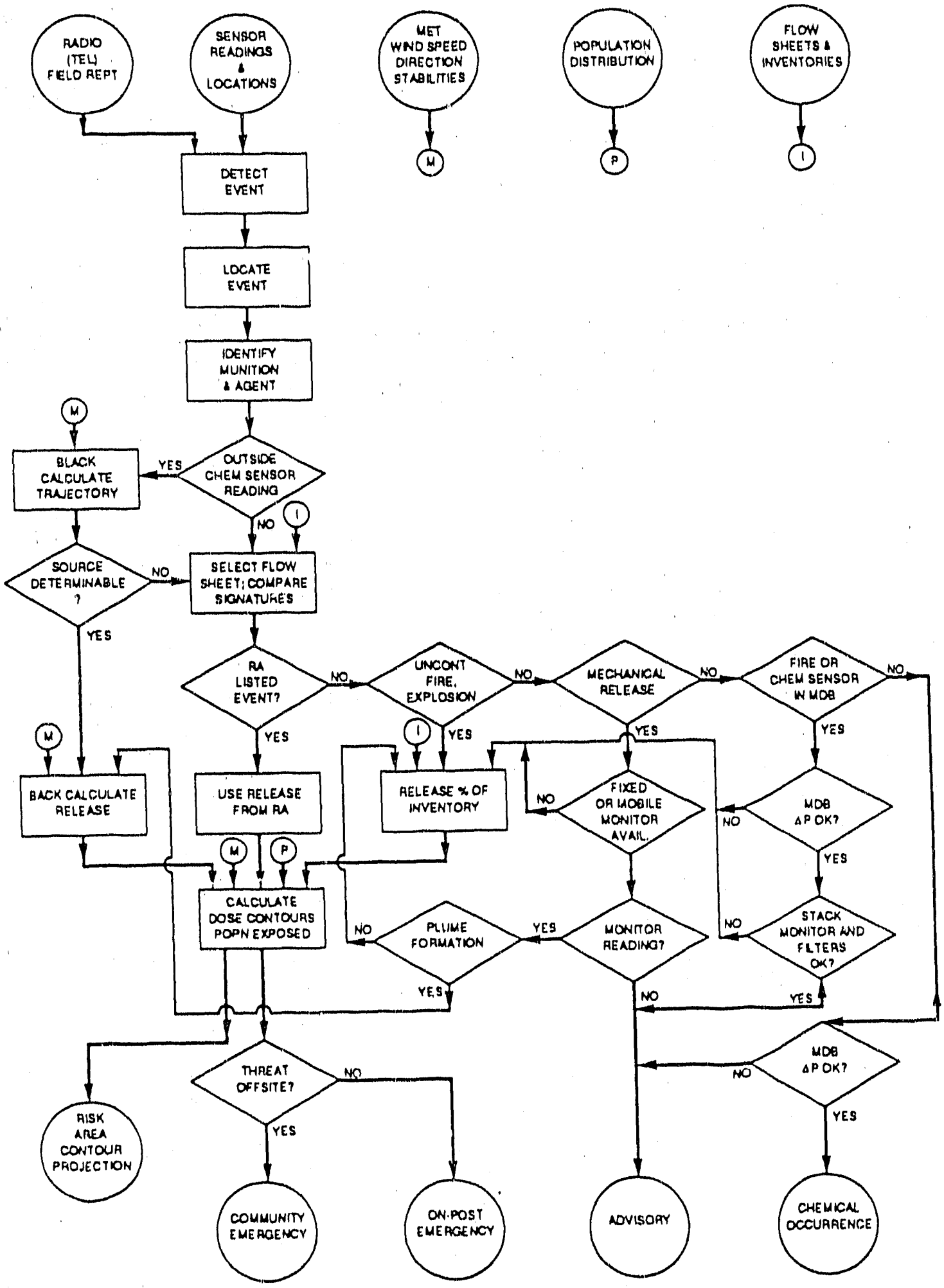

Fig. 1. Rapid accident assessment. 
processing steps for that combination and the accidents identified in the risk analysis with each step in the process (Sect. 3). In general, if there is one or more accidents associated with a given step in the process, other information about the accident (such as the presence or absence of fire, explosion, earthquakes, plane crashes, chemical sensor reading, and pressure sensor reading) will unambiguously identify the accident or reduce it to one of a small set, with roughly the same consequences. Once the specific accident is identified, the prediction of the release expected from the accident can be obtained from the risk analysis. The prediction obtained becomes the input to the calculation of exposure contours and population exposed.

If the event cannot be found on the flow sheets with the risk analysis accidents, then the logic branches to a side program. The first step is to determine, from sensors or radioed reports of field personnel, if there is an uncontained fire or explosion. If there is a fire or explosion, the inventory of agent involved in the area is extimated from either field personnel input, truck capacity, or operating plans. From the inventc $y$ and the nature of the accident, the percentage released (assumed in the risk analysis for that type of accident) and the quantity released can be determined. A chemical sensor reading in the Container Handling Building (CHB) is a special case of an outside sensor reading because the CHB is not pressurized in the present design (Parsons Co. 1989). A release rate can be estimated from the change of concentration with time, estimated exfiltration rate, and building volume.

If there is no fire or explosion, the next step is to determine if the accident is some type of mechanical accident, such as a forklift collision, a vehicle collision, a plane crash, an earthquake, or a dropped munition. If the answer is yes, the next step is to determine if there is a chemical detector, either portable or fixed, which can monitor the area of the accident. If the answer is no, one reverts to the previous method of estimating the inventory involved in the accident and the percentage of release from the nature of the accident. If a monitor is available, then it would be used to monitor the accident and determine if any agent had been released. If no agent is detected, then the accident would be declared an advisory until it could be ascertained that the accident truly did not release any agent.

If the monitor on the accident indicates a release, an attempt would be made to move downwind to determine if a plume is emanating from a damaged munition or facility. If a plume could be measured, then the concentration reading and its distance downwind from the point of the accident could be used to back-calculate the rate of release or the total release that would provide input to the calculation of dose contours and the population exposed. If no plume could be identified or detected, then the calculation would revert to estimating the iriventory involved in the mechanical accident and making an estimate of the rate of evaporation from the damaged munition or process equipment.

If there is no fire, explosion, or mechanical accident, then the fire detectors and chemical detectors in the MDB would be interrogated. If a positive reading is obtained, the vacuum reading with respect to atmosphere of the toxic areas in the MDB would be checked. If the negative pressure on the $\mathrm{MDB}$ is not maintained, then an estimate of the inventory of the affected area would be obtained from operating plans. A percentage inventory release would be estimated by the nature of the condition in the MDB. If the negative pressure in the MDB is maintained, then the system would interrogate the stack and filter monitors on the ventilation system of the MDB. If an agent is detected in the stack, or even between the filters in the filter system on the ventilation system, the calculation would revert to an estimation of the inventory in the affected area and the appropriate percentage release. If the stack and filter monitors give no indication of any agent breaxthrough, then the event would be classified as an advisory. Agent would be loose in the MDB but contained in the MDB, presenting no immediate threat to site personnel not in the MDB. 
If there is no fire or chemical reading in the $\mathrm{MDB}$, then the program would check the pressurization of the toxic areas in the MDB. If pressurization has been lost as part of the event activating the system, then the incident would be classified as an advisory. There would be no agent loose in the MDB, but there would be no containment in the MDB, an abnormal condition with the potential for getting worse. If the MDB were properly pressurized, then the event triggering the alert would be classified as a chemical occurrence. Examples might be a small propellant fire without release of an agent, or a mechanical accident without release of an agent.

Tables 2.2.1 through 2.2.4 give examples for each class of incidents that could be put in that class.

Table 2.2.1. Examples of chentical occurrence

- Out-of-specification reading on incinerator instrumentation during agent processing

- Any automatic process shutdown during agent processing

- Dropped munition without damage

- Collision of vehicle carrying munitions, without damage to munitions

- Single instrument failure

- Small fire, causing no damage and releasing no agent

Table 2.2.2. Example of accidents evoking an advisory

- Loss of one layer of containment in $N / D B$

- Unplanned agent spill in agent containment area because of piping or equipment failure

- Mechanical a cident (e.g. vehicle collision) resulting in damaged muritions, with no leaks in unfavorable meteorological conditions

- Failure of automatic process shutdown with out-of-specification instrument reading during agent processing 
Table 2.2.3. Example of accidents evoking on-post emergency

Accident and meteorological conditions to produce
no-potential-deaths dose contour inside post fence
Detonation or fire of a single munition (not bulk container or bomb)
or spill of GB outdoors in favorable meteorological conditions
(unstable atmosphere and high wind)
Complete loss of electric power during agent processing
Tomado damage to buildings. Some agent released
Most truck or forklift accidents releasing agent in favorable
meteorological conditions

Table 2.2.4 Example of accidents evoking community emergency

- Accident and meteorological conditions with potential to produce no-deaths contour in off-site populated area

- Explosion and/or uncontrollable fire in storage iglon

- Large aircraft crash with fire on igloo, storage warehouse, CHB, or MDB

- Major earthquake, damaging building integrity and/or starting fires

- Fire-induced launch of M-55 mcket off post 


\section{USE OF RISK-ANALYSIS DATA}

This section indicates how risk analysis data could be used to classify an accident (primarily by identifying its location and the munition involved) and obtain a rough upper bound of its severity. Appendix B describes accident scenarios. Sorted data from the risk analysis are tabulated in Appendix C.

\subsection{ACCIDENT PROBABILITY}

The use of probabilistic risk analysis (PRA) to predict accident risk during normal operation is quite proper, as is the exclusion of many accidents on the basis of low probability. However, some classes of unique events result from concatenations of improbable human decisions, emotional reactions, and equipment failures, to which it is quite difficult to assign meaningful probabilities (e.g., Three-Mile Island). The probabilities usually can be made lower by security precautions, training, and institutional designs. It is necessary to accommodate these events when designing an accident response system, even though they may be properly excluded by the risk analysis.

Similarly, accidents below a certain severity can be excluded from lists of risk analysis accidents but must be included in an accident assessment system, because the emergency manager at the EOC must know that an accident is inconsequential to make a decision regarding an appropriate response.

\subsection{ACCIDENT LOCATION TABLES}

Tables 3.2.1 to 3.2.16 indicate the locations of accidents identified in the risk analysis for each of the 16 combinations of munitions and agents (excluding the small supplies of GA and $\mathrm{L}$ ) in the stockpile. All steps in the demilitarization process for each munition are listed under "location" in column 1. Column 2 lists the code numbers of accidents from the risk analysis that were considered possible for that location (or step in the process) for the given agent-munition combination. Most of these accidents have been screened to eliminate those with a probability lower than $10^{-8}$, or a downwind no-deaths contour extending less than $0.5 \mathrm{~km}$, under worst-case meteorological conditions. Column 3 lists the maximum downwind distance of the no-deaths contours for worst-case meteorology $(1.0-\mathrm{m} / \mathrm{s}$ windspeed, E stability). Associated with this number is a unique value for the quantity of agent airbome for each agent.

The values for the worst-case downwind distance are, at best, accurate to one significant figure. The numbers given were generated by the computer that did the risk analysis calculations. The nonsignificant additional digits have been retained to point out instances of an assumption of identical releases from similar accidents.

Column 4 gives a brief indication of the nature of the accident, indicated by the accident number. Column 5 lists the signature of the accident, which includes those properties of the accident that are easily identified and are generally available to the person on duty in the EOC either by a sensor alarm or a telephone or radio message from field workers. Causes may include such things as an explosion, fire, earthquake, plane crash, vehicle collision, a dropped munition, loss of pressure control in the toxic handling areas of the MDB, or alarm from a chemical sensor. 


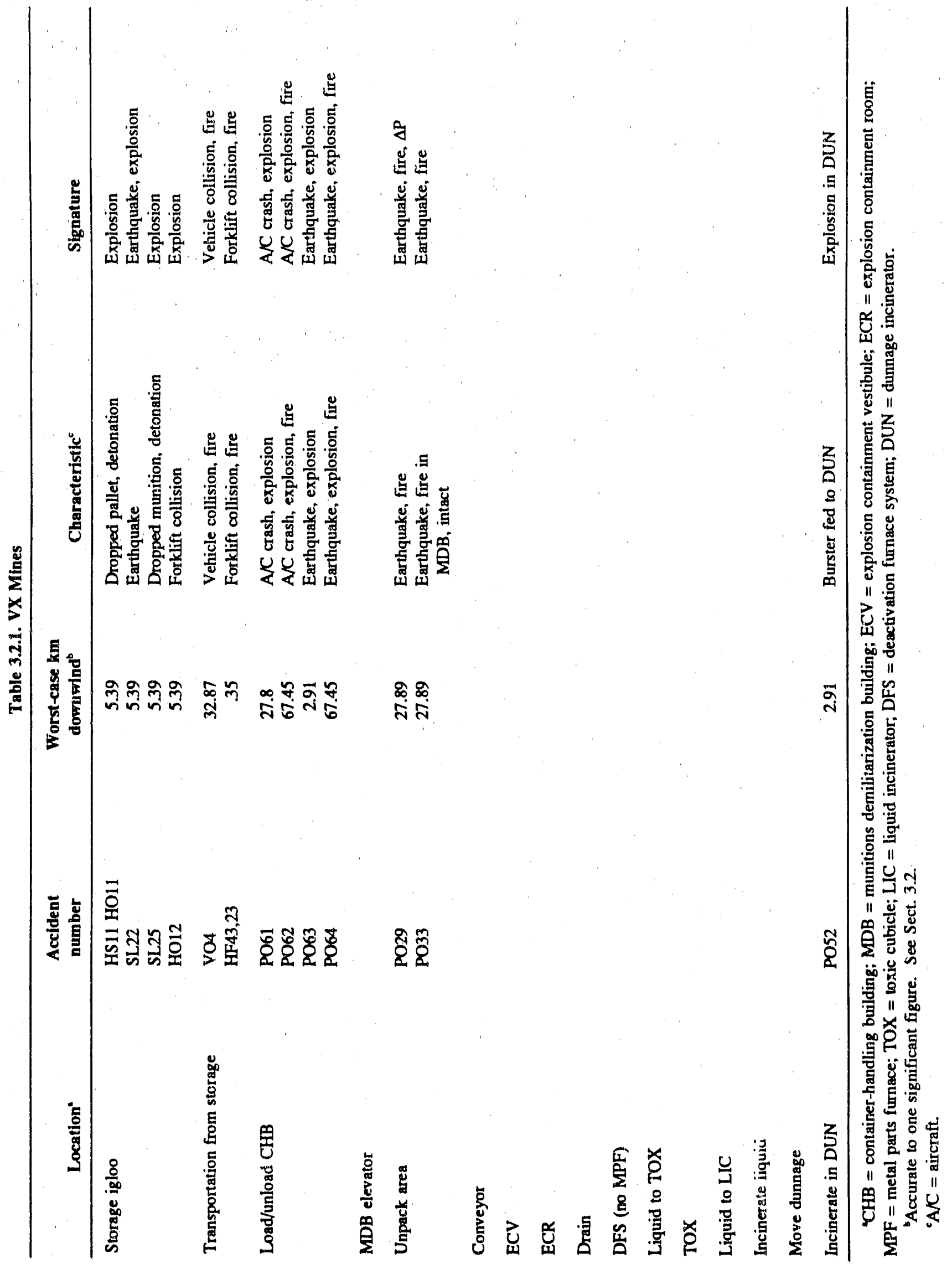




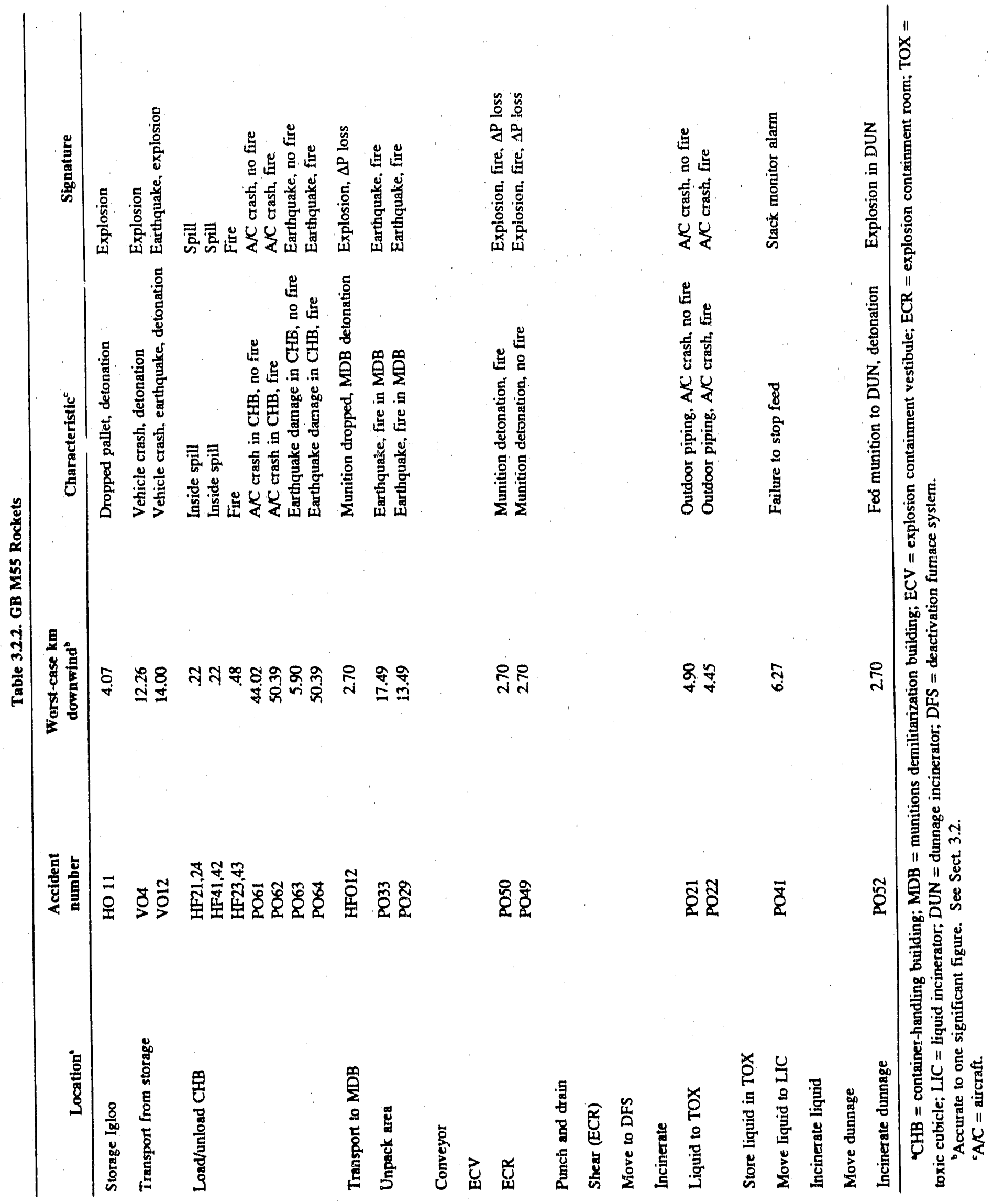




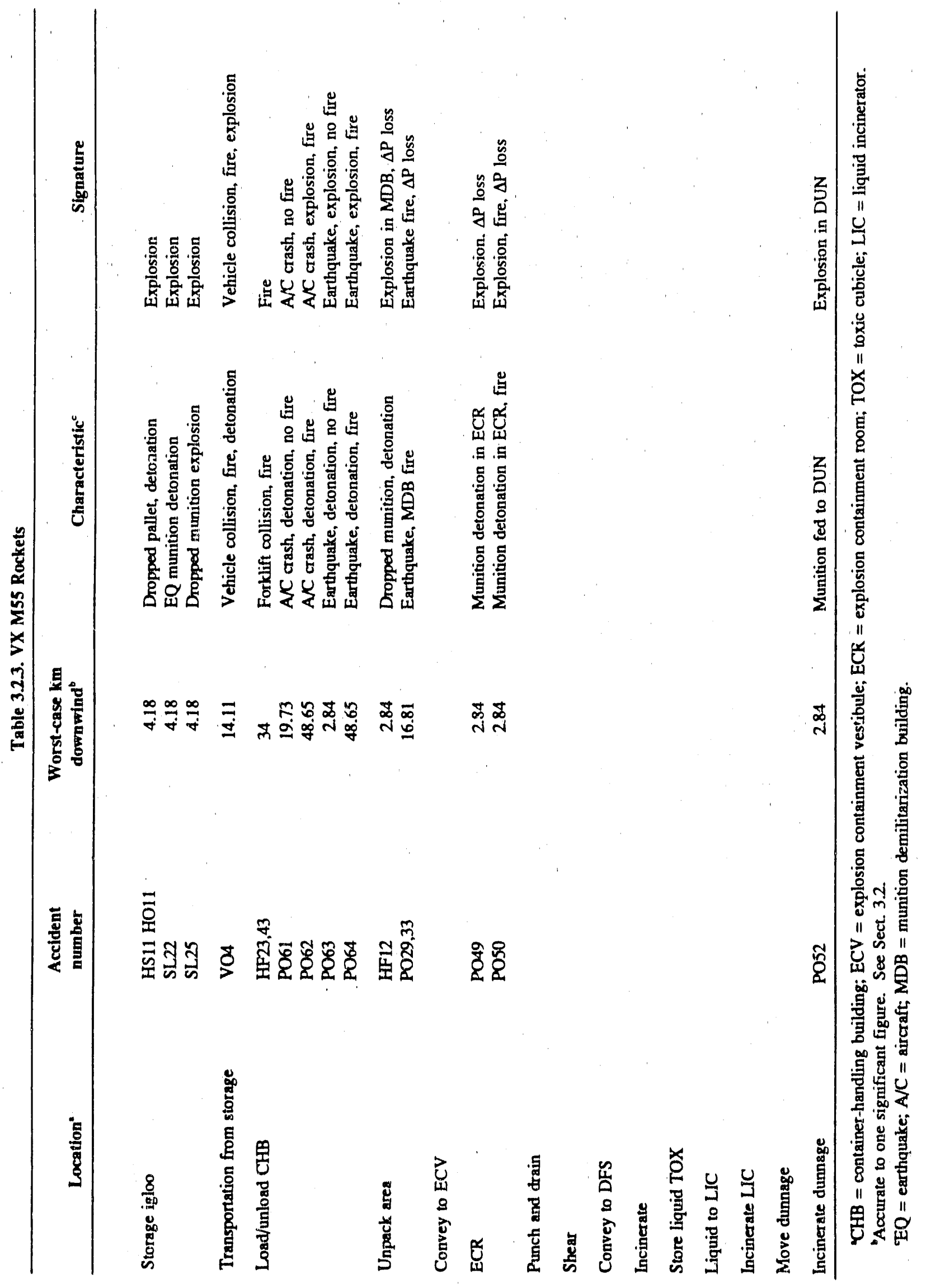


营

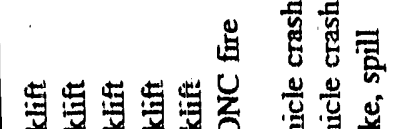

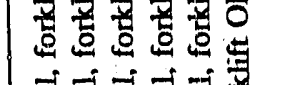

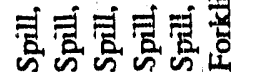

要要

容宓盇

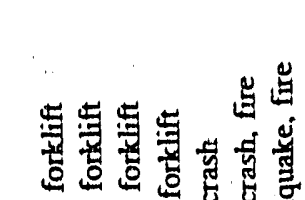

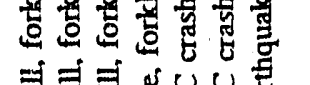

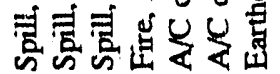

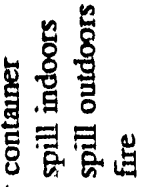

雚
害

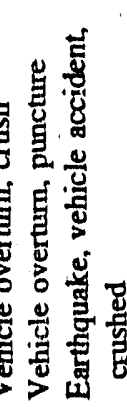

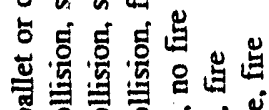

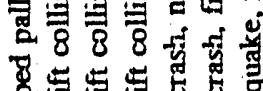

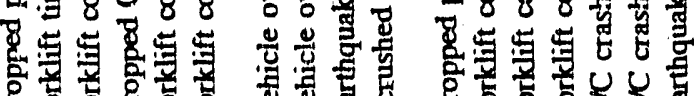

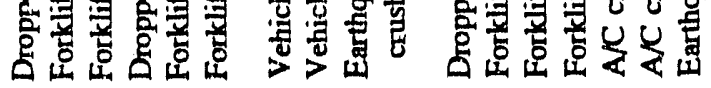

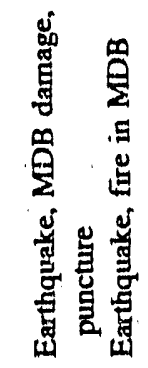

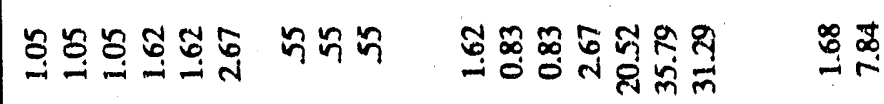

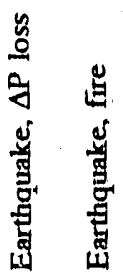

商

뼝

夤

岁焉

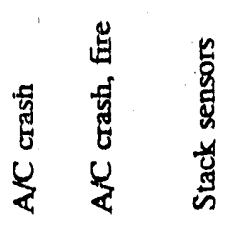

䓢言

鯯

ה

过 ̛ั

กู่

ฉี ฐ

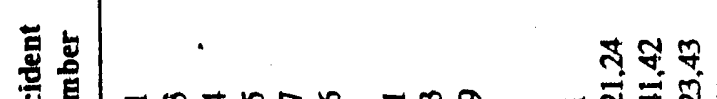

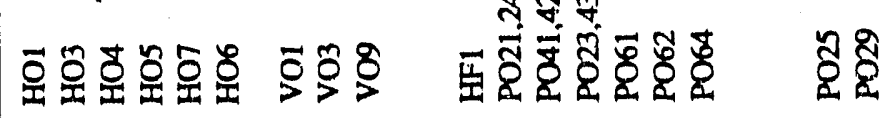

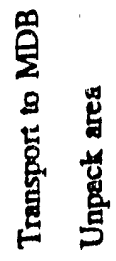

氖

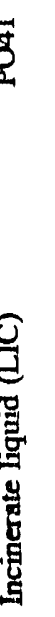

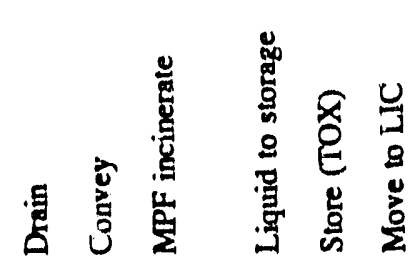

兽 


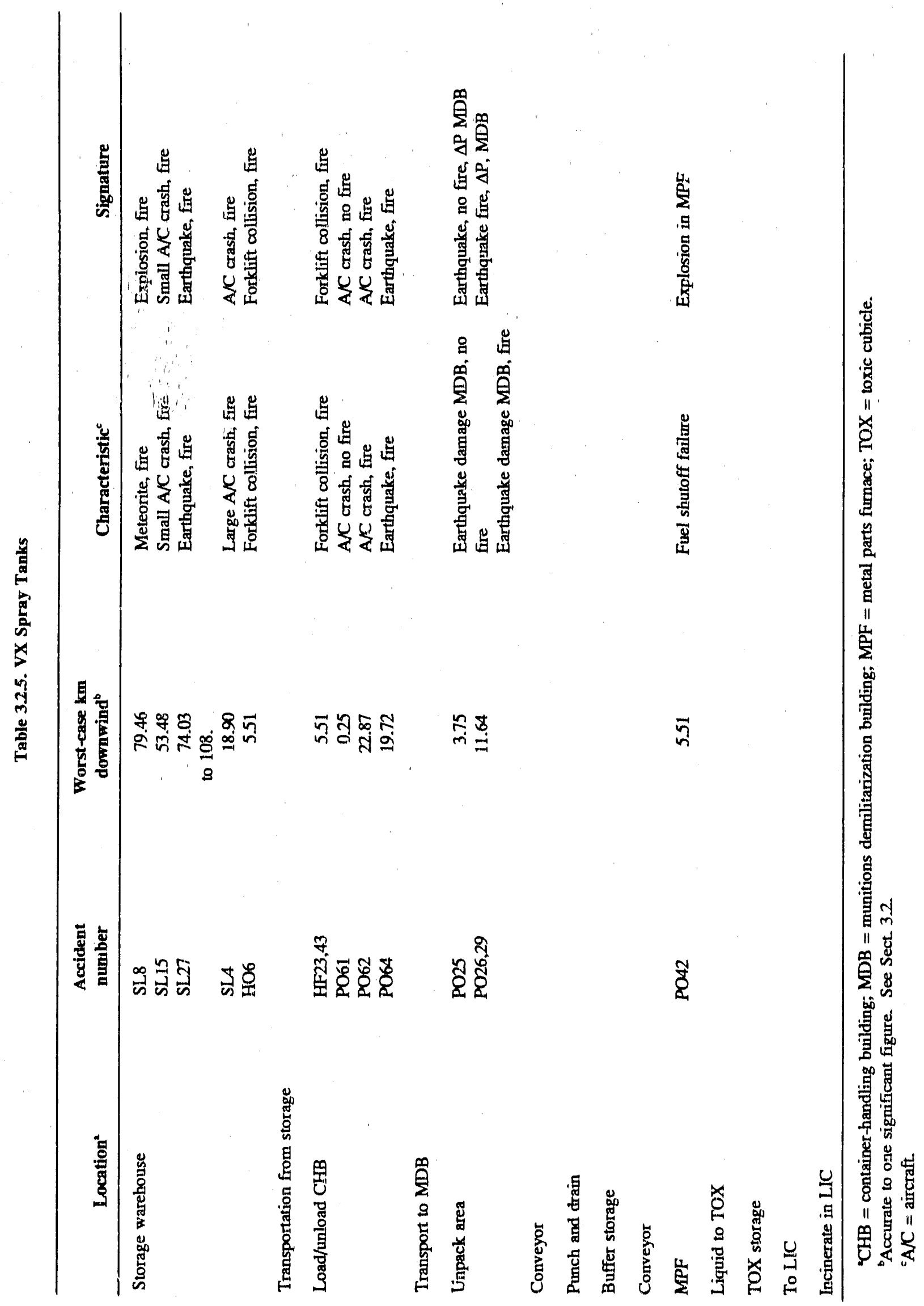




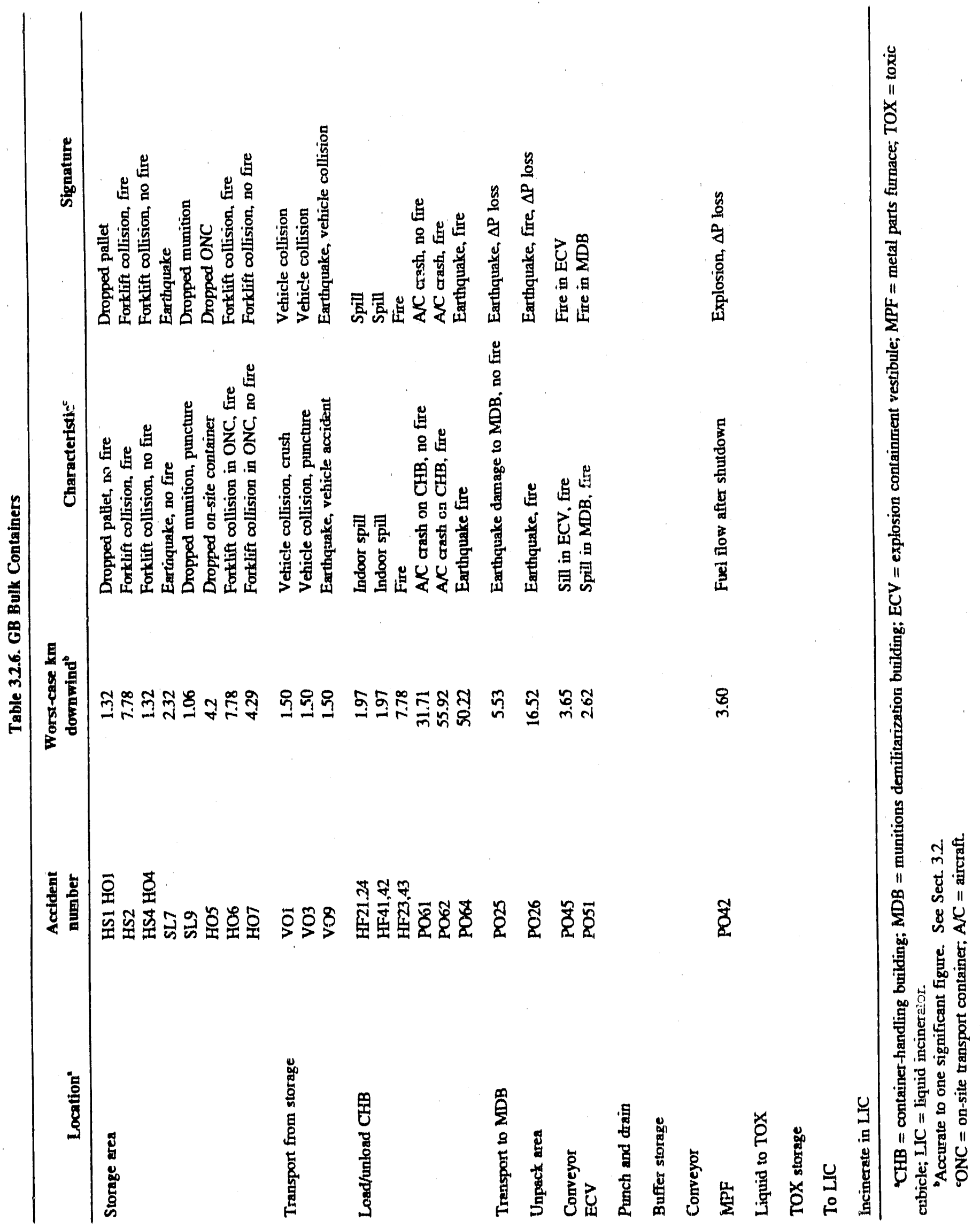




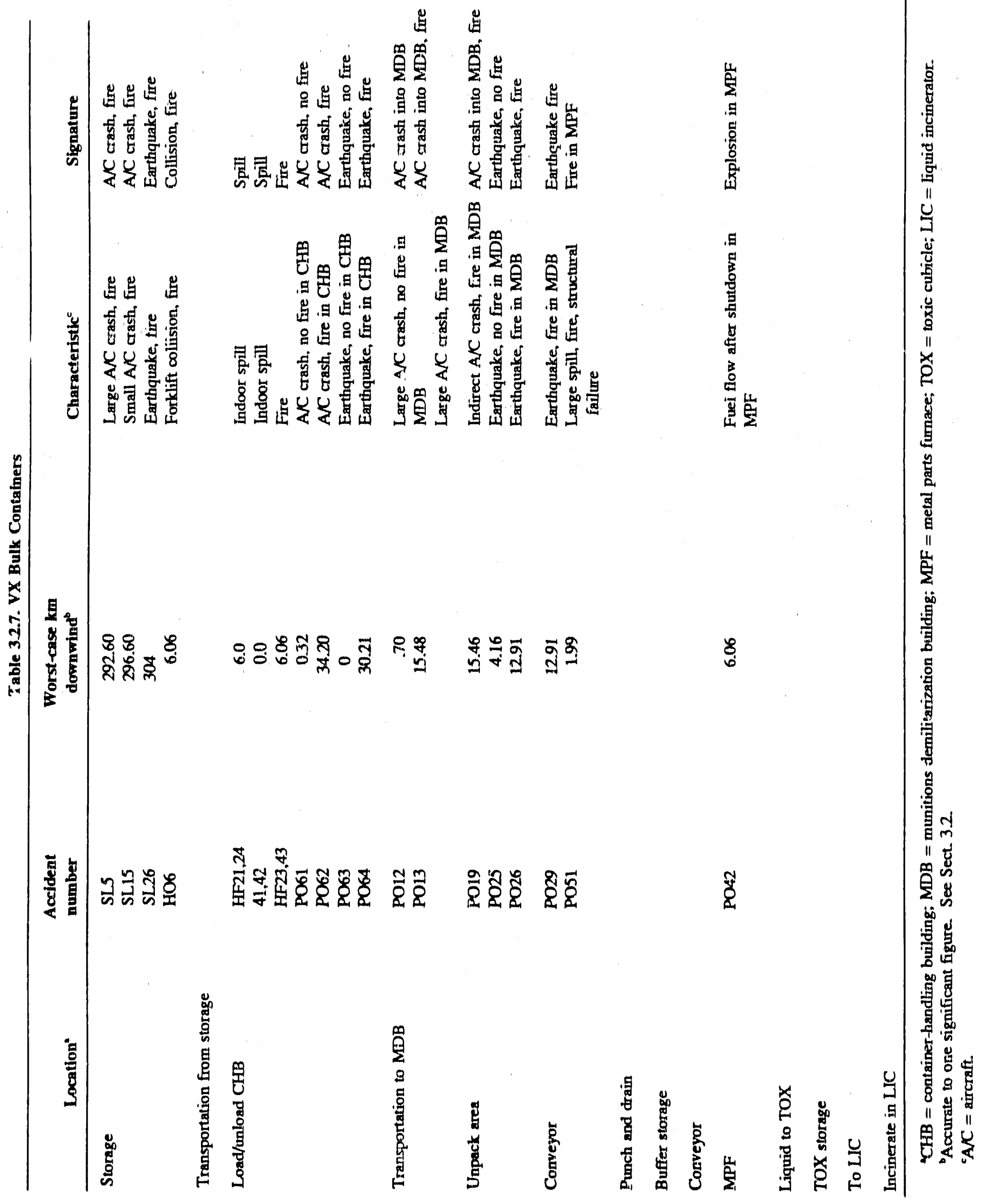


19

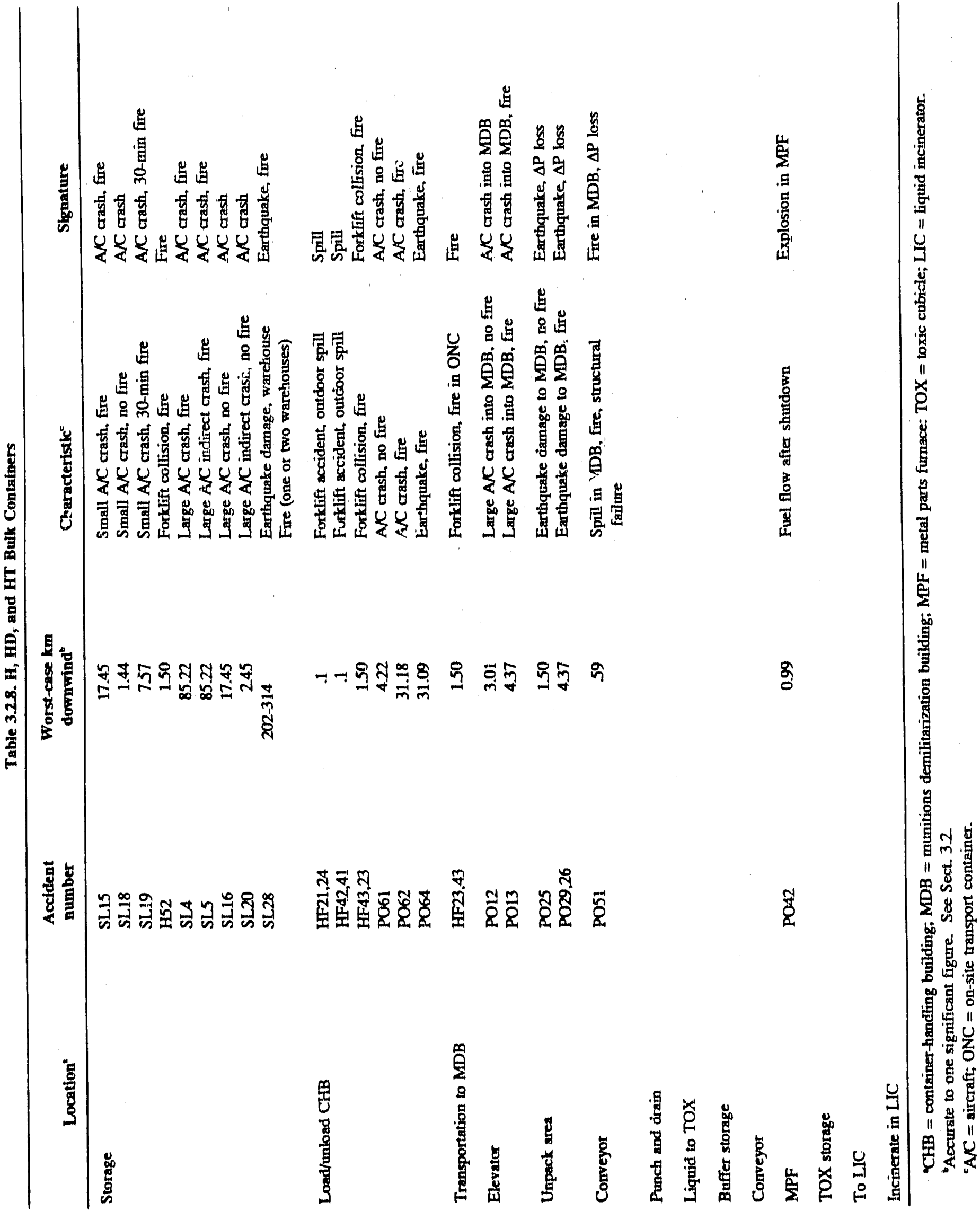




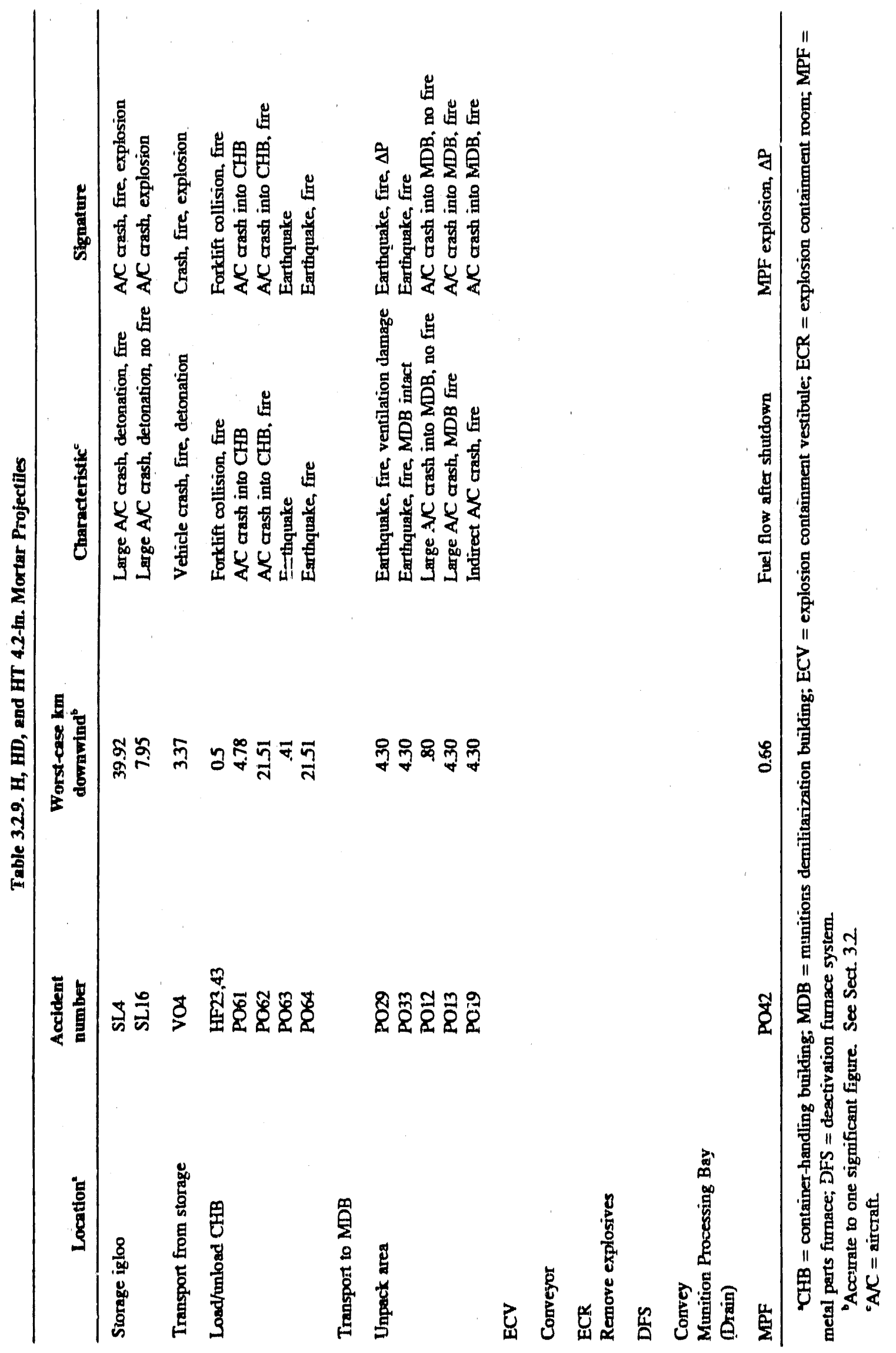




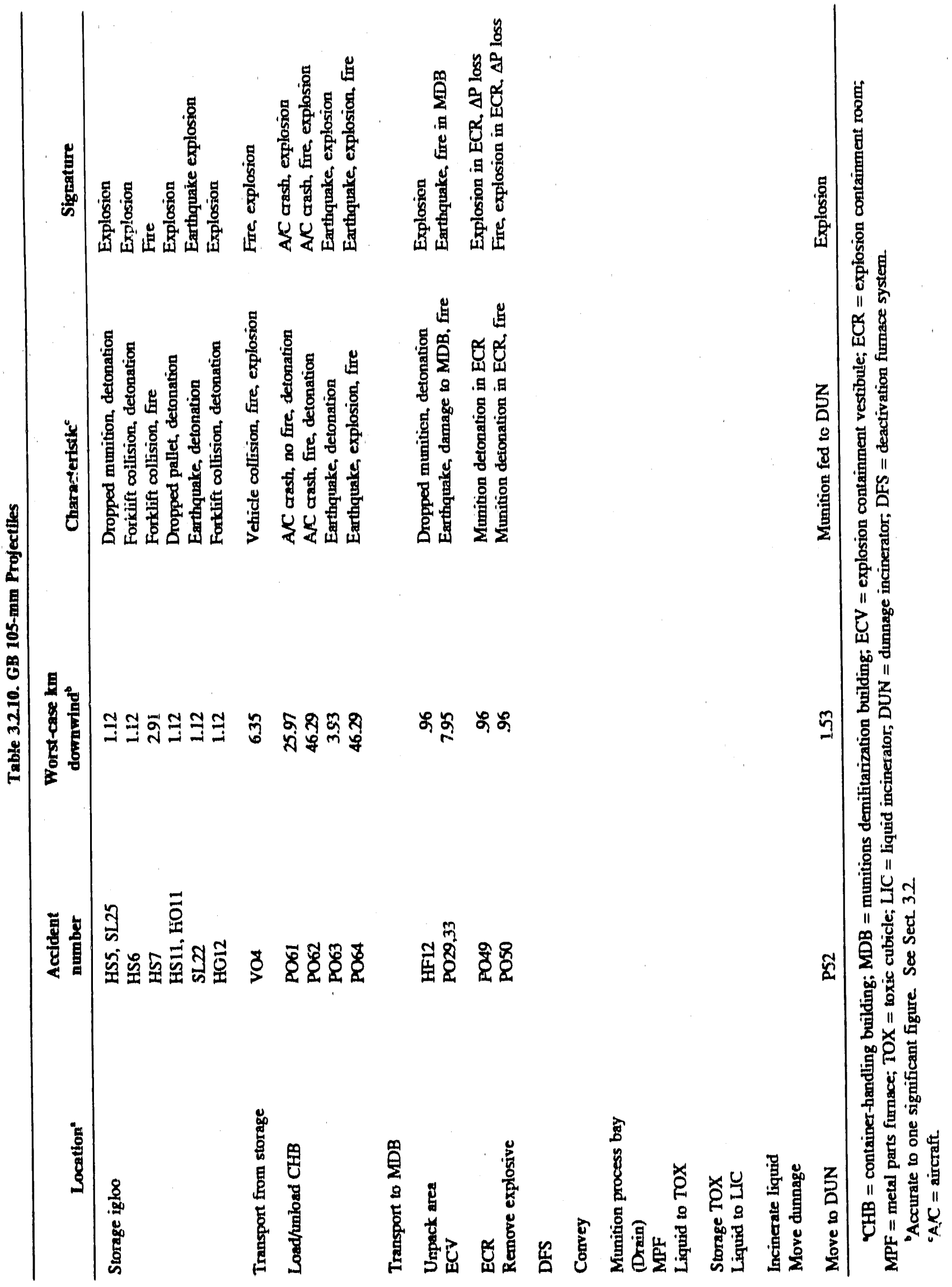




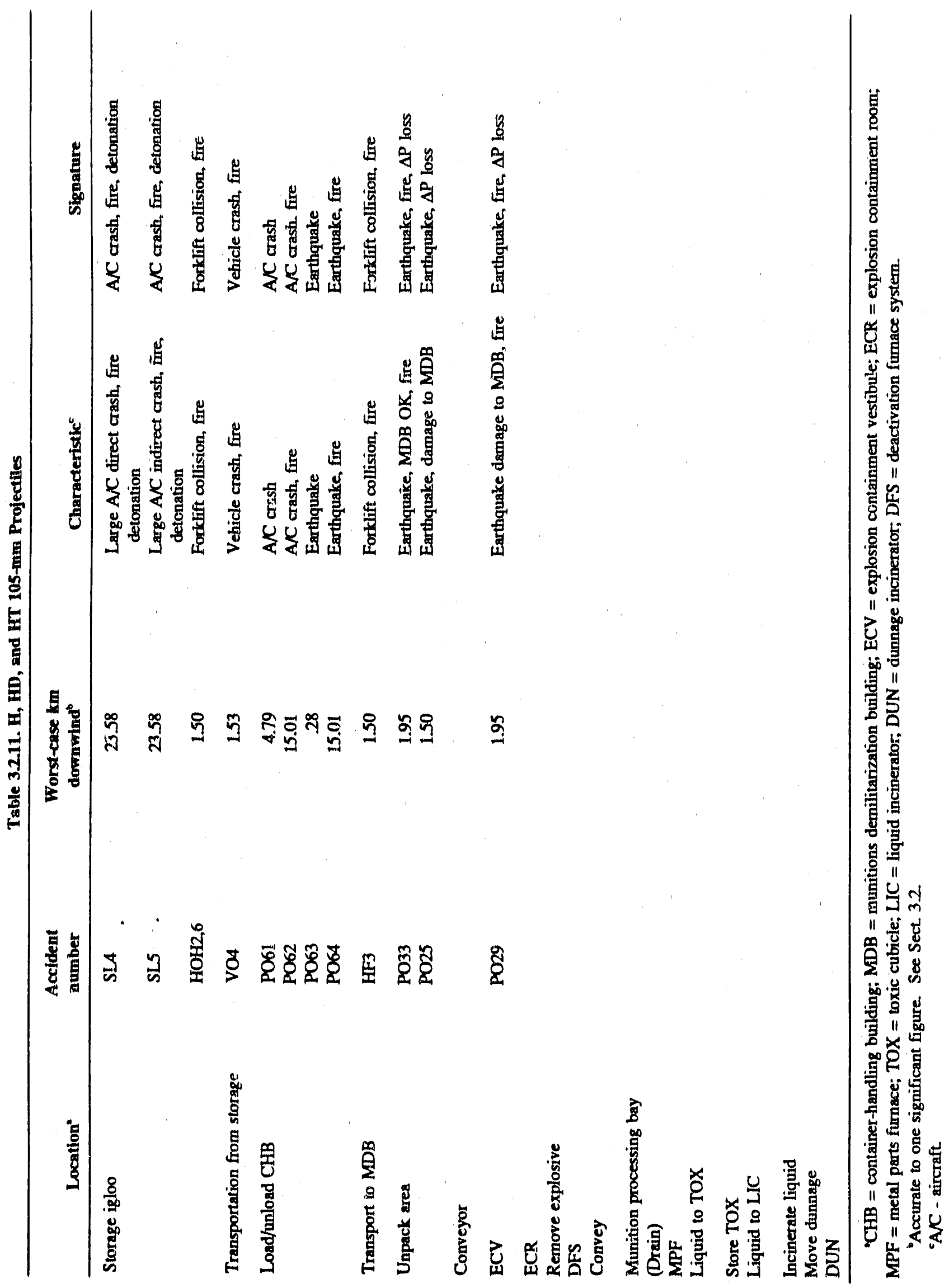




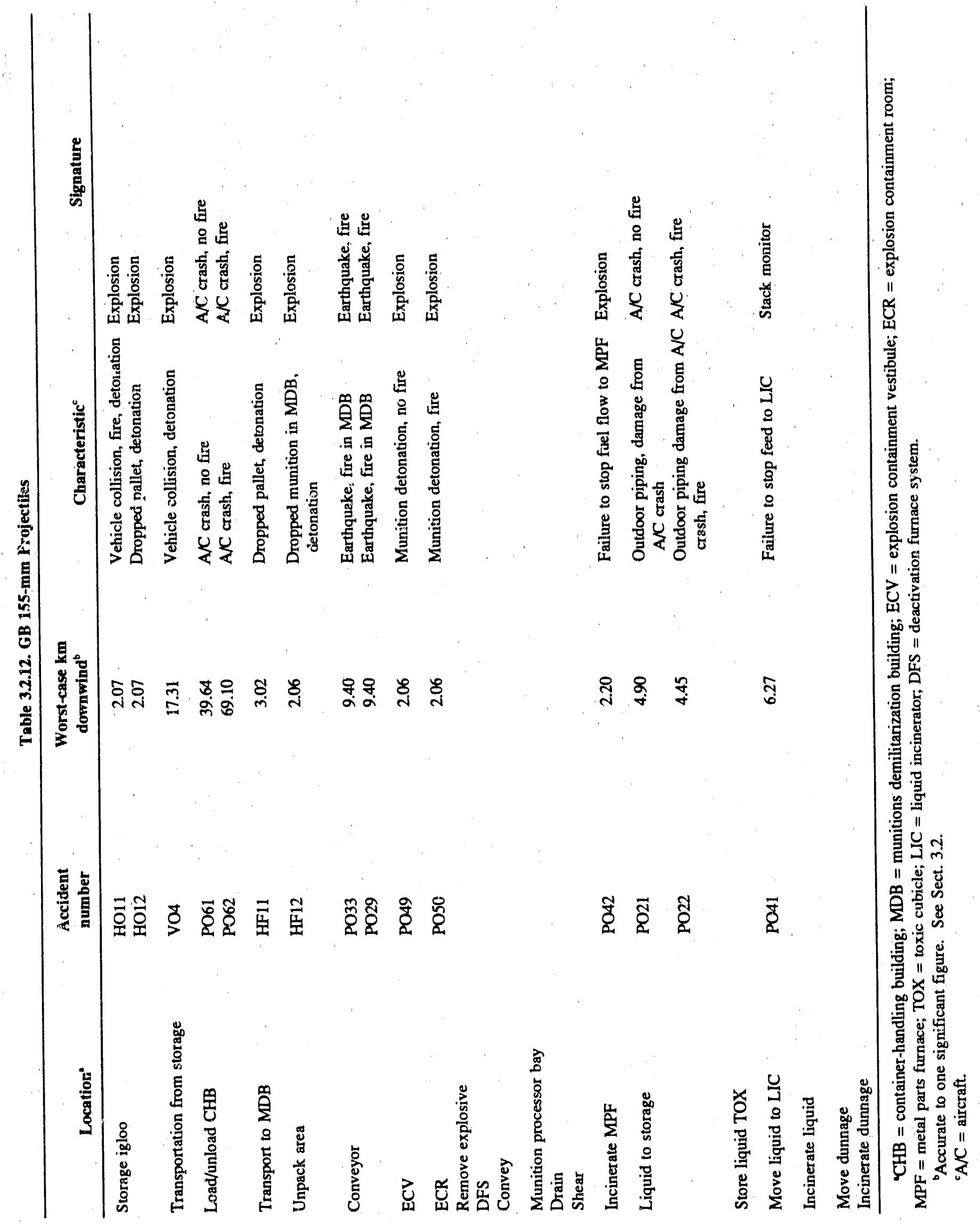




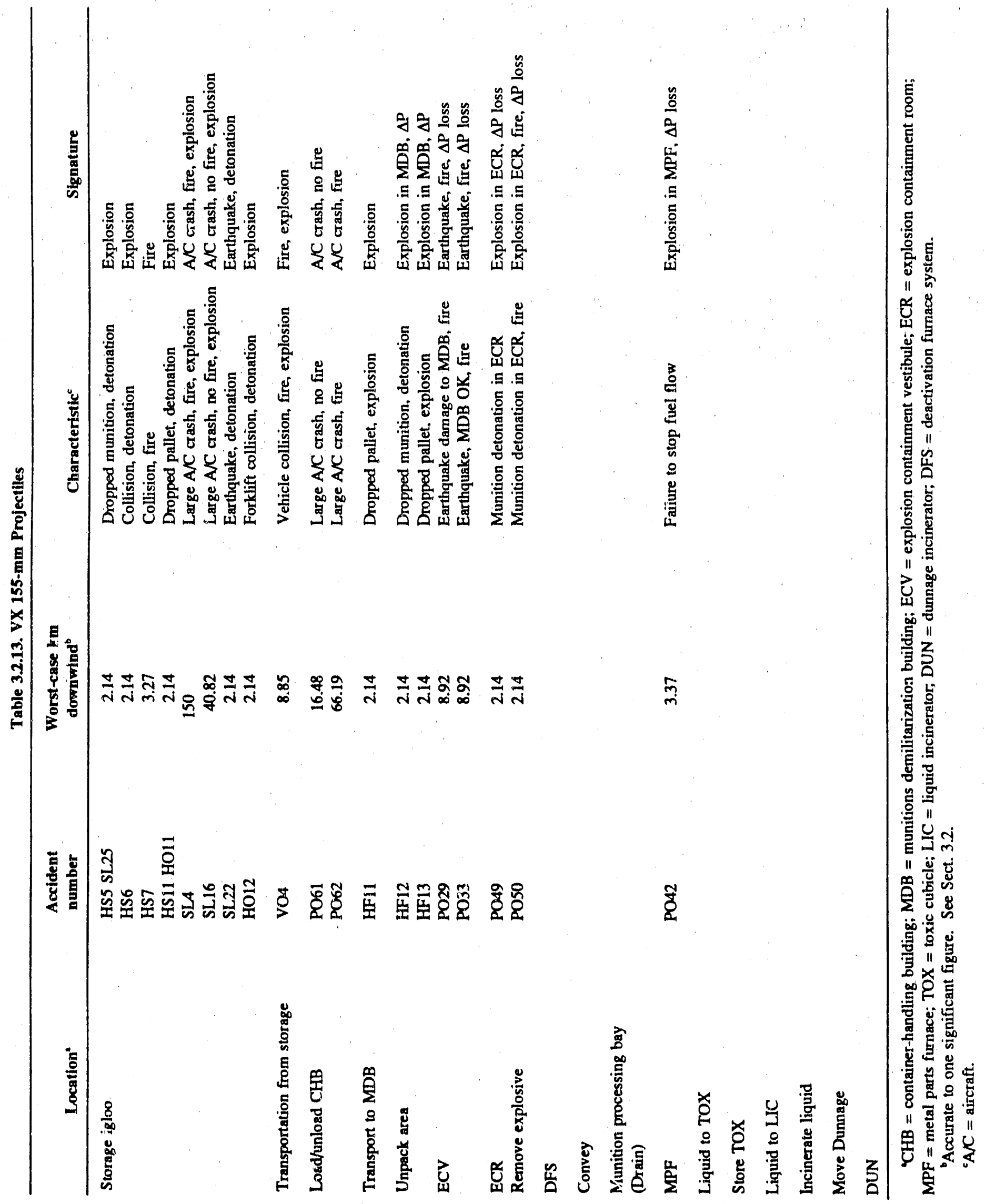




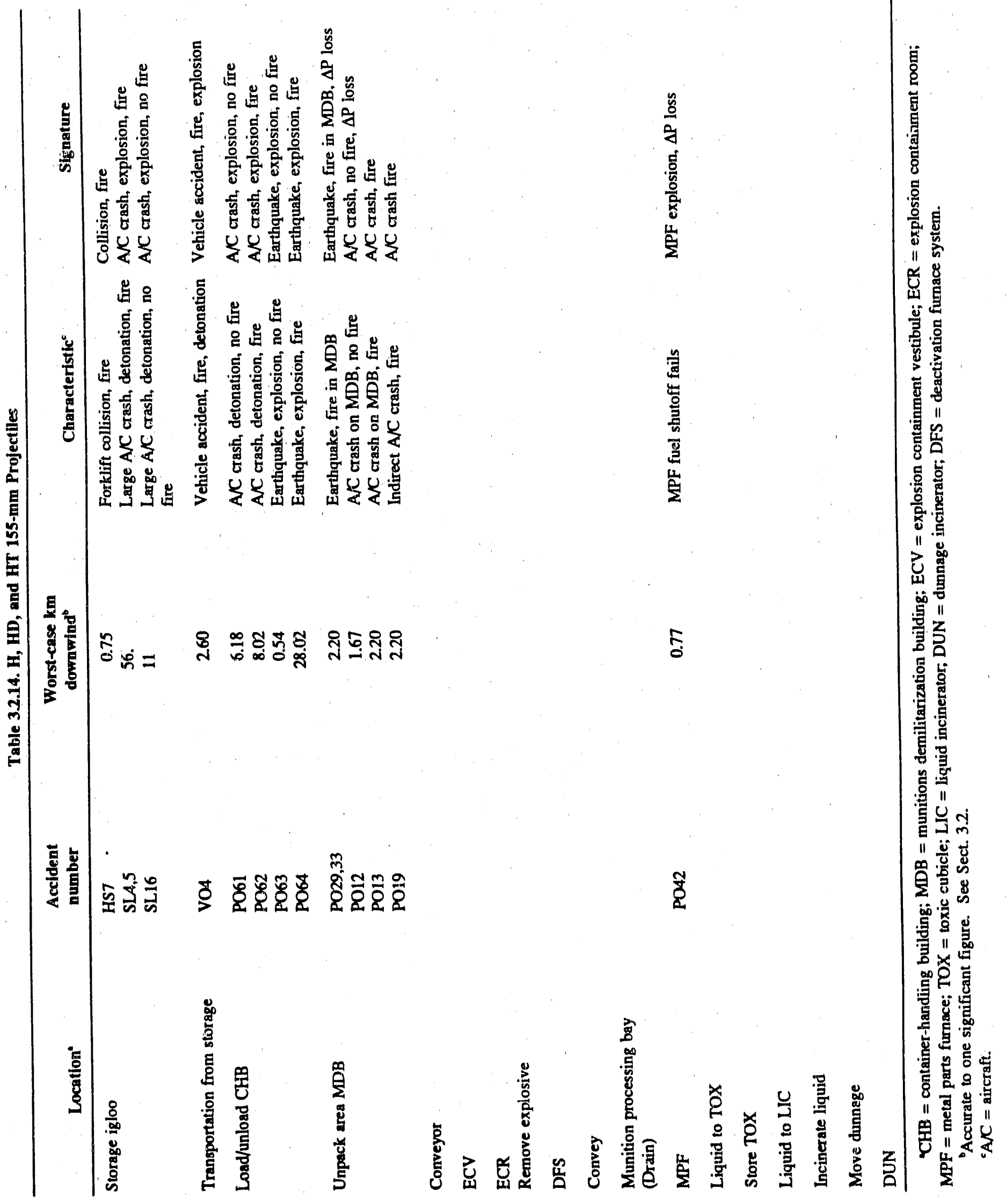




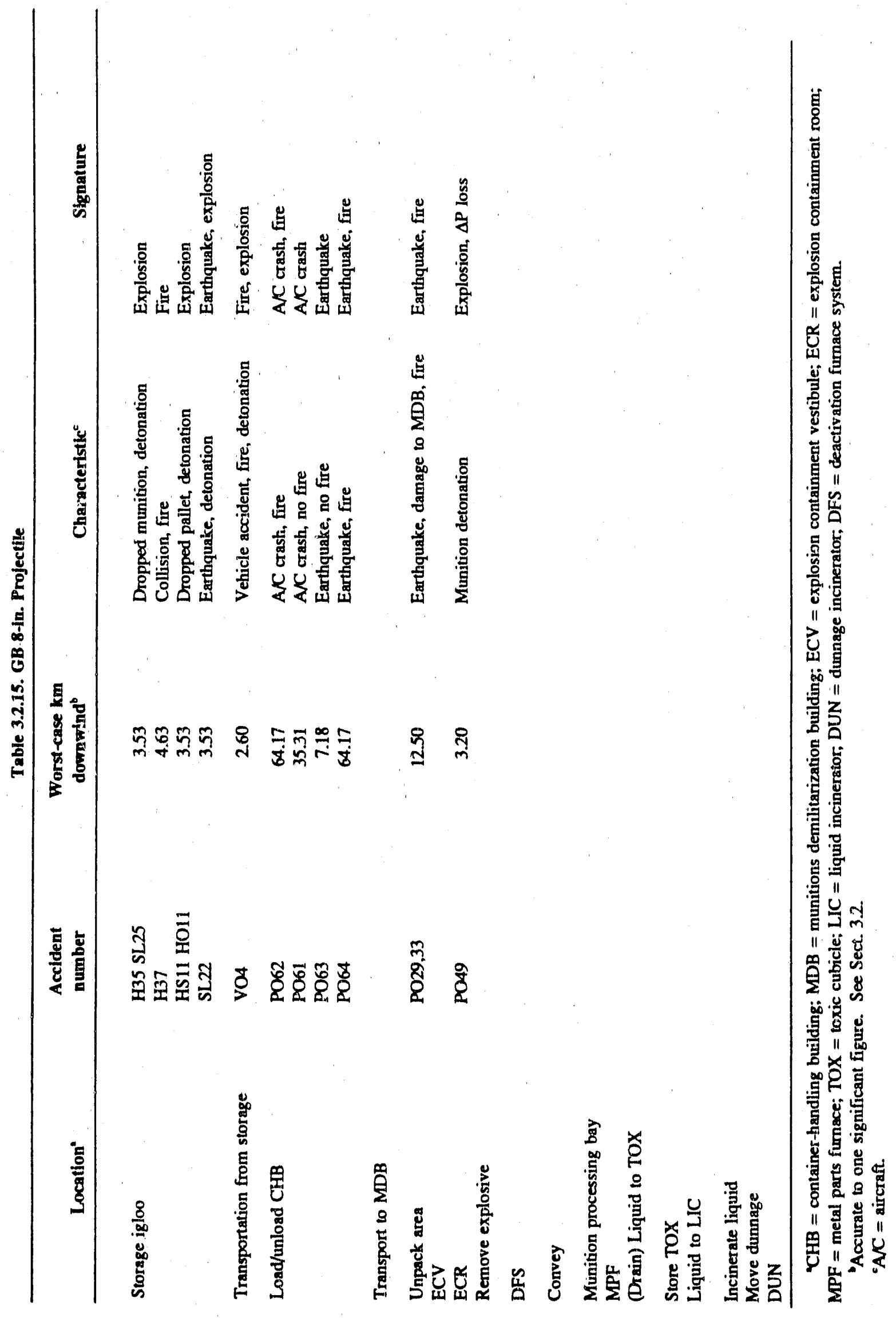




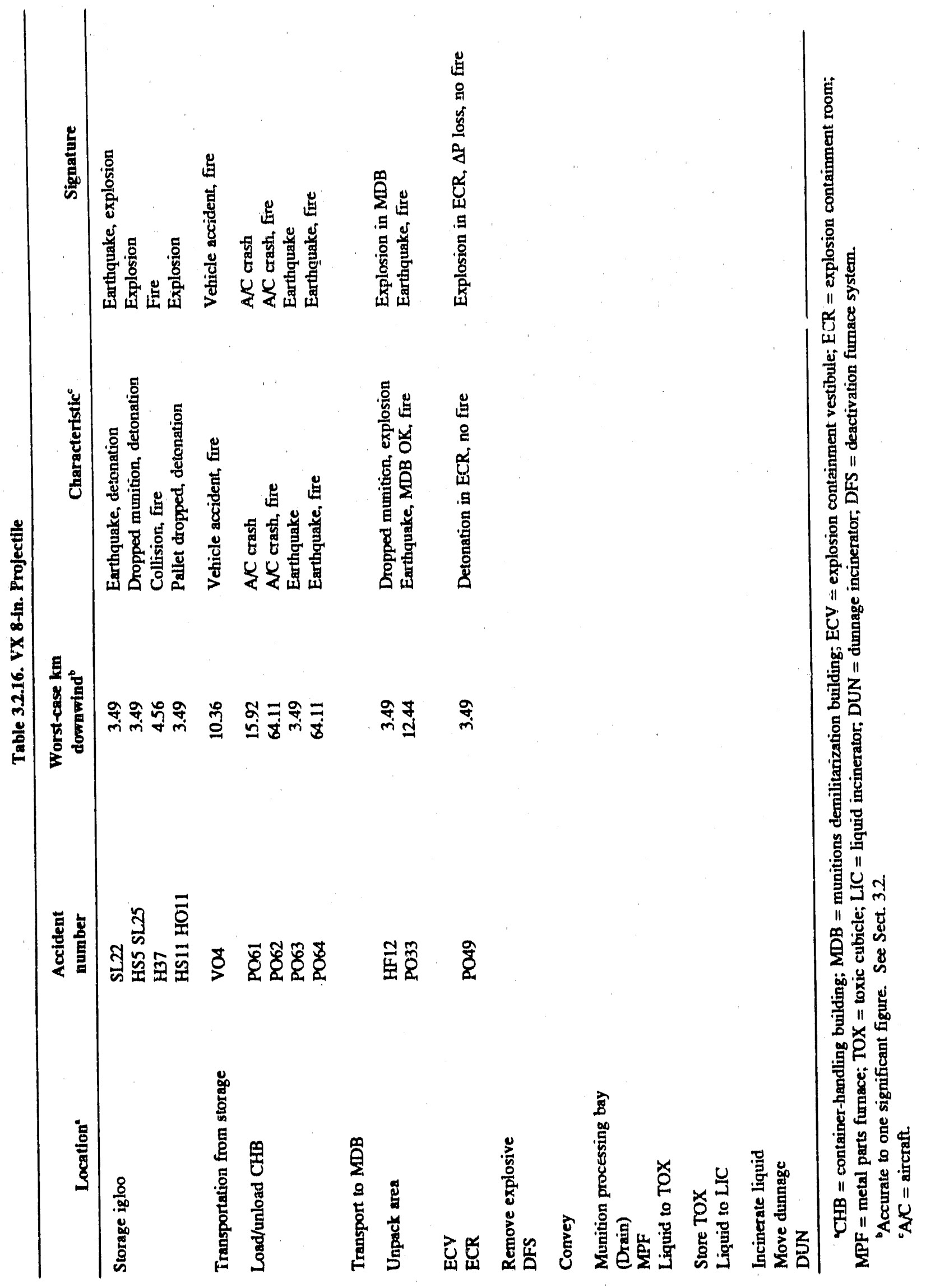


In many cases, a single accident is listed for a given munition/agent combination at a given location in the processing scheme. In all cases, so far, several accidents at a given location have been differentiated to a single-release magnitude or single-worst-case downwind range on the basis of the accident signature.

The tables in this version have been modified to include the addition of a container-handling building (CHB) to the flowsheet.

Propellant unloading operations on $105-\mathrm{mm}$ cartridges and $4.2-\mathrm{in}$, mortars have not been included on the flowsheets at this writing.

\subsubsection{VX Mines}

Table 3.2.1 lists the accidents in the risk analysis involving mines filled with agent VX. Mines are equipped with bursters. The accidents listed at the storage location all occur outside the igloo on the pad and involve the detonation of one munition. All are signaled by an explosion at the storage location not involving the entire igloo. The risk analysis indicates that the worst-case downwind distance of the no-deaths contour from this type of accident is $5.39 \mathrm{~km}$. Most meteorological conditions would result in a plume of much less length (in most cases) not getting off site.

An accident involving a plane crash or earthquake igniting the whole igloo has been screened out of the risk analysis on the basis of low probability. This accident would have a worst case downwind range of no-deaths contour of tens to hundreds of kilometers. It would be identified by the logic tree described in Sect. 2.2 .

The risk analysis lists as a potential accident a collision with the vehicle carrying munitions, followed by a fire that involves the entire truckload. Under worst-case meteorological conditions, this could result in a plume extending $32 \mathrm{~km}$ downwind. The signature for this accident is a vehicle collision and a fire. A forklift collision with a fire occurring at the CHB would be expected to produce a plume extending only $0.35 \mathrm{~km}$ downwind under worst-case conditions. The signature of this accident is a forklift collision, followed by a fire.

The large inventory in the CHB can result in accidents with considerable area coverage if the CHB is subjected to massive external force from an airplane crash or a large earthquake; with fire following either of these incidents, the no-deaths contour approaches $70 \mathrm{~km}$ downwind under worst-case conditions. The distinguishing signature of these accidents is the initiating event-an earthquake or large airplane crash followed by fire. An airplane crash on the $\mathrm{CHB}$ (without fire) could be expected to cause the explosion of some of the bursters of the munitions, which can still produce a potential plume extending tens of kilometers downwind. A fire involving this munition in the MDB (PO29 and PO33) can have the same result through failure of the ventilation system. The signature is an earthquake followed by a fire in the MDB. The final accident considered for mines is the inadvertent transfer of a burster to the dunnage incinerator in the dunnage from the unpacking area. Worst-case conditions would produce effects $2.9 \mathrm{~km}$ downwind, and the signature would be an explosion in the dunnage incinerator (DUN).

\subsubsection{GB M55 Rockets}

Accidents considered in the risk analysis involving GB-filled M55 rockets are listed in Table 3.2.2. The only accidents listed at the storage site are HO11, SL22, and SL25. These involve detonation of a single munition because of the dropping of a munition or pallet or 
because of a severe earthquake. The signature would be an explosion of a single munition in the handling area at a storage igloo. Under the worst conditions, detonation of a single $G B$ warthead would produce a plume (no-deaths contour) extending a little more than $4 \mathrm{~km}$ downwind.

An igloo fire that was sureened out by low probability must be ronsidered in an accident assessment.

During transportation to storage, a vehicle crash, or one caused by an earthquake, could result in fire and detonation of one or more warheads. The signature would be the vehicle crash accompanied by an explosion and fire reported by escort personnel.

An aircraft crash into the $\mathrm{CHB}$, with or without fires, could result in a plume extending about $50 \mathrm{~km}$ downwind under worst-case meteorological conditions (PO61, PO62). The signature of this accident is a plane crash into the CHB.

Handling accidents inside the CHB could result in a spill of an agent with no fire. These accidents, in general, will not produce a plume that escapes the site. In munitions handling operations between the CHB and the MDB, a munition drop could occur in the MDB, resulting in detonation and a $2.7 \mathrm{~km}$ plume under worst-case meteorological conditions. The signature would be an explosion of a munition in the MDB, probably followed by loss of nugative pressure in the MDB.

A pair of accidents (PO33 and PO29) Initiated by an earthquake, resulting in fire in the MDB, which eventually causes the ventilation system to fail, results in a $17-\mathrm{km}$ plume (worst-case conditions). The signature for this accident is an earthquake, followed by indications of fire in the MDB.

Detonation of a single munition in the explosive containment room could result in structural fallure, ventilation fallure, and a small fire (PO49, PO50). The plume from this accident, under worst-case conditions, could extend about $3 \mathrm{~km}$ downwind. The signature is an explosion in the explosion containment room.

Accidents PO21 and 22 are the result of a plane crash in the outdoor piping of the MDB. With or without fire, they produce a plume under worst-case conditions that might extend nearly $5 \mathrm{~km}$ downwind. The unambiguous signature of this accident would be a plane crash into the external piping of the MDB.

Failure to stop the feed of toxic agent to the liquid incinerator after a shutdown can result in overload of the ventilation filters and escape of agent from the building, producing a plume extending approximately $6 \mathrm{~km}$ under worst-case meteorological conditions. The signature of this event would be detection of agent in the stack effluent by a chemical monitor (PO41).

It is considered possible to feed a munition inadvertently to the dunnage incinerator, resulting in an explosion that can release enough agent to produce a no-deaths contour that can reach $2.7 \mathrm{~km}$ downwind under worst-case meteomlogical conditions. The signature of this accident is an explosion in the dunnage incinerator.

\subsubsection{VX M55 Rockets}

Table 3.2.3 lists the risk analysis accident for M55 rockets with warheads containing VX. Accidents given for the storage site for these munitions are SH11, HO11, SL22, a SL25, all of which involved the detonation of a single munition from a dropped pallet, a dropped munition, or an earthquake. The signatures are all the same, and the explosion of a single munition could result in a no-deaths contour extending as much as $4 \mathrm{~km}$ downwind under werst-case meteorological conditions. 
An igloo fire that was sereened out of the risk analysis on the basis of low probability must be considered in an accident assessment.

The accident listed during transportation (VO4) is a vehlole collision, followed by a fire and detonation of more than one of the warticads. The signature is a vehilcle collision, followed by a fire and explosions, that can result in a downwind plume as long as $14 \mathrm{~km}$ under worst-case meteorological conditions.

Accidents at the CHB that do not involve fire or explosions do not produce any off-site effects because of the low volatility of $\mathrm{VX}$.

Externally caused aceidents at the CHB (almplane crash, followed by explosion with or without fire, or a severe earthquake, with or without fire (PO61, 62, 63, and 64)] result in plumes extending tens of kilometers downwind. The signature of these is obviously the external cause of the accident and the presence of a fire and explosion.

Explosion of the single munition in the unpack area of the MDB can result in a $2.8 \mathrm{~km}$ plume under worst-case meteorological conditions. The signature is an explosion in the MDB and a loss of negative pressure in the munitlons-handling areas. An eartliquake, followed by fire and explosion at the MDB (PO29,33), can result in a 17-km-long plume under worst-case meteorological conditions. The signature of this event is the earthquake followed by a fire and loss of negative pressure in the MDB. Explosion of a munition in the explosive containment room can damage the structure and result in a $2.84 \mathrm{~km}$ plume under worst-case meteorologlcal conditions. An explosion in the dunnage incinerator due to a munition fed wt th the dunnage has the same result. In this case, from the standpoint of accident analysis, it does not matter where in the bullding an explosion occurs, as long as it involves only one wartiead.

\subsubsection{GB 750 lb. Bombs}

Table 3.2.4 lists the risk analysis accidents and their locations for 750-lb bombs filled with G.B. A variety of forklift accidents are listed at the storage location. There are no explosions, because the bombs are not equipped with bursters. These accidents would result in a downwind plume of a little more than $1 \mathrm{~km}$ under worst-case conditions. If a fire resulted, a worst-case plurne might extend as far as $3 \mathrm{~km}$ downwind. A signature for this group of accidents is any type of accident that occurs from handling of bombs at the storage location.

During transport to storage, three accidents are considered possible. All involve vehicle accidents that crush or puncture the bombs, and all have downwind no-deaths contours, under worst-case meteorological conditions, of a little more than $500 \mathrm{~m}$ in length. A handling accident (dropped pallet or container) at the $\mathrm{CHB}$ or at the MDB could result in a spill producing a downwind no-deaths contour of $1.6 \mathrm{~km}$. The same would result from a handling accident in the MDB, resulting in puncturing of munitions from an earthquake. Here the signature would be the earthquake and the loss of negative pressure in the toxic handling areas in the MDB. Presence of fire would indicate a longer potential plume, up to $7.8 \mathrm{~km}$ (PO29).

Forklift accidents in and around the CHB would result in spills with downwind no-deaths distances less than $1 \mathrm{~km}$. The same accident resulting in a fire could produce a downwind no-death distance of a little less than $3 \mathrm{~km}$ (PO21, 24, 41, 42, 23, 43).

Externally caused accidents involving the CHB are more serious. A plane crash into the CHB will produce downwind no-deaths plumes under worst-case conditions of $20.5 \mathrm{~km}$ with no fire and $35.8 \mathrm{~km}$ with a post-crash fire. A no-deaths plume under worst-case conditions of $31.3 \mathrm{~km}$ would be caused by a severe earthquake followed by a fire and a negligible release with no fire. The signature for these accidents would be the initlating event (plane crash or earthquake) and the presence or absence of fire. 
In the same veln, a plane crash into the outdoor piping (PO21, PO22) produces a no-deaths dowinwind plume under worst-case conditions of $4.9 \mathrm{~km}$ in the case of no fire and $4.45 \mathrm{~km}$ in the case of flre.

Fallure to tum off the fuol in the metal parts fumace on shutdown, leading to an explosion, can produce a no-deaths downwind plume under a worst-case condition of $2.7 \mathrm{~km}$. The signature for this incident is the detection of an explosion in the metal parts furnace, followed by a loss of negative bullding and pressurtzation in the toxic handling areas. Failure to stop the feed to the liquild incinerator on shutdown would overload the filters on the exhaust stack, resulting in the release of agent. The risk analysis estimates that this incident has a potential of producing a plume of $6.3 \mathrm{~km}$ under worst-case meteorological conditions, Its signature would be the detection of toxic chemlcals by the chemical monitor on the stack.

\subsubsection{VX Spray T'anks}

Table 3.2.5 lists the risk analysis accidents for spray tanks containing VX. Spray tanks in storage areas are especially vulnerable to energetic externally caused accidents that result in fires. The externally caused accident can be a result of meteorite impact; a small or large alrcraft crash on a storage warchouse or earthquake, which results in damage to some of the spray tanks; and a fire. In general, these accidents produce no-deaths plumes extending for tens of kilometers downwind under worst-case meteorological conditions. A handling accident, such as a forklift colliston resulting in a fire, will produce a no-deaths plume extending downwind only a few kilometers. In general, VX spills not accompanied by fire produce little or no off-site damage. Similarly, extemally caused accidents, involving the CHB, such as an aircraft crash with fire or a severe earthquake-induced fire, can produce accidents with no-deaths plumes extending tens of kilometers downwind (PO62, 64). Earthquake damage to the MDB involving loss of containment is estimated to cause a no-deaths plume extending as much as $3.7 \mathrm{~km}$ downwind under worst-case meteorological conditions. If the earthquake results in a fire in the $\mathrm{MDB}$, the no-deaths plume extends $11.6 \mathrm{~km}$ downwind.

Failure to shut off fuel on shutdown of the metal processing fumace can result in an explosion in that area that could release enough agent to cause a downwind no-deaths plume extending as far as $5.5 \mathrm{~km}$ under worst-case meteorological conditions.

\subsubsection{GB Bulk Containers}

Table 3.2.6 lists the risk analysis accidents for bulk containers (1 ton) containing GB. Handling and storage accidents involving a single tank generally result in no-deaths downwind plumes under worst-case conditions of 1 or $2 \mathrm{~km}$, which under most meteorological conditions would not produce any off-site effects. Vehicle collisions involving fire-prorluced downwind no-deaths plumes under worst-case conditions of over $7 \mathrm{~km}$ involve a situation with the potential for off-site effects. Transportation accidents between the storage igloos and the CHB do not include any accidents involving fire and, as a result, have downwind no-death plumes of less than $2 \mathrm{~km}$.

Forklift accidents without fire at the $\mathrm{CHB}$ can result in spills with downwind no-deaths plume distances of a little less than $2 \mathrm{~km}$. The presence of fire will extend this to more than $7 \mathrm{~km}$. Extemally caused accidents at the CHB, such as a plane crash or an earthquake. with or without fires, will produce downwind plumes on the order of tens of kilometers, posing a serious off-site problem for almost any meteomlogical conditions (PO61, 62, 63, 64).

An earthquake can produce a release from the MDB, extending the no-deaths contour to more than $5 \mathrm{~km}$ downwind under worst-case meteorological conditions (PO25). The signature 
would be an earthquake accompanied by a loss of negative pressure in the MDB and indications on any chemlcal sensors in the MDB. If the earthquake results in a fire, the calculated no-death downwind distanoe would be more than $16 \mathrm{~km}$. The signature would be an earthquake followed by a fire in the MDB.

The splll accompanied by a fire in the explosion containment vestlbule (ECV) (PO45) could result in a downwind no-deaths plume distance under worst-case meteorological conditions of $3.6 \mathrm{~km}$. A signature would be a fire in the ECV. A fire elsewhere in the MDR (PO51) is estimated to have the downwind no-deaths plume distance under worst conditions of $2.6 \mathrm{~km}$. The signature would be a fire in some other part of the MDB.

An explosion in the metal processing fumace, caused by fallure to shut off the fucl flow after shutdown (PO42), can produce a downwind no-deaths plume of $3.6 \mathrm{~km}$. The signature would be an explosion in the metal-processing fumace.

\subsubsection{VX Bulk Containers}

Table 3.2.7 contains the accidents estimated in the risk analysis for bulk containers containing VX. Although these containers have no explosives with them, their presence in large numbers in accidents that can start fires produces very large theoretical plumes from the storage area following plane crashes or earthquakes that rupture containers. In all cases, no-deaths downwind contours theoretically can reach hundreds of kllometers. It is clear that fire from any source, whether it be earthquake, plane crash, or vehicle collision involving large numbers of bulk containers of VX, will produce rele sses extending well off site (SL5, SL15, SL.26, PO13, PO19, PO26, PO29, PO51, PO62, and PO64). A forkllft collision in the storage area, involving a single tank in a fire, could produce a no-deaths contour extending $6 \mathrm{~km}$ downwind under worst-case meteorological conditions. The signature would be a report of a forkllift collision, followed by a fire. The same accident (HF23, 43) could occur at the CHB. Similar results are obtained from an explosion caused by failure to shut off fuel after shutdown on the metal processing fumace (PO42).

\subsubsection{H, HD, and HT Bulk Containers}

Table 3.2.8 lists the accidents in the risk analysis for bulk containers of mustard gas. The large accidents are those involving aircraft crashes, especially large aircraft, and fires, which are also the signatures of these very serious accidents. A large aircraft or a meteorite striking a storage area, followed by a fire, is calculated to be capable of producing a no-deaths contour under worst-case meteorological accidents extending $85 \mathrm{~km}$ downwind. For a small aircraft, this distance is listed as $17 \mathrm{~km}$ and $7 \mathrm{~km}$ for a fire that is extinguished after $30 \mathrm{~min}$ (SL15,SL19). Crashes without fire produce plumes of $1.4 \mathrm{~km}$ for a small aircraft and $7.4 \mathrm{~km}$ for a large aircraft. Severe earthquake damage (SL28) to the storage warehouse, involving variously one or two warehouses and fire, can produce downwind no-deaths contours under worst-case conditions greater than $100 \mathrm{~km}$. Aircraft crashes or earthquakes producing fires in the CHB can produce plumes of tens of $\mathrm{km}$. Fires produced by forklift collisions are estimated to produce a no-deaths contour extending $1-1 / 2 \mathrm{~km}$ downwind. For any location, extemally caused accidents without fire, such as aircraft crashes or earthquakes, produce no-deaths contours only a few kilometers downwind from the MDB. An air crash resulting in fire and an earthquake-induced fire in the MDB produce a no-deaths contour extending $4.4 \mathrm{~km}$ downwind. All violations of the integrity of the MDB would be accompanied by loss of negative pressure in the toxic areas of the MDB. There is one accident listed in which a spill 
In the MDB followed by a fire and structural fallure produces a no-deaths contour of less than $1 \mathrm{~km}$ downwind.

Fallure of fuel flow shutdown in the metal-processing fumace can result in an explosion that can release enough agent to produce a no-deaths contour of a little less than $1 \mathrm{~km}$ downwind.

\subsubsection{H, HD, and HT 4.2-in. Mortar Projectlles}

Table 3.2.9 lists the risk analysis accidents calculated for $4.2-\mathrm{mn}$, moruar shells fllled with mustard. At the storage location, an alrcraft crashing into the igloo could detonate the bursters of some shells and cause a flre. This could produce a no-deaths contour extending downwind a little less than $40 \mathrm{~km}$ under worst-case conditions. The same crash without a fire would have a no-deaths contour that extends downwind a little less than $8 \mathrm{~km}$. The signature woulu be an aircraft crash on the storage gloo, followed by an explosion and a fire. In one case (SLA, SL16) the accident listed for transport from storage is a vehicle crash, resulting in detonation of the bursters of the munition and a fire $(\mathrm{VO}-4)$. The no-deaths contour for this accident is calculated to extend downwind a little less than $3.4 \mathrm{~km}$. A forklift accident resulting in fire at the CHB would produce a downwind no-deaths contour of $0.5 \mathrm{~km}$. An aircraft crash into the $\mathrm{CHB}$ or an earthquake destroying the $\mathrm{CHB}$, followed by fire, produce the same no-deaths downwind contours under worst-case conditions of $21.5 \mathrm{~km}$ (PO62, PO64). An alrcraft crash into the CHB, without fire, will cause detonation of the bursters and result in a downwind no-deaths contour extending $4.8 \mathrm{~km}$. An earthquake that destroys the CliB but that does not cause a fire inight produce a downwind no-deaths contour of $0.4 \mathrm{~km}$. The signatures of these accidents are the combinations of aircraft crashes, earthquakes, and fires. At the MDB the same combination of possible accidents exists for the case of earthquakes or aircraft crashes accompanied by fire. The downwind no-deaths contour is $4.3 \mathrm{~km}$ in the worst meteorological case. In the case of an aircraft crash with no fire, the downwind no-deaths contour for the worst case extends $0.8 \mathrm{~km}$. In the case of any major external accident to the MDB, the key variable is whether or not a fire is started (PO29, PO33, PO12, PO19).

Failure of the fuel flow shutdown valve on the metal-parts furnace can result in an explosion, damaging the integrity of the containmerit of the MDB. This could result in a no-deaths downwind worst-case contour of $0.6 \mathrm{~km}$.

\subsubsection{GB 105-mm Projectile}

Table 3.2.10 lists the risk analysis accidents for $105-\mathrm{mm}$ projectiles filled with GB. In the storage area, a number of handling accidents are listed, involving forklift collisions that result in dropped munitions or pallets but no fire. All are estimated to produce a downwind no-deaths contour extending $1.1 \mathrm{~km}$ under worst-case meteorological conditions. In the event that the accident is associated wi'h a fire, the downwind no-deaths contour is expected to extend $2.9 \mathrm{~km}$. The signature of these accidents is a handling accident at the storage location, involving the detonation of a single munition.

On transport from storage (VO4), a vehicle collision resulting in explosion of one or more munitions and a fire is estimated to cause a downwind no-deaths contour extending $6.35 \mathrm{~km}$.

Externally caused accidents at the CHB include aircraft crashes and earthquakes. An aircraft crash producing detonations but no fire was estimated to produce a no-deaths contour for worst-case meteorological conditions extending about $26 \mathrm{~km}$. An aircraft crash with a fire is expected to produce a no-deaths contour of $15 \mathrm{~km}$ downwind. An earthquake producing 
detonations of bursters but no fire is expecter to produce a downwind no-deaths contour for worst-case conditlons of a little less than $4 \mathrm{~km}$; an earthquake producing detonations and a fire is estimated to produce a downwind no-deaths contour of a llttlo more than $46 \mathrm{~km}$. In the MDB, dropped munitions resulting in detonation produce downwind no-deaths contours of a little less than $1 \mathrm{~km}$ (HF12, PO49, PO50). Earthquake damage to the MDB, resulting in a flre, is estimated to cause a release producing a no-deaths downwind contour extending a little less than $8 \mathrm{~km}$.

With this munition it is possible to inadvertently feed a round to the dunnage incinerator, producing a release of an agent that can rosult in a no-deaths contour extending $1.5 \mathrm{~km}$ downwind.

\subsubsection{H, HD, HT 105-mm Projectiles}

Table 3.2.11 lists the risk analysis accidents for $105-\mathrm{mm}$ projectlles fllled with mustard gas. At the storage area, an aircraft crash on or near the munitions igloc, followed by detonations and fire, can result in a no-deaths contour for worst-case metcorological conditions extending a little less than $24 \mathrm{~km}$ downwind. A forklift collision followed by a fire can release mustard, producing a plume with a no-death contour extending $1.5 \mathrm{~km}$ downwind. The signature of the aircraft crash is the crash itself and the following fire. The signature of the forklift collision is the observation of the forkllft by the work party. During transportation of the munition from storage to the CHB, a vehicle crash followed by a fire is possible and would result in the release of an agent, producing a no-deaths contour extending $1.5 \mathrm{~km}$ downwind.

At the $\mathrm{CHB}$, an aircraft crash without fire would produce a downwind no-deaths contour extending $4.8 \mathrm{~km}$. The same crash followed by a fire would produce a contour extending $15 \mathrm{~km}$ downwind. An earthquake followed by no fire would produce a downwind no-deaths contour extending $2.8 \mathrm{~km}$ but, followed by a fire, would produce the sarne contours as an aircraft crash with a fire, $15 \mathrm{~km}$ (PO61, 62, 63, 64). At the MDB, an earthquake starting a fire but not damaging the integrity of the bullding, has the same release as an earthquake damaging the building, producing a no-deaths contour extending a litule less than $2 \mathrm{~km}$ downwind.

\subsubsection{GB 155-mm Projectiles}

Table 3.212 lists the risk analysis accidents for $155 \mathrm{~km}$ projectiles loaded with GB. Accidents in the storage area include a vehicle collision followed by a fire and detonation of burstered munition as well as the drop of a pallet followed by an explosion of a single munition. In both cases a toxic vapor plume is produced, with a no-deaths contour extending a little more than $2 \mathrm{~km}$ downwind. A signature would be an explosion during the handling operations of the storage area.

On transport a vehicle collision is possible, resulting in detonation of several munitions and producing a toxic cloud that would have a no-deaths contour, under worst-case meteorological conditions, extending $17 \mathrm{~km}$ downwind.

At the CHB, an aircraft crash into the building, with no resulting fire, could result in the release (by explosion) of a toxic cloud that would leave a no deaths contour extending a little less than $40 \mathrm{~km}$ downwind. In the event of a fire, the downwind extent would be a little less than $70 \mathrm{~km}$. It is estimated that dropping a pallet in the course of transport between the CHB and $\mathrm{MDB}$ could result in the explosion of a munition and a dowriwind no-deaths contour extending $3 \mathrm{~km}$ under worst-case meteorological conditions. Several accidents involve detonation of munition in the MDB elther in the unpack area, the ECV, or the explosion 
containment room. In all cases, the signature is the same and wistimated downwind distance of the no-deaths contour would be the same, a little more than $2 \mathrm{~km}$. An earthquake followed by a fire in the MDB is estumated to produce a downwind no-deaths contour extending 9.4 $\mathrm{km}$.

Fallure of the fuel cutoff to the MPF could result in an explosion in the MPF, which would result in the release of a toxic cloud producing a no-deaths contour extending $2.2 \mathrm{~km}$ downwind (PO42), An alreraft crash into the outdoor piping on the MDB could result in a release producing a downwirid no-deaths contour extending $4.9 \mathrm{~km}$ in a case of a crash without a fire and $4.45 \mathrm{in}$ a case of a crash followed by a fite. The signature of this event would be an aircraft crash into the outdoor piping on the MDB.

Fallure to stop the feed onto the liquid incinerator when the furnace is shut down would result in overloading the charcoal filters on the gas cleanup system. This could result in the release of a toxic cloud, with the downwind no-deaths contour extending $6.3 \mathrm{~km}$. It probably would be first indicated by an alam, whilch is connected to the stack monitor.

\subsubsection{VX 155. $\mathrm{mm}$ Projectiles}

Table 3.2.13 lists the risk analysis for accidents involving $155-\mathrm{mm}$ projectles filled with VX. At the storage igloo are a variety of handling accidents that result in the detonation of a single projectile through dropping or falling. A vehicle collision followed by a fire can result in a release of a cloud with a no-deaths contour extending $3.3 \mathrm{~km}$ downwind. A large aircraft crash into a storage area can produce a massive release, in the case of no fire, of a cloud that has a theoretical no-deaths contour extending for more than $40 \mathrm{~km}$ downwind. If the aircraft crash is followed by a fire, the contour has a theoretical capability of reaching $240 \mathrm{~km}$ downwind. These accidents are easily differentiated from the forklift collisions and other munitions mishandling accidents by the presence of a large aircraft crash.

During transport of munitions to a storage area or to the CHB, a vehicle collision followed by a fire and explosion could release enough toxic agent to produce a downwind no-deaths contour extending $9 \mathrm{~km}$ (VO4). At the CHB, an aircraft crash into the building not resulting in a fire can produce a toxic cloud that would have a no-deaths downwind contour extending about $16.5 \mathrm{~km}$. If the crash is followed by a fire, the contour may extend as far as $66 \mathrm{~km}$ downwind.

The explosion of a single munition, whether it is from a dropped pallet during transport to the MDB, a dropperd munition in the unpack area, a dropped pallet in the unpack area, or a detonation in the explosion containment ronm, would result in the release of an agent that would produce a no-deaths downwind contour, under worst-case meteorological conditions, of a little more than $2 \mathrm{~km}$. Earthquake damage to the MDB, followed by fire, whether or not the building structure is damaged, would result in the release of a toxic cloud having a no-deaths contour extending downwind for a little less than $9 \mathrm{~km}$.

Failure of fuel-flow shutoff in the metal-parts furnace could cause an explosion strong enough to release toxic agent to produce a no-deaths contour extending downwind $3.4 \mathrm{~km}$.

\subsubsection{H, HD, HT 155-mm Projectiles}

Table 3.2.14 lists the risk analysis accidents tabulated for demilltarization of $155-\mathrm{mm}$ projectiles filled with mustard. Accidents at the storage igloo include a large aircraft crash into the iglco, followed by burster detonations and fire. This would release a toxic cloud, which under worst-case meteorological conditions would produce a no-deaths contour extending $56 \mathrm{~km}$ in the downwind direction. If there is no subsequent fire, the downwind 
no-deaths contour is reduced to $11 \mathrm{~km}$. A forklift collision and fire would release a toxic cloud with a downwind no-deaths contour of $0.75 \mathrm{~km}$ (SL16,SLA,5,HF7).

During transportation from storage, a vehicle accident followed by fire and detonation of the munitions would produce a toxic cloud that could have a no-deaths contour extending $2,6 \mathrm{~km}$ downwind.

At the CHB, aircraft crashes and earthquakes are potentlal sources of extemally caused accidents. An aircraft crash with no fire would release a cloud producing a no-deaths contour extending $6.2 \mathrm{~km}$ downwind. If the crash is followed by a fire, the estimated contour would extend a little more than $8 \mathrm{~km}$ downwind. An earthquake without a fire would possibly release an agent producing a no-deaths contour of $0.5 \mathrm{~km}$ downwind. If the earthquake is followed by a fire, tho downwind no-deaths contour could be as far as $28 \mathrm{~km}$.

At the MDB, an earthquake, aircraft crash, or indirect alrcraft crash followed by a fire would result in the release of an agent that would produce a no-deaths contour extending 2.2 $\mathrm{km}$ downwind. If there is no fire, the corresponding figure would be $6.67 \mathrm{~km}$. The signatures would be the aircrait crash and the presence or absence of fire.

Failure of fuel shutoff at the metal-parts fumace would result in an explosion that could release enough agent to produce a downwind no-deaths contour of $0.8 \mathrm{~km}$.

\subsubsection{GB 8-in. Projectile}

Table 3.2.15 lists the risk analysis accidents considered in the demilitarization of 8-in. projectiles filled with GB. Explosion of single projectiles from mishandling is estimated to produce a toxic cloud, which under worst-case meteorological conditions would produce a no-deaths downwind contour extending $3.5 \mathrm{~km}$. If a fire followed a vehicle collision, it could result in the release of an agent that would produce a no-deaths contour $4.6 \mathrm{~km}$ downwind.

An accident during transportation from the storage igloo to the $\mathrm{CHB}$ could be a vehicle collision resulting in fire and projectile detonation. It is estimated that this would release a toxic cloud, producing a no-deaths contour extending $2.6 \mathrm{~km}$ downwind under worst-case meteorological conditions. Accidents listed for the CHB include aircraft crashes and earthquakes with and without an ensuing fire. Either an aircraft crash or an earthquake followed by a fire could produce a plume having a no-deaths contour extending approximately $64 \mathrm{~km}$ downwind. If there is no fire, the aircraft crash would produce a contour extending 35 $\mathrm{km}$ downwind and an earthquake $7 \mathrm{~km}$ downwind. The signature of these accidents is obvious from the aircraft crash and the earthquake and fire.

Earthquake damage of the MDB, followed by a fire, is estimated to produce a toxic

- cloud that would have a no-deaths contour extending $12.5 \mathrm{~km}$ downwind. The detonation of a single munition in the MDB explosion containment room could cause ventilation equipment and the structure to fail, releasing a toxic cloud that would have a downwind no-deaths contour extending $3.2 \mathrm{~km}$.

\subsubsection{VX 8-in. Projectile}

Table 3.2.16 lists the risk analysis accidents for the demilitarization of 8-in. projectiles filled with VX. The detonation of a single munition from mishandling (dropping) would produce a cloud with a toxic agent that, under worst-case meteorological conditions, would produce a no-deaths contour extending for $3.5 \mathrm{~km}$ downwind. A forklift collision resulting in a fire could result in the release of an agent that would produce a no-deaths contour extending a little more than $4.5 \mathrm{~km}$ downwind. 
A vehicle accident followed by a fire, during transport between the storage igloo and the $\mathrm{CHB}$, would produce a plume having a no-deaths contour extending $10.4 \mathrm{~km}$ downwind (VO4) under worst-case meteorological conditions.

Accidents listed for the CHB include those caused by large aircraft crashes and earthquakes, followed by fire in one case and no fire in the other case. Both the aircraft crash and the earthquake followed by fire are estimated to release a quantity of agent, producing a no-deaths contour that extends more than $64 \mathrm{~km}$ downwind under worst-case meteorological conditions. An aircraft crash with no fire would produce a corresponding no-deaths contour extending a little less than $16 \mathrm{~km}$ downwind. The earthquake with no fire has the same effect as the explosion of a single round, producing a toxic cloud with a no-death contour extending $3.5 \mathrm{~km}$ downwind. A similar consequence is produced by dropping a munition, producing an explosion in the MDB or detonating of a munition in process in the explosion containment room, each with no firi: In the event of an earthquake followed by a fire, even if the MDB structure is intact, a quantity of agent could be released, which would produce a no-deaths contour extending a little more than $12 \mathrm{~km}$ downwind under worst-case meteorological coriditions. 


\section{SENSORS}

Any accident assessment system will depend to a certain degree on sensors: chemical detectors, smoke detectors, fire detectors (ionization detectors), pressure sensors, and acoustical detectors (a sensitive type of pressure sensor). These sensors must have a readout in the EOC, as well as in the control room. If not, they would be less useful in rapid accident assessment. Also, they must read in real time or near real time if the overall systems have a rapid response.

Here, it is impractical to attempt to deploy enough sensors to detect every conceivable accident at every conceivable location on the facility. Very important input to the accident assessment process will be verbal reports from field personnel, communicating by radio or telephone, to the EOC. Accidents such as vehicle and aircraft crashes and handling accidents not resulting in any agent release would normally be reported verbally. Most releases from transport accidents would be detected by escort personnel with chemical agent detectors and reported verbally.

\subsection{Chemical Sensors Available}

Chemical sensors of interest to this problem are high-level, rapid-acting sensors, both fixed and portable, with the fixed capability of activating a remote alarm. They are described by Kuryk et al. (1987). Historical monitoring systems, such as DAAMS or bubbler absorption systems, are of little help in a system requiring rapid response. The instrument probably used most for fixed installation is ACAMS. Another possibility for fixed location sensors is the real-time monitor. However, with a low level of agent, it can have a response time of up to 12 min compared with 2 min for the ACAMS monitor, for similarly low levels. Portable monitors are the M8A1 and the CAM. These all have response times of less than 2 min for $\mathrm{GB}$, and most of them respond to other agents in a minute or less. The M8 is not reliable for mustard detection and must use a fluorinating filter for the detection of VX. These detection response times are for concentrations immediately dangerous to life and health.

\subsection{Remote Sensing Systems}

Development is under way, in more than one location, for systems that can use optical properties to detect hazardous chemicals in air from long distances. Some of these systems use infrared or ultraviolet light sources to measure the absorption, at one or more wavelengths, of the airborne contaminant, employing either a widely separated transmitter and receiver or a co-located transmitter and receiver, with a comer reflector at the other end of the path to be monitored (Simpson, 1989). Length of the path can be up to $5 \mathrm{~km}$. At least one instrument can be programmed to scan across an array of mirrors and retroreflectors to construct a "detection cage" around a building or other location where toxic chemicals are expected.

The systems can be expensive, costing up to $\$ 100$ to 200 thousand per site. However, they offer the possibility of high-confidence perimeter detection of very toxic vapors. 


\section{CONCLUSIONS}

1. Many of the accidents/incidents covered in the risk analysis can be quickly and unambiguously assigned to one of the four accident categories (chemical occurrence, advisory, on-post emergency, and community emergency) on the basis of the already known munition and agent involved and the location. Ambiguous cases can be resolved by the accident's signature (extemally observable characteristics).

2. Accidents not considered significant or credible by the probabilistic risk analysis can be assigned to one of the four accident categories by a simple decision tree, given the inputs of munition type, agent, meteorology, inventory in affected area, and accident signature, including sensor readings.

3. In some circumstances the magnitude of an outdoor release may be estimated from a concentration-time integral reading by a fast chemical sensor, the nieteorology, and the position of the sensor with respect to the point of release and the wind direction.

4. Five-minute assessment time appears to be achievable if:

a. The EOC or other assessment facility is manned and operating when the accident/incident occurs,

b. Personnel at the accident site are able to communicate directly with th $E O C$,

c. Meteorological data are being collected and stability conditions are being calculated,

d. Computer analytical program is up and running. 


\section{REFERENCES}

Kuryk, B. A., R. G. Roux, W. R. Brankowitz, K. J. Flamm, P. M. Owens, L. C. Rowe, W. F. Spurgeon, T. W. Thomas, C. F. Whyne 1987. Chemical Stockpile Dispisal

Program Monitoring Concept Study SAPEO-CDE-I3-87006 APG-MD 21010-5401.

Parsons Co. PMCD-CSDP 1989. Container Handling Building (CHB) Project Development Brochure, Tooele Army Depot (TEAD) USACE, Huntsville, Alabama.

PEO-PMCD 1987. Risk Analysis of the On-Site Disposal of Chemical Munitions, SAPEO-CDE-IS-87010, Aberdeen Proving Ground, Maryland, August.

Program Executive Officer-Program Manager for Chemical Demilitarization (PEO-PMCD) 1988. "Chemical Stockpile Disposal Program. Final Programmatic Environmental Impact Statement" Vol. 3, Appendix C, APG-MD21010-5401, Aberdeen Proving Ground, Maryland.

Rogers, G. O., A. P. Watson, J. H. Surensen, R. D. Sharp and S. A. Carnes 1990. Evaluating Protective Actions for Chemical Agent Emergencies, ORNL/TM-11340, Oak Ridge National Laboratory, Oak Ridge, Tennessee.

Schneider Engineers 1989. Emergency Response Program Guidance for the Chemical Sinckpile Disposal Program, for Office of the Program Manager for Chemical Demilitarization, Fifth Draft.

Simpson, O., personal communication, TECAN Remote, Norcross, Ga., Sept. 1, 1989.

Sorensen, J. H. 1988, Evaluation of Warning and Protective Action Implementation Times for Chemical Weapons Accidents, ORNL/TM-10437, Oak Ridge National Laboratory, Oak Ridge, Tennessee.

Whiteside, J. R., personal communication, E.I. DuPont de Nemours Co., Wilmington, DL, 27 July 1989. 
APPENDIX A

CHEMICAL DEMILITARIZATION PROCESS FLOW SHEET (JACADS) 

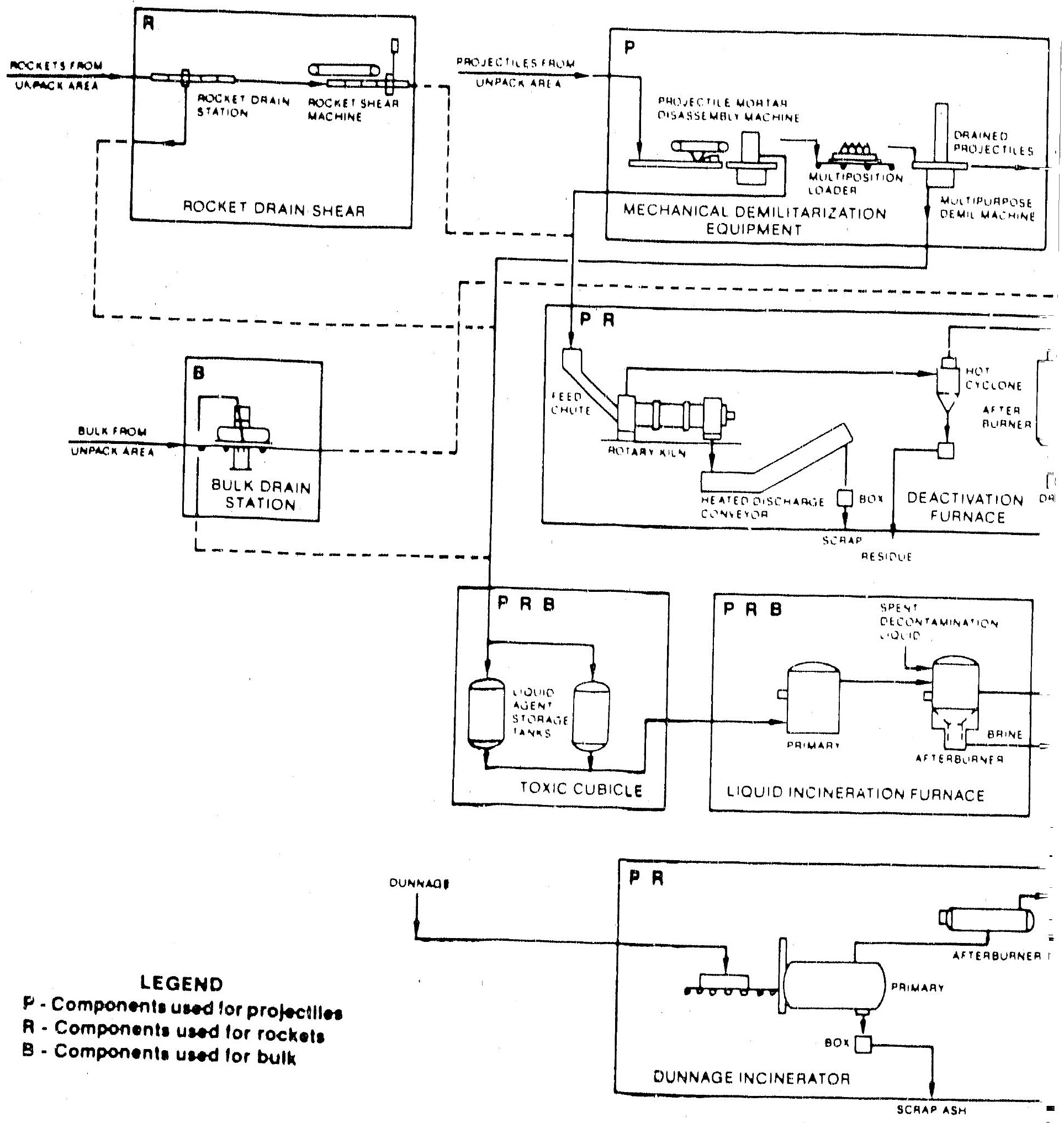
OFNL.OWG 86.11961
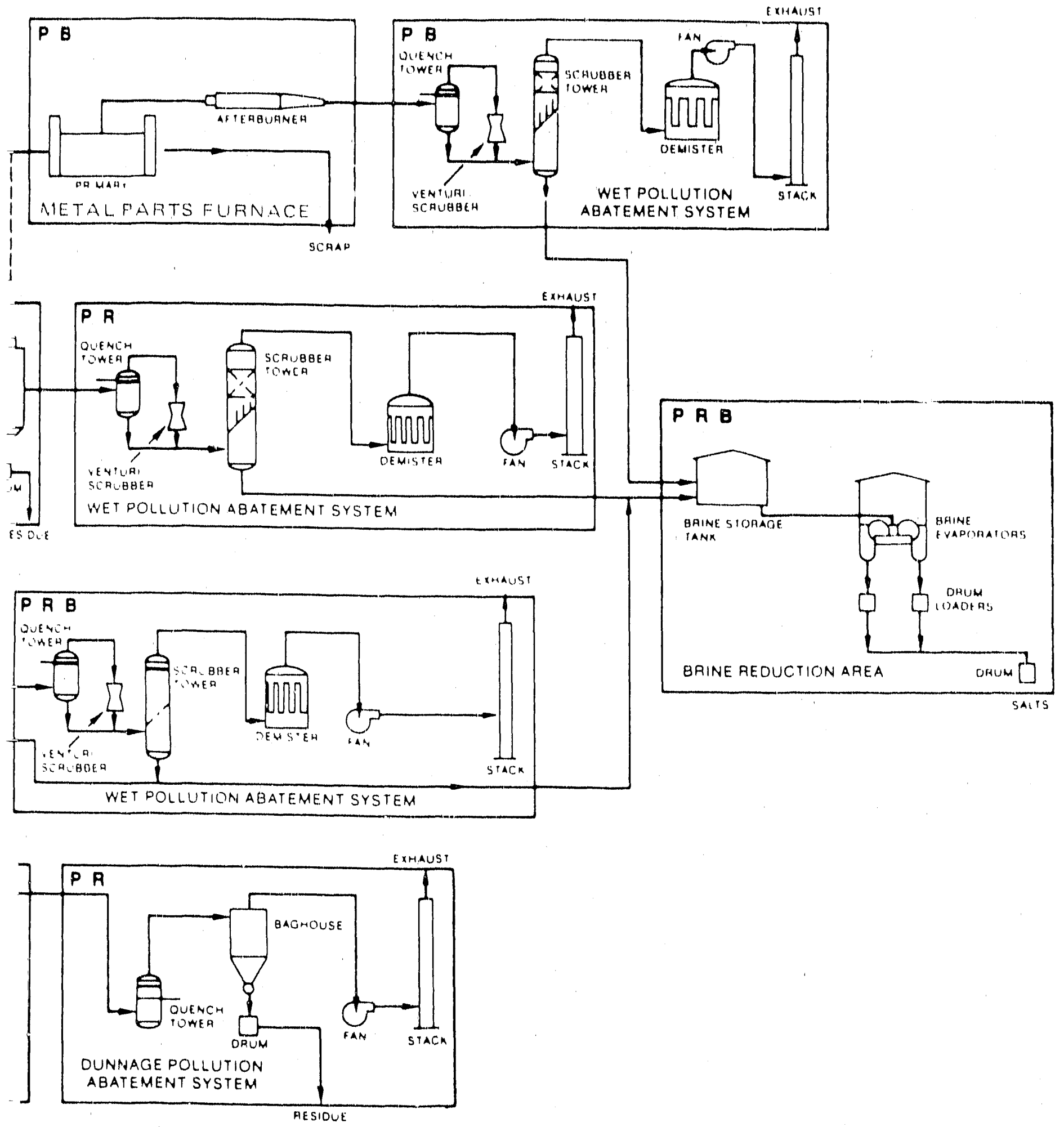
APPENDIX B

ACCIDENT DESCRIPTIONS 
Table B.1. Long-term storage and handling accident scenario descriptions

Code Accident Description

HS 02 Forkllit collision with short-duration fire

HS 03 Forklift the puncture

HS 04 Forklift collision without fire

HS 05 Drop of munition leads to detonation

HS 06 Collision accident leads to detonation

HS 07 Collision accident with prolonged fire

HS 08 Munition pallet dropped during pallet inspection

HS 09 Forklift the puncture during pallet inspection

HS 10 Forklift collision during pallet inspection

HS 11 Munition pallet dropped during pallet inspestion; detonation occurs

HS 12 Forklift collision; detoration occurs

SL 02 Munition punctured by forklift tine during leaker-handling activities

SL 03 Spontaneous ignition of rocket during storage (not analyzed for lack of quantitative data)

SL 04 Large aircraft direct crash onio storage area; fire not contained in $30 \mathrm{~min}$ (note: assume that detonation occurs if burstered munitions are hit, fire involving burstered munitions not contained at all)

SL, 05 Large aircraft indirect crash onto storage area; fire not contained in $30 \mathrm{~min}$ (see note in SL04)

SL 06' Tomado-generated missiles strike the storage magazine, warehouse, or open storage area; munitions breached (no detonation)

. SL, 07 Severe earthquake breaches the munitions in storage igloos; no detonation

SL 08 Meteorite strikes the storage area; fire occurs; munitions breached (if burstered, detonation also occurs)

SL 09 Munition dropped during leaker isolation operation; munition punctured

SL 10 Storage igloo or warehouse fire from internal sources

SL 11 Munitions are dropped because of pallet degradation

SL 12 Liquid petroleum gas (LPG) infiltrates igloo/building

SL 13 Flammable liquids stored in nearty facilities explode: fire propagates to munition warehouse

SL 14 Tomado-induced building collapse leads to breaching/detonation of munitions 
Tuble B.1. (continued)

\begin{tabular}{|c|c|}
\hline Code & Accident Descriptlon \\
\hline SL 15 & Small alreraft direct crashi; no fire: detonation (If burstered) \\
\hline SL 16 & Large alreraft direct crash; no flre: detonation (If burstered) \\
\hline SL 17 & $\begin{array}{l}\text { Large alreraft direct crashi, fire contuined within } 30 \mathrm{~m} / \mathrm{ln} \text { (applies to nonburstered } \\
\text { munitlons only) }\end{array}$ \\
\hline SL 18 & Small aircraft direct crash onto warchouse or opon storage yard; no firo \\
\hline Sl. 19 & $\begin{array}{l}\text { Small alreraft direct crash onto warchouse or open storage yardi fire contained in } \\
30 \mathrm{~min}\end{array}$ \\
\hline
\end{tabular}

SL 20 Large aircraft indirect crash onto storage area; no fire

SL 21 Large alrcraft indirect crash onto storage area; fire contained in $30 \mathrm{~m} / \mathrm{n}$

SL. 22 Severe earthquake leads to munition detonation

SL 23 Tomado-generated missiles strike the storage iglon and lead to munition detonation

SL 24 Lightning strikes ton containers stored outdoors

SL. 25 Munition dropped during leaker isolation, munition detonates

SL A26 Earthquake occurs; NAAP warehouse is intact; no ton containers damaged; fire occurs

SL. A27 Earthquake occurs; Tooele Army Depot (TEAD) warchouses intact: munitions intact; fire occurs at one warehouse

SL A28 Earthquake occurs; Umatilla Depot Activity (UMDA) warehouses intact; munitions intact; fle occurs at one warehouse

SL B26 Earthquake occurs; NAAP warehouse is intact; ton container darnaged; no fire

SL B27 Earthquake occurs; TEA.D warchouses intact; munitions intact; fire occurs at two warehouses

SL B28 Earthquake occurs; UMDA warchouses intact; munitions intact; fire occurs at two warehouses

SL C26 Earthquake occurs; NAAP warehouse is intact; ton container damaged; fire occurs

SL C27 Earthquake occurs; one TEAD warehouse is damaged; munitions intact; fire occurs at one warehouse

SI C28 Earthquake occurs; UMDA warchouses intact; munitions in one warehouse damaged; no fire occurs

SL D26 Earthquake occurs; NAAP warchouse is damaged; ton containers damaged; fire occurs

DL D27 Earthquake occurs; one TEAD warehouse is damaged; munitions intact; fire occurs at two warehouses 
Table B.1. (continued)

Code Accident Description

SL D28 Earthquake occurs; UMDA warehouses intact; munilions in one warehouse damaged; fire occurs at warehouse with undamaged munitions

SL E26 Earthquake occurs; NAAP warehouse is damaged; ton containers damaged; no firo occurs

SL E27 Earthquake occurs; two TEAD warehouses damaged; munitions intact; firc occurs at one warchouse

SL. E28 Earthquake occurs; UMDA warehouses intact; munitions in one warehouse damaged; flie occurs at warehouse with undanaged munitions

SL F27 Earthiquake occurs; two TEAD warehouses damaged; munitions intact; fire occurs at two warehouses

SL F28 Earthquake occurs; UMDA warchouses intact; munitions in one warchouse damaged; fire occurs at two warehouses

SL G28 Earthquake occurs; UMDA warehouses intact; munitions in two warehouses damaged; no fire occurs

SL H28 Earthquake occurs; UMDA warehouses intact; munitions in two warehouses damaged; firo occurs at warehouse with damaged munitions

SL K2.8 Earthquake occurs; one UMDA warehouse damaged; munitlons in one warehouse damaged; fire occurs at warehouse with damaged munitions 
T'able B.2. Accident scenario description

\begin{tabular}{ll}
\hline Code & \multicolumn{1}{c}{ Accident Description } \\
\hline HF 01 & $\begin{array}{l}\text { Muniton pallet or contalnor dmpped during movement from munitions holding } \\
\text { igloo (MHI) to munitions demilitarization bullding (MDB) }\end{array}$ \\
HF 03 & $\begin{array}{l}\text { Forkllft colllsion accident with short-duration fire during handing from MHI } \\
\text { to MDB }\end{array}$
\end{tabular}

HF 07 Collision accident without fire

HF 11 Drop of munition pallet from the MHI to MDB leads to detonation

HF 12 Drop of baro, single munition inside the MDB leads to detonation

HF 13 Drop of palletized munition (in container) Inside the MDB leads to detonation

HO 01 Drop of bare pallet or single item at storage ar.

HO 02 Forkllft collision with short duration fire at storage area, involving bare munitions

HO 03 Forklift the accident involving bare munitions at storage area

HO 04 Forklift collision accident without fire at storage area, involving bare munitions

HO 05 Drop of on-site container

HO 06 Forklift collision with short-duration fire during handling of on-site container

HO 07 Forklift collision without fire during handling of on-site container

HO 11 Drop of bare palletized munition leads to detonation

HO 12 Forklift collision accident at storage area leads to detonation of burstered munition

PO 21 Direct crash of a large or small alrcraft damages the outdoor agent piping system at Tooele Army Depot (TEAD); no fire

PO 22 Direct crash of a large or small aircraft damages the outdoor agent piping system at TEAD; fire occurs and is not contained

PO 12 Direct crash of large aircraft on MDB; no fire

PO 13 Direct crash of large aircraft on MDB; fire

PO 19 Indirect crash of large aircraft on MDB; fire

PO 25 Earthquake damages the MDB structure; munitions fall and are purictured; fire is suppressed 
Table B.2. (continued)

\begin{tabular}{ll}
\hline Code & \multicolumn{1}{c}{ Accldent Description } \\
\hline PO 26 & $\begin{array}{l}\text { Earthquake damages the MDB structure; munitions fall and are puncturedi } \\
\text { earthquake also initlates fire; fire suppression system fulls }\end{array}$ \\
PO 29 & $\begin{array}{l}\text { Earthquake damages the MDB; munitions are intact; fire occurs; fire } \\
\text { suppresslon system falls }\end{array}$ \\
PO 30 & $\begin{array}{l}\text { Earthquake damages the MDB; munitions are intact; toxic cubicle (TOX) } \\
\text { damaged; no fire occurs }\end{array}$ \\
PO 33 & $\begin{array}{l}\text { Earthquake causes munitions to fall, but no detonation occurs; the MDB is } \\
\text { intact; the TOX is intacti earthquake also initiates fire; fire suppression system } \\
\text { falls }\end{array}$
\end{tabular}

PO 34 Earthquake causes munitions to fall, but no detonation occurs; the MDB is intact; the TOX is damaged; fire occurs; fire suppression system falls

PO 41 Failure to stop agent feed to the llquid incinerator (LIC) overloads the ventilation system

PO 42 MPF explosion due to failure to stop fuel flow after a shutdown

PO 45 Ton container is spllled in the explosion a ntainment vestlbule (ECV); MDB structure falls due to subsequent agent fire

PO 49 Munition detonation in explosion containment room (ECR) causes structural and ventllation system fallure

PO 50 Munition detonation in ECR causes structural failure, a fire, and a ventilation failure

PO 51 Ton container spill in the MDB results in fire and structural fallure

PO 52 A burstered munition is fed to the dunnage incinerator (DUN)

vo 01 A munitions vehicle collision/overtum occurs, and crush forces fail the agent containment

Vo 03 A munitions vehicle collision/overturn occurs, and puncture forces fall the agent containment

Vo 04A A munitions vehicle accident with fire occurs, causing detonation of burstered munitions. Ignition of the propellant by a probe could also detonate the burster of a cartridge, and the burster of a rocket could be detonated by induced impact

VO 04B Ignition of the rocket propellant

vo 09 A severe earthquake occurs, causing a munitions vehicle accident, and crush forces fail the agent containment

Vo 12. A severe earthquake occurs, causing a munitions vehicle accident and fire that detonates burstered munitions 
Table B.2. (continued)

\begin{tabular}{ll}
\hline Code & \multicolumn{1}{c}{ Accident Description } \\
\hline PO 61 & $\begin{array}{l}\text { Direct or indirect crash of large alrcraft on container-handling building (CHB) } \\
\text { results in rupture of agent contalnment and (for burstered munitions) detonation }\end{array}$ \\
PO 62 & $\begin{array}{l}\text { Direct or indirect crash of large alrcraft on CHB results in fire; burstered } \\
\text { munitions detonate }\end{array}$ \\
PO 63 & $\begin{array}{l}\text { Severe earthquake damages CHB structure and results in rupture of agent } \\
\text { containtment and (for burstered munitions) detonation }\end{array}$ \\
PO 64 & $\begin{array}{l}\text { Severe earthquake damages CHB structure and results in fire: burstered } \\
\text { munitions detonate }\end{array}$ \\
\hline
\end{tabular}


Table B.3. CHB handling accident scenarios

Code

Accident Description

HF 21 Forklift collision at unloading dock or during movement to storage location results in rupture of agent containment

HF 22 Forklift collision at unloading dock or during movement to storage location results in detonation

HF 23 Forklift collision at unloading dock or during movement to storage location results in fire

HF 24 On-site container dropped at unloading dock or during movement to storage location results in rupture of agent containment

HF 25 On-site container dropped at unloading dock or during movement to storage location results in detonation

HF 41 Forklift collision during movement from storage to lift results in rupture of agent containment

HF 42. On-site container dropped during movement from storage to lift results in rupture of agent containment

HF 43 Forklift collision during movement from storage to lift results in fire

HF 44 Forklift collision during movement from storage to lift results in detonation

HF 45 On-site container dropped during movement from storage to lift results in detonation 


\section{APPENDIX C}

\section{CALCULATED ACCIDENT DATA FROM RISK ANALYSIS}

(Results are accurate to one significant figure) 


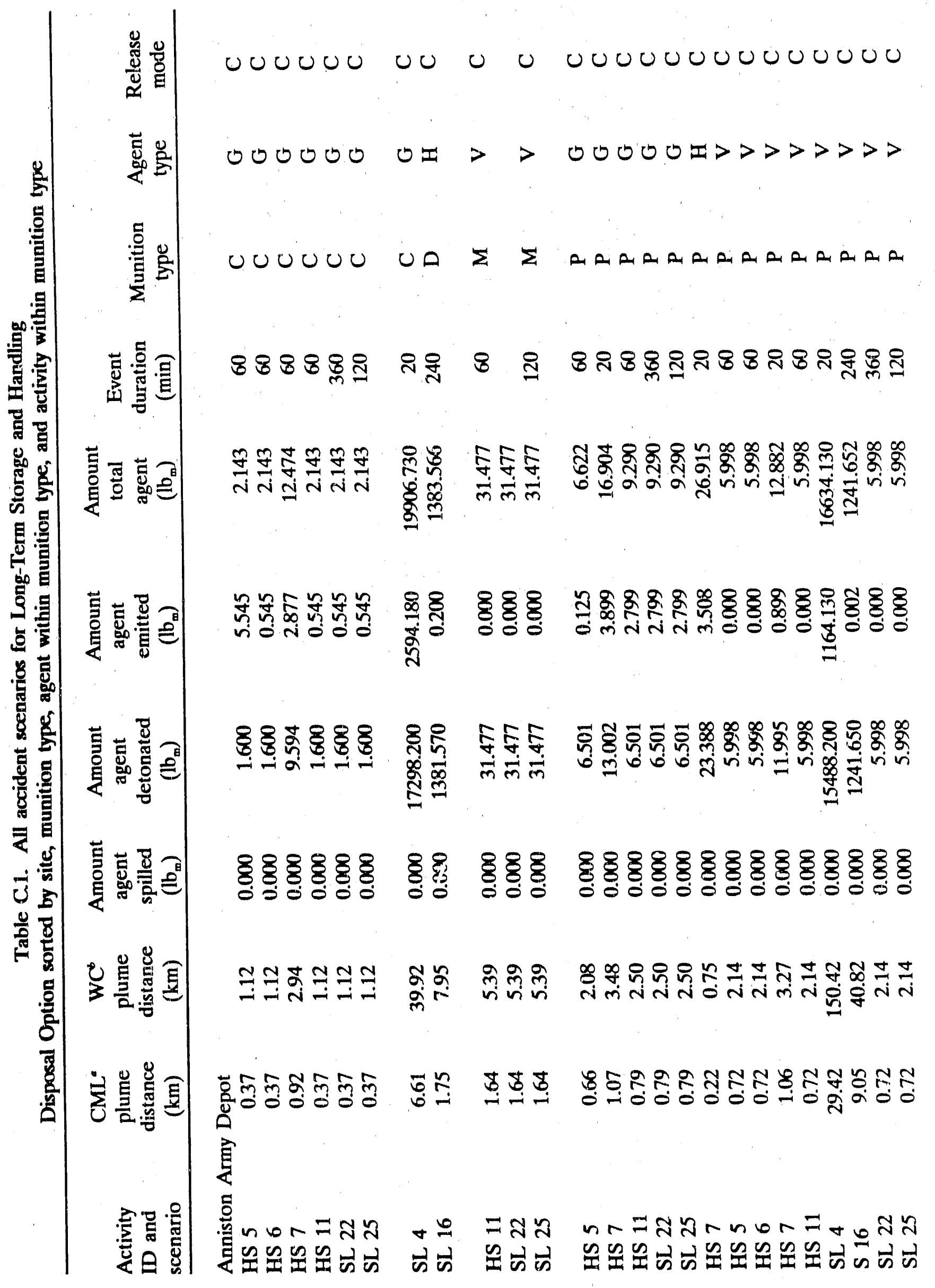




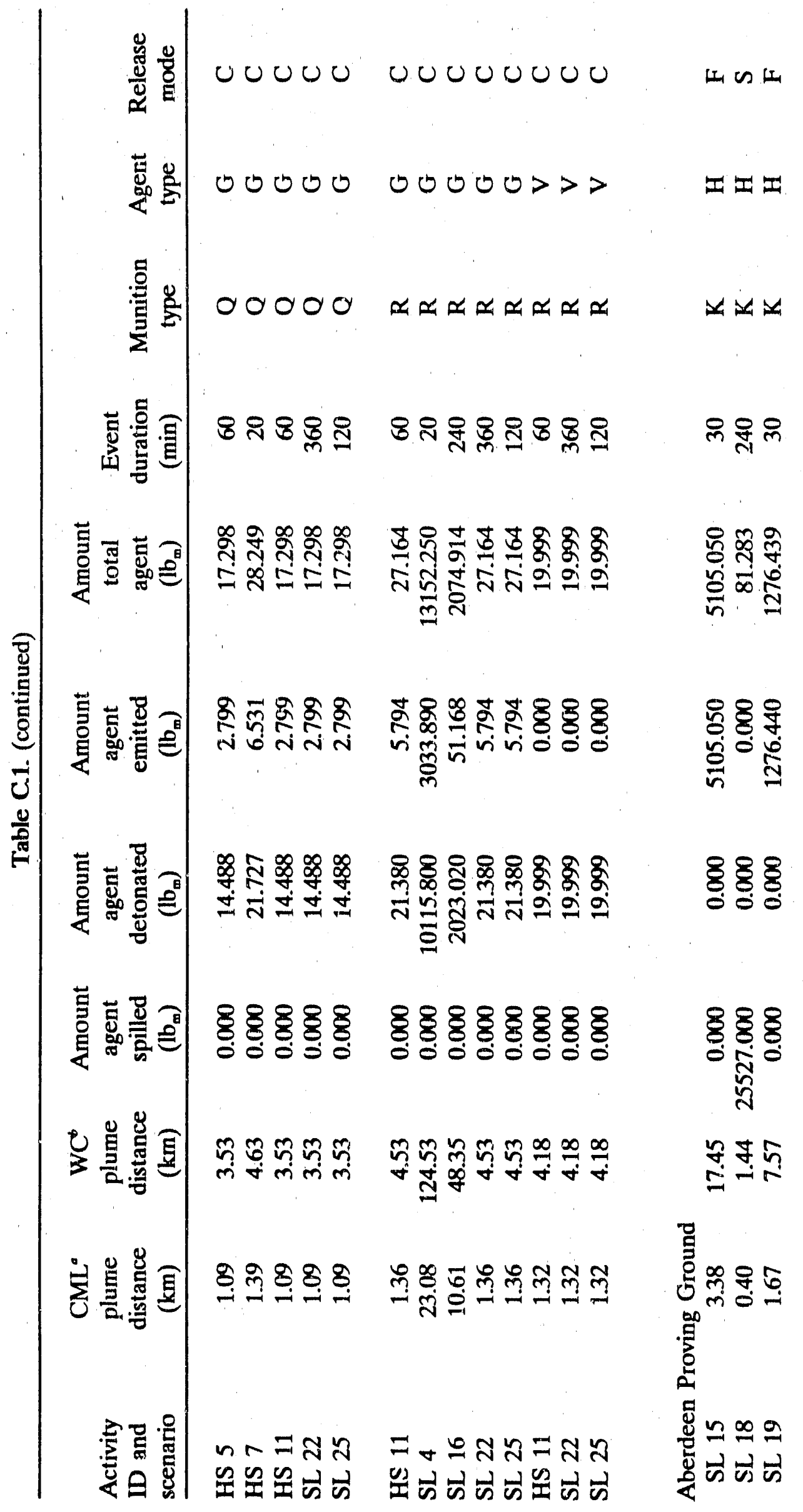




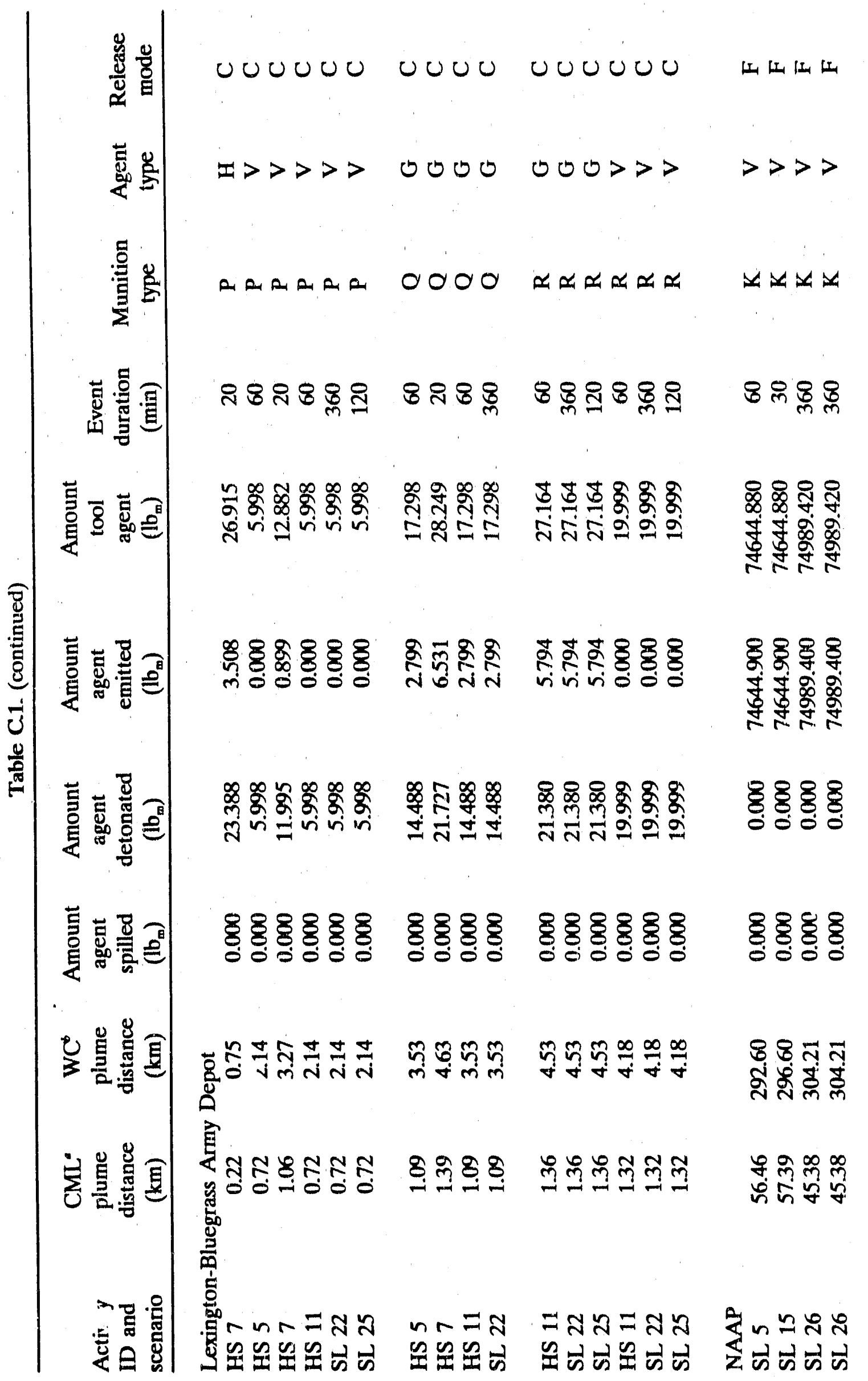




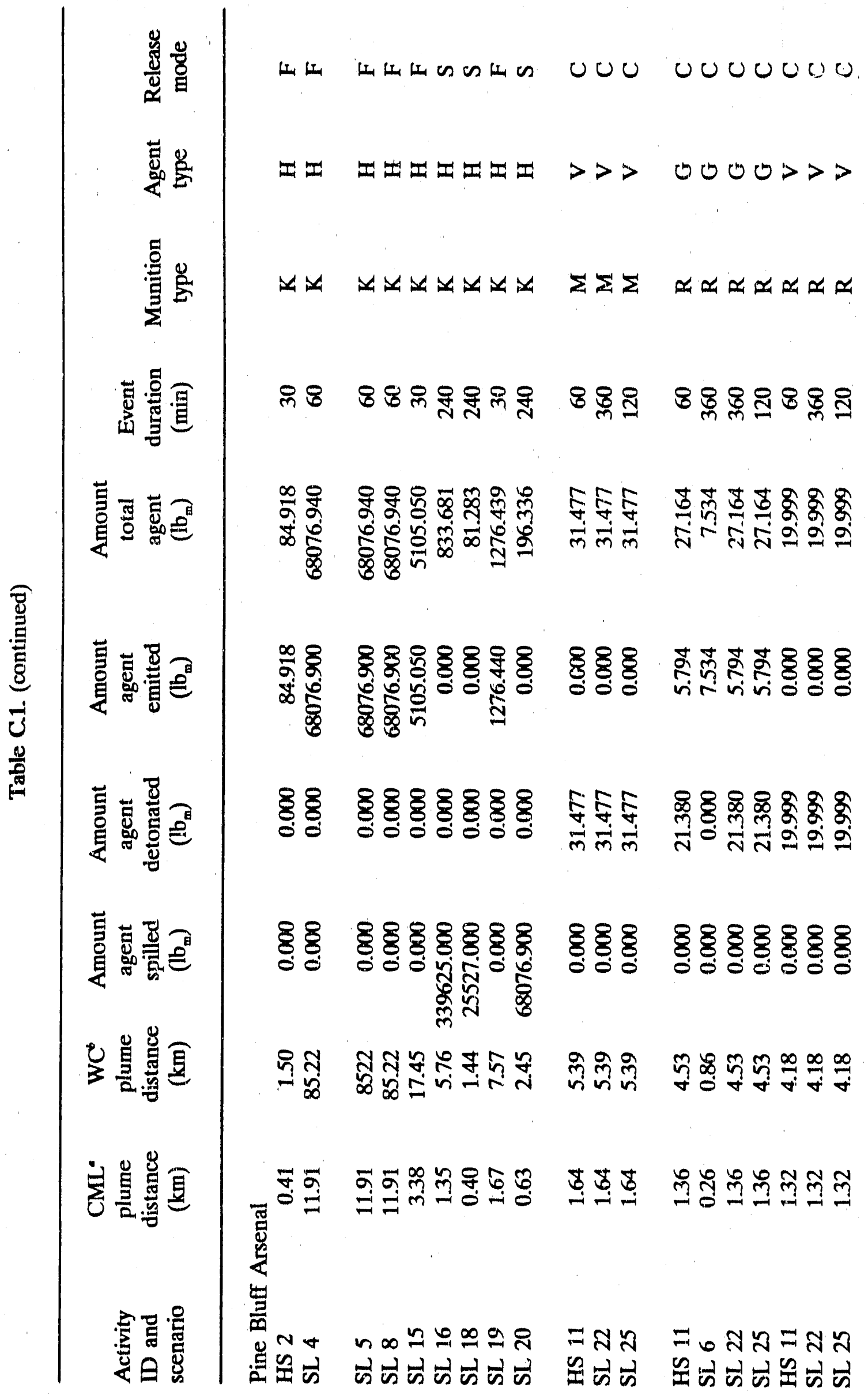




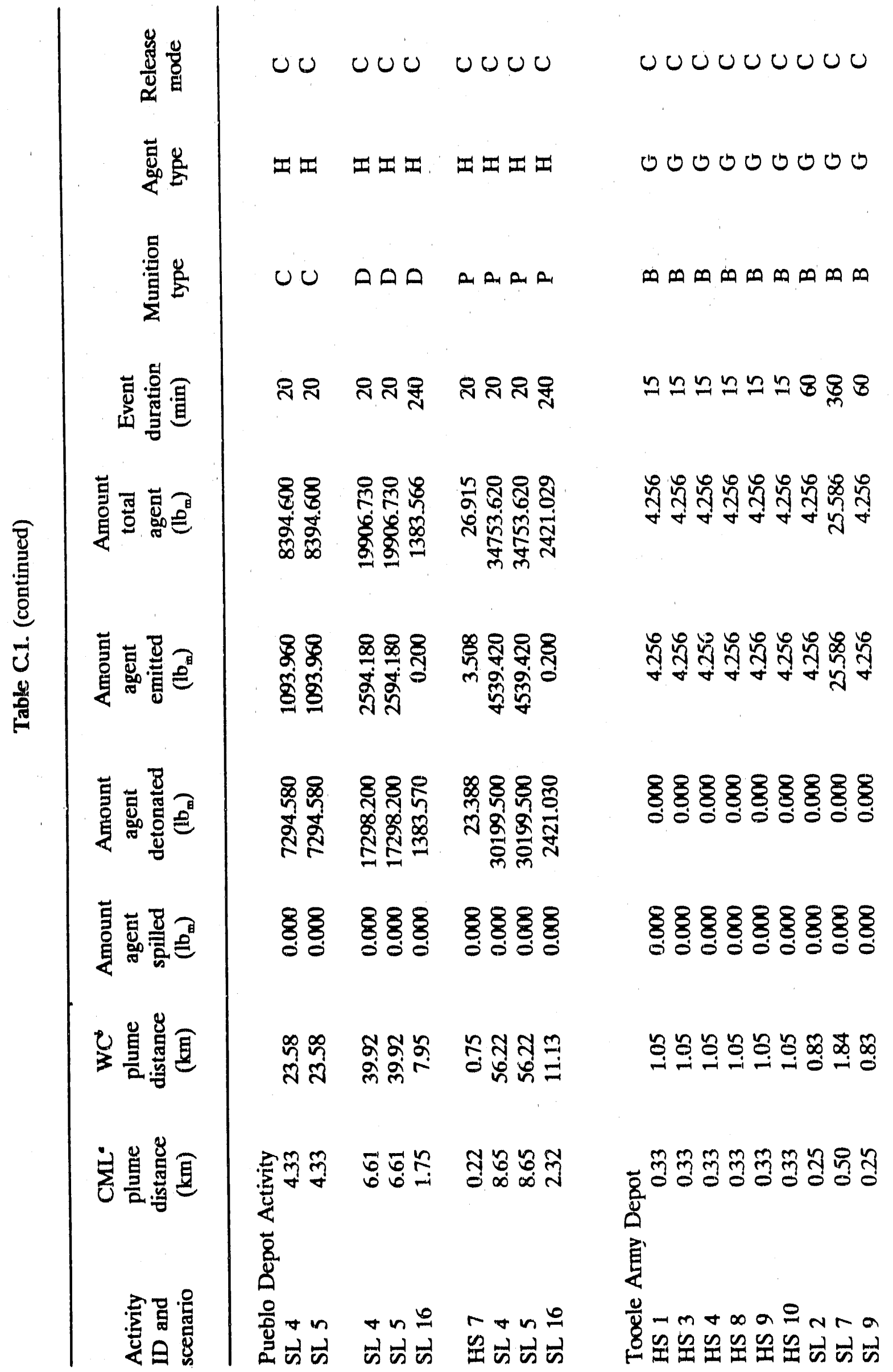




\begin{tabular}{|c|c|c|c|}
\hline 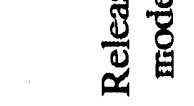 & 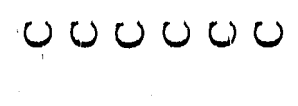 & 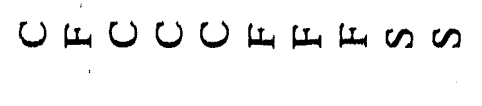 & 000 \\
\hline 若戛 & ט ט ט ט ט & し ט ט U & $>>>$ \\
\hline 总曾 & 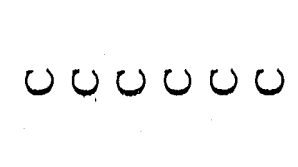 & 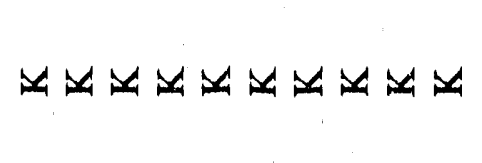 & $\sum \Sigma \Sigma$ \\
\hline 莒总冒冒 & 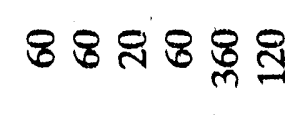 & ص요묠 & 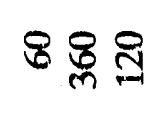 \\
\hline 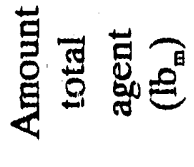 & 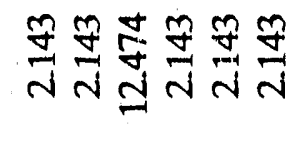 & 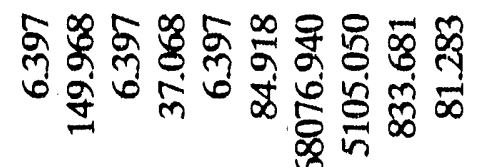 & $\begin{array}{l}\text { 守守守 } \\
\text { लें लं }\end{array}$ \\
\hline 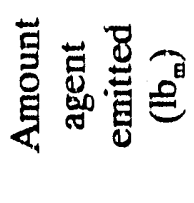 & 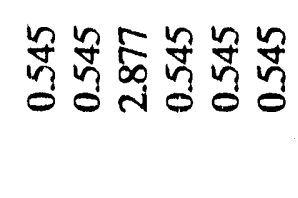 & 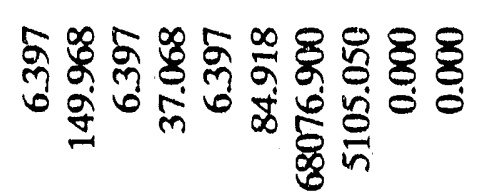 & 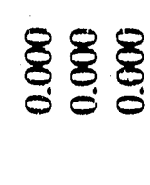 \\
\hline 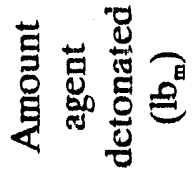 & 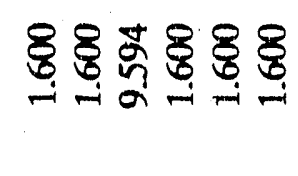 & 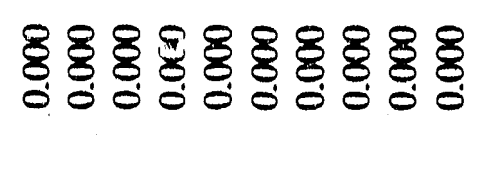 & 害安守 \\
\hline 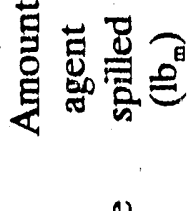 & 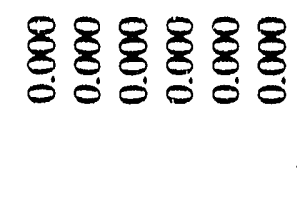 & 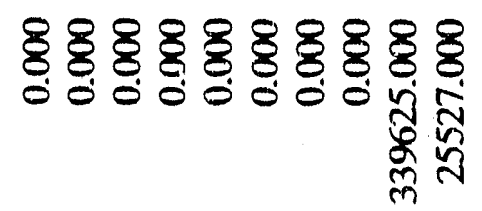 & 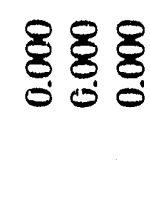 \\
\hline 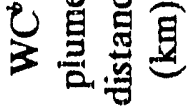 & 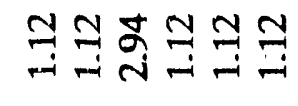 & 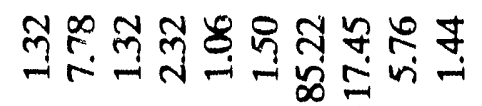 & लेलें ले \\
\hline 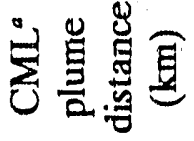 & 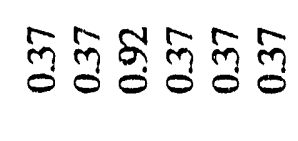 & 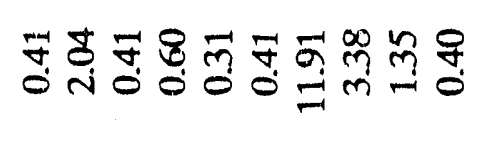 & 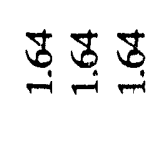 \\
\hline 蛋号曷 & 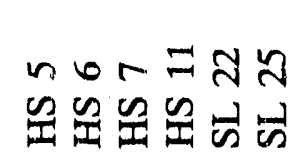 & 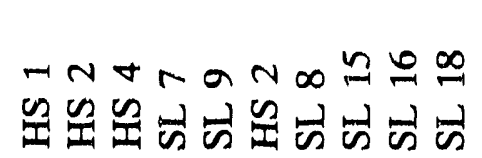 & 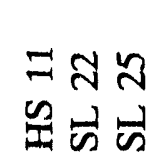 \\
\hline
\end{tabular}




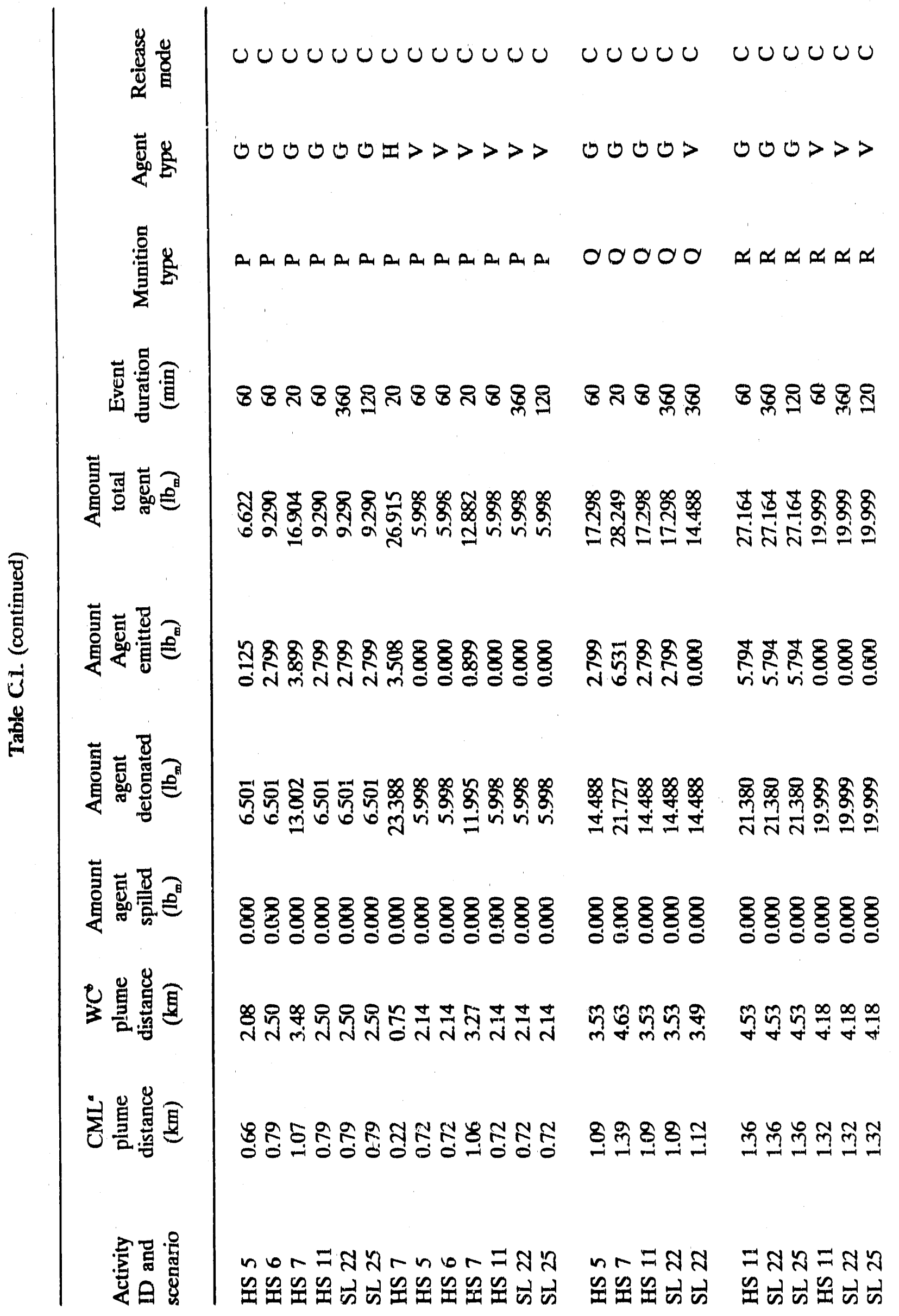




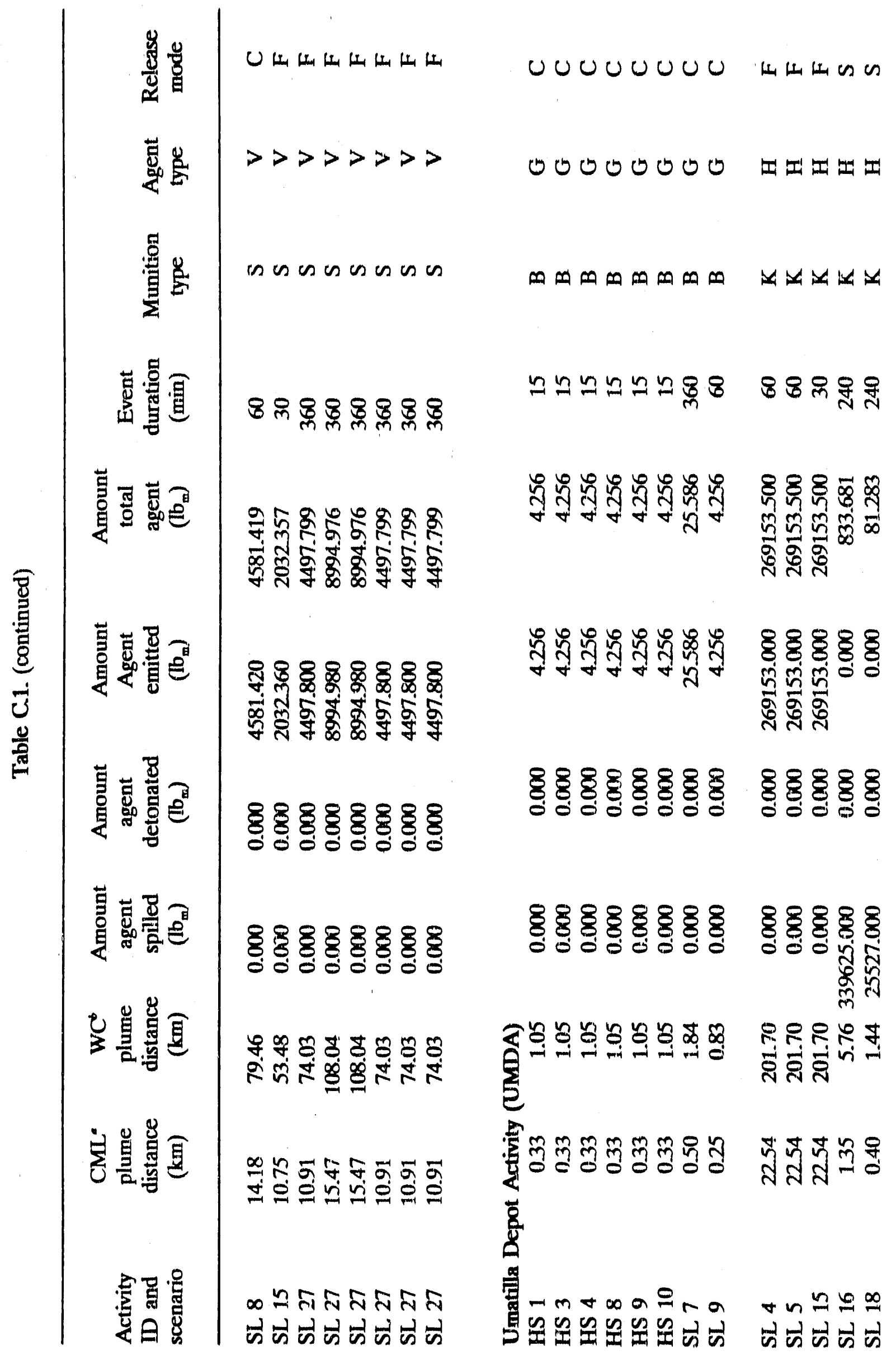




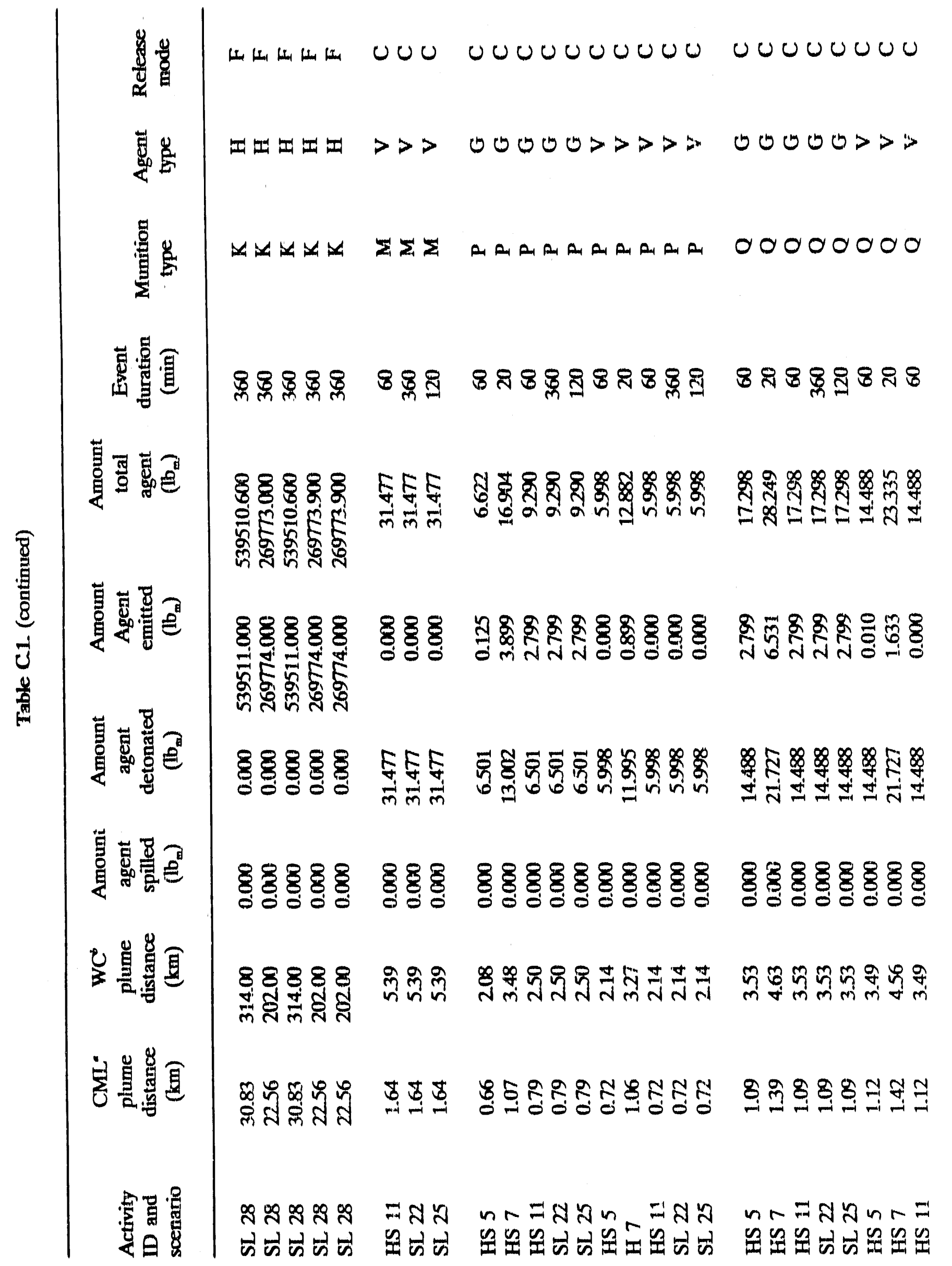




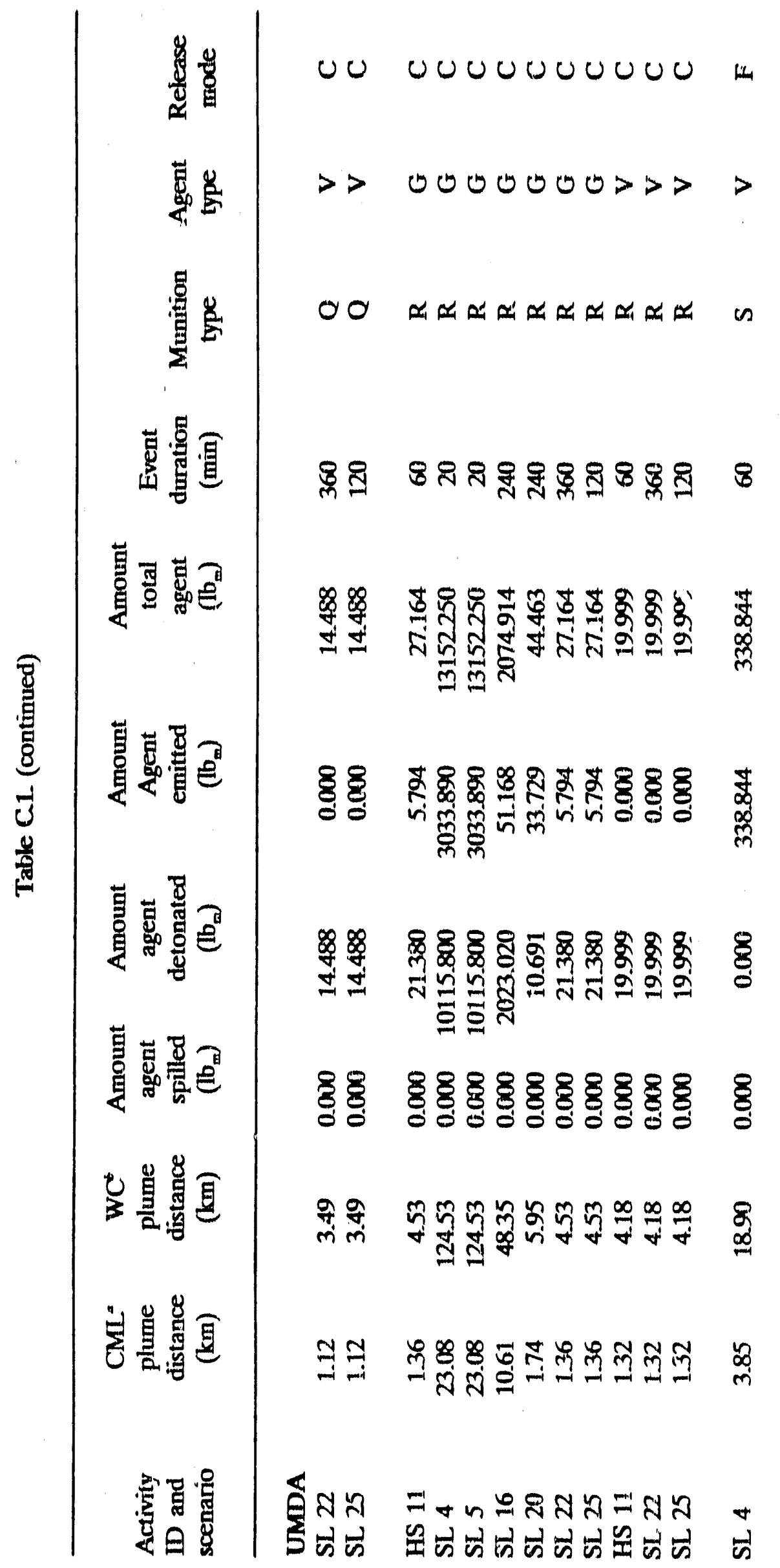




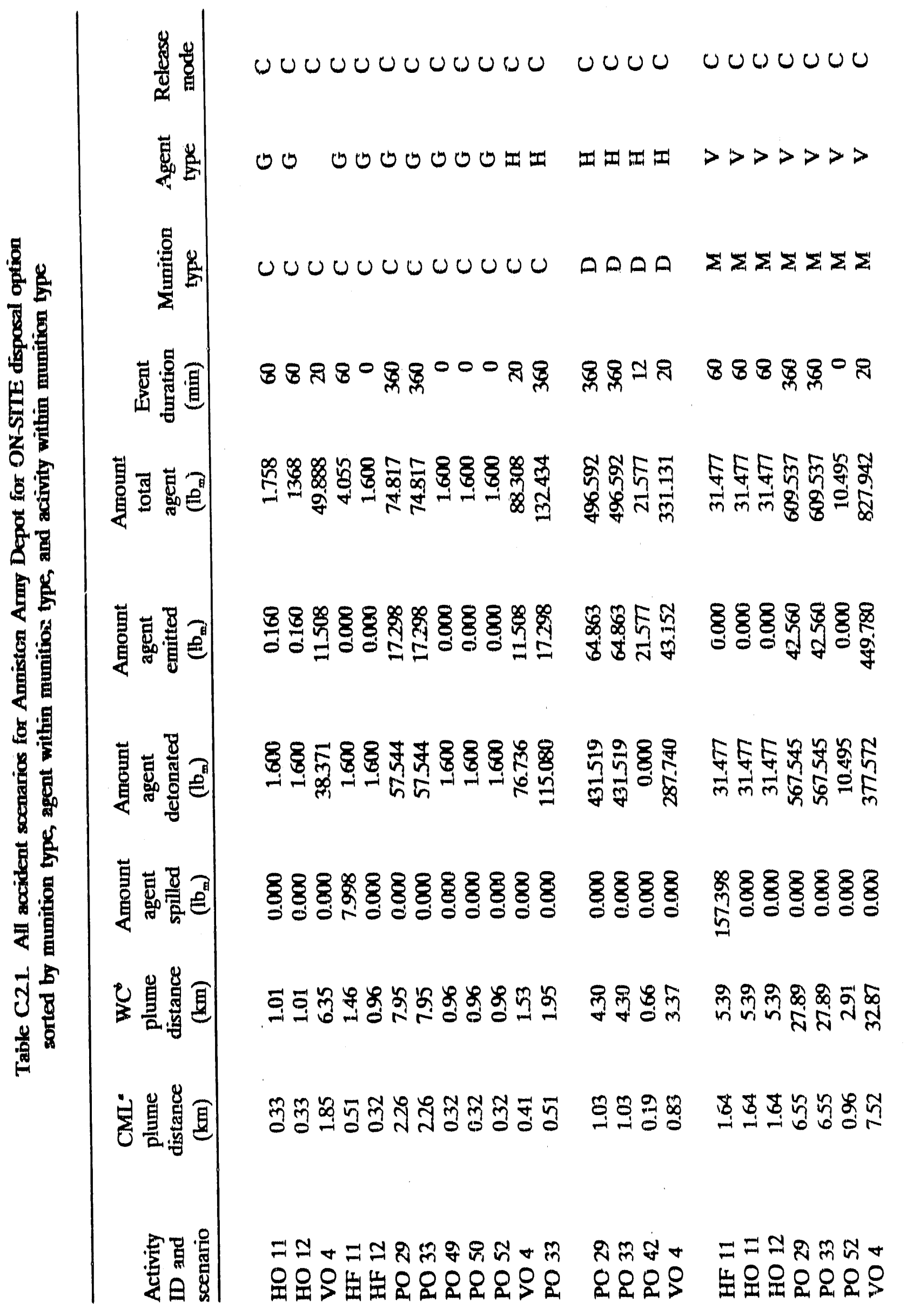




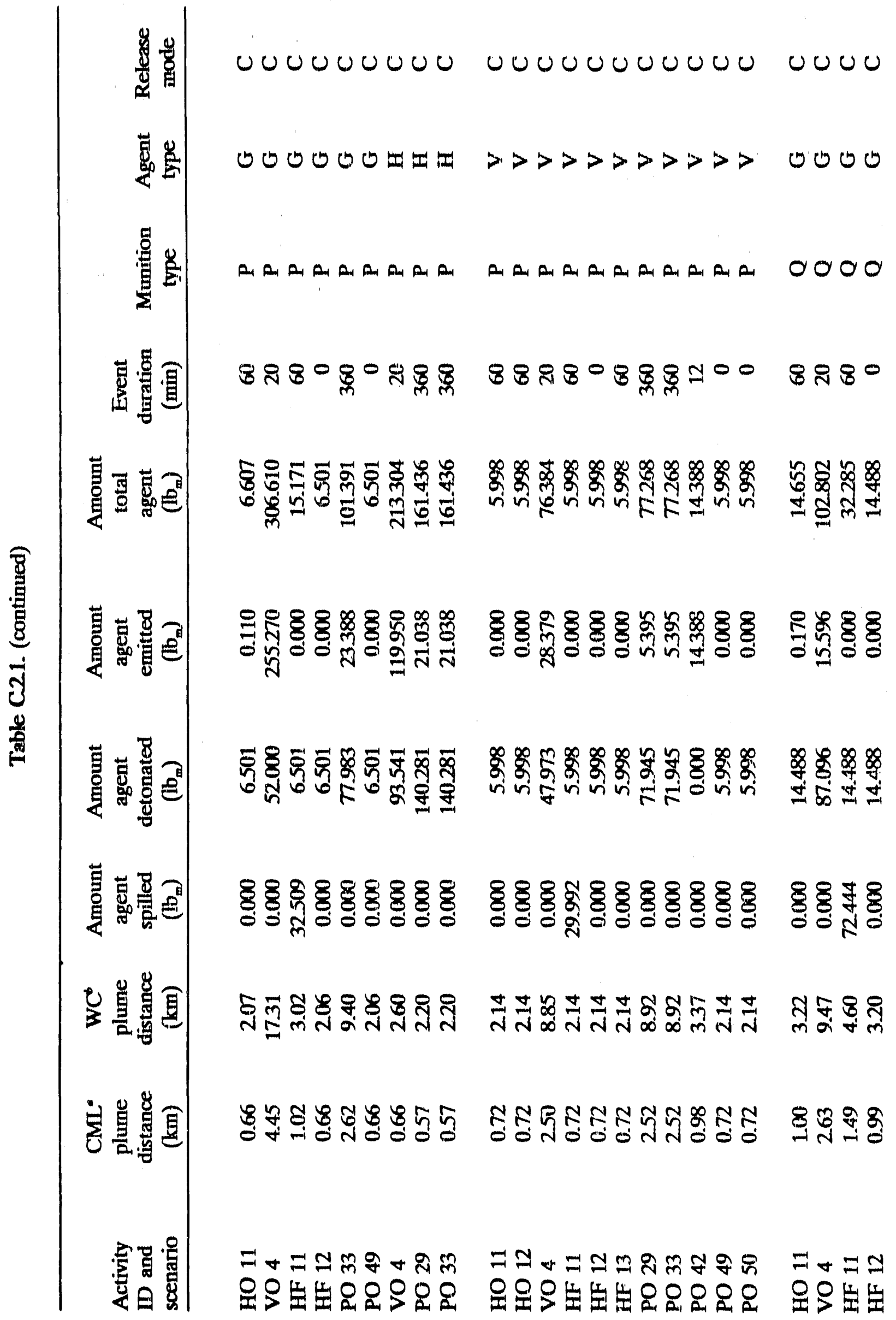




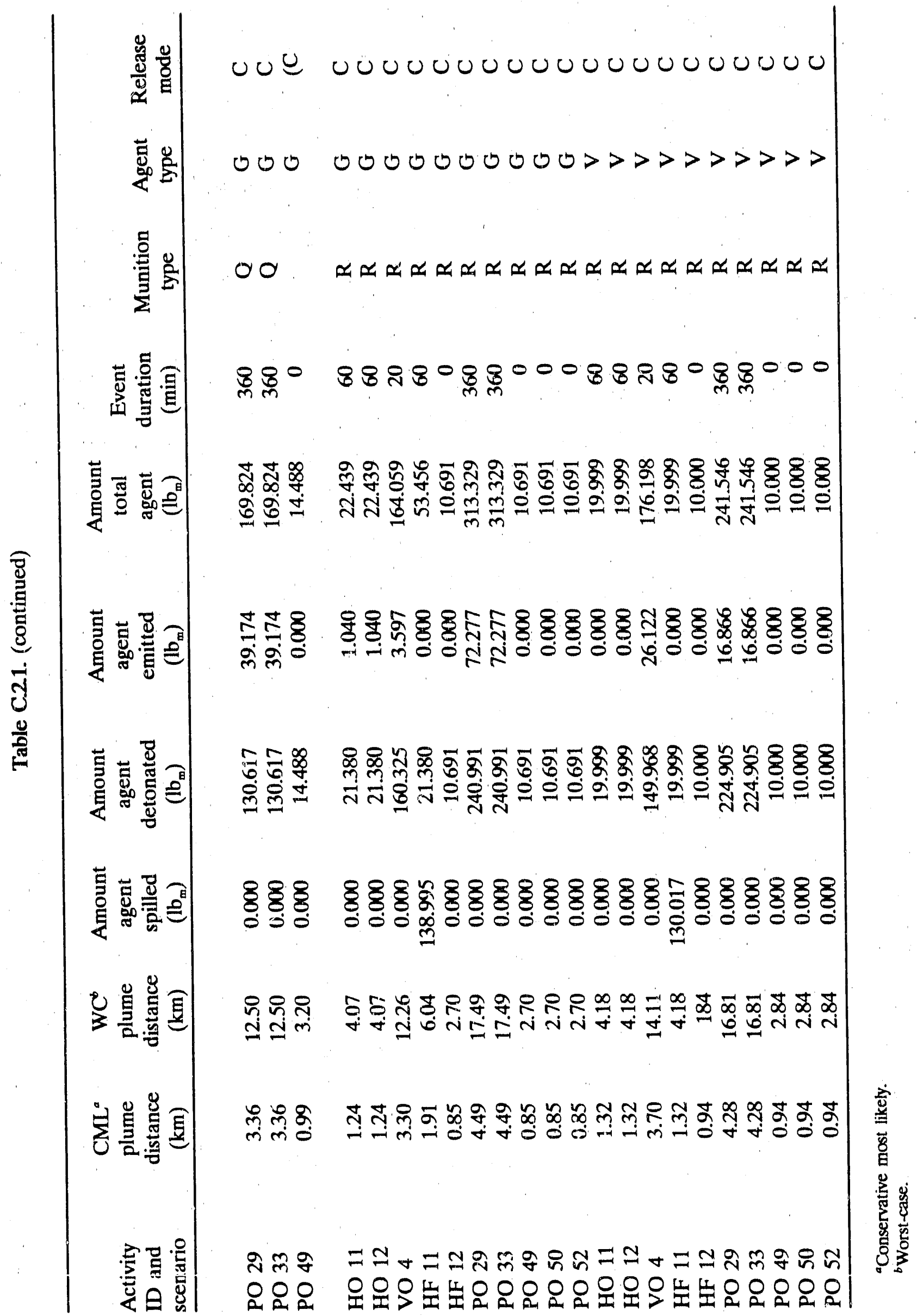




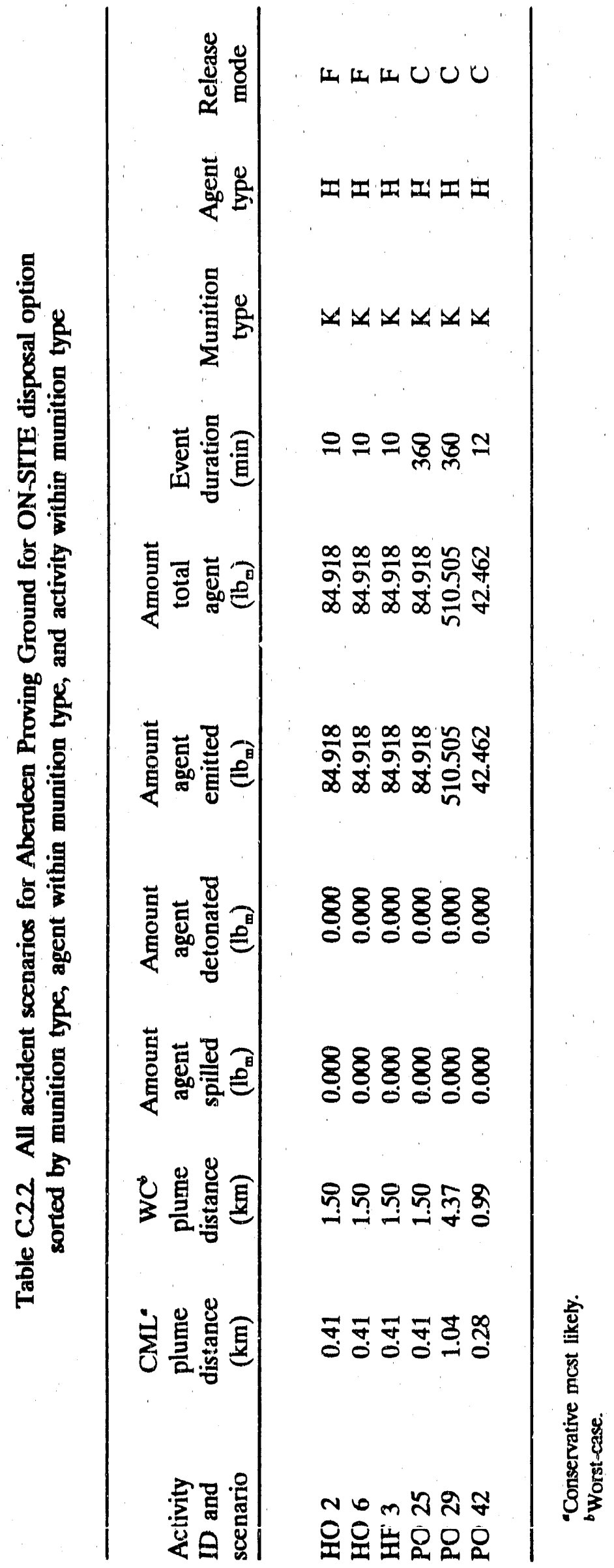




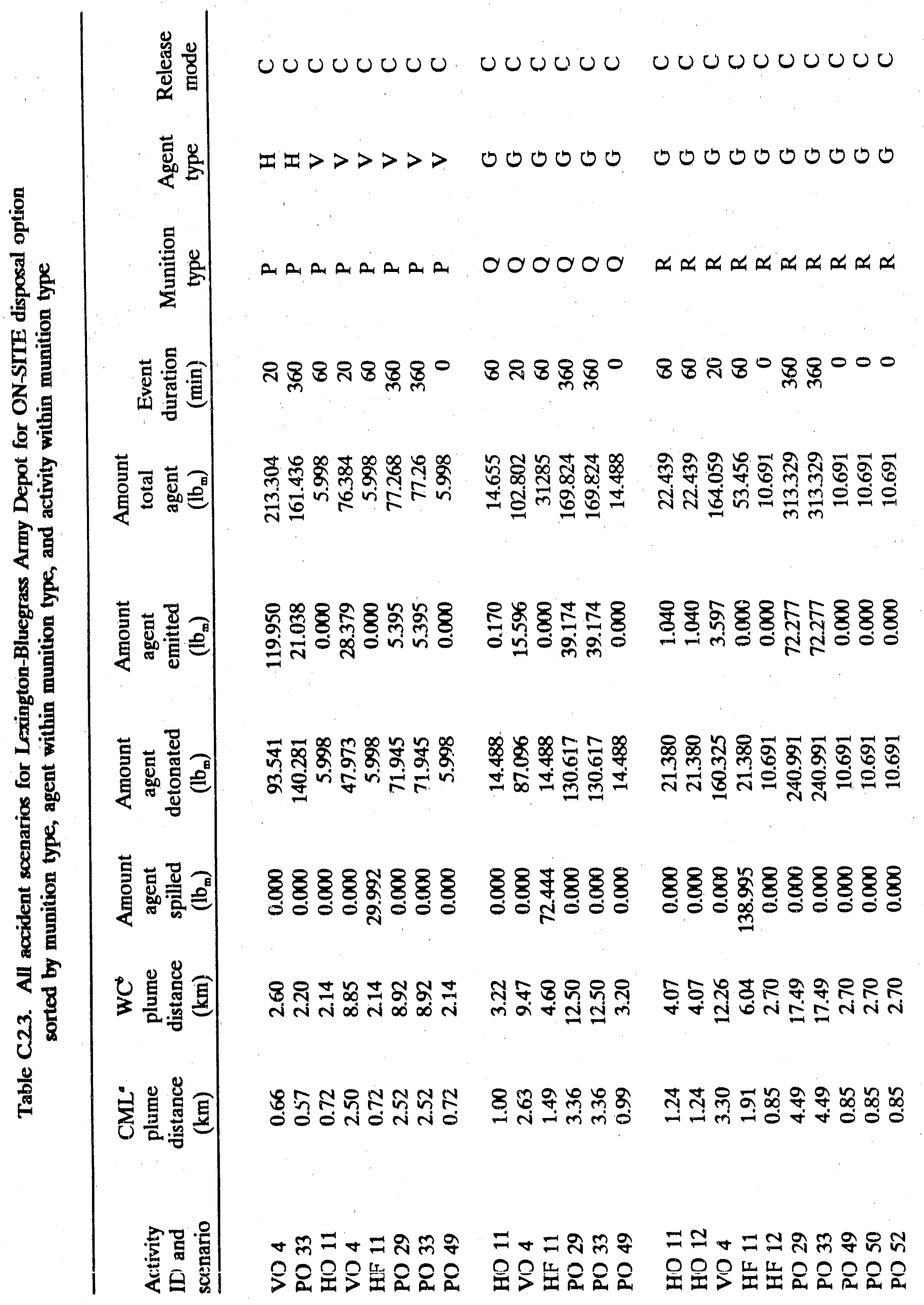




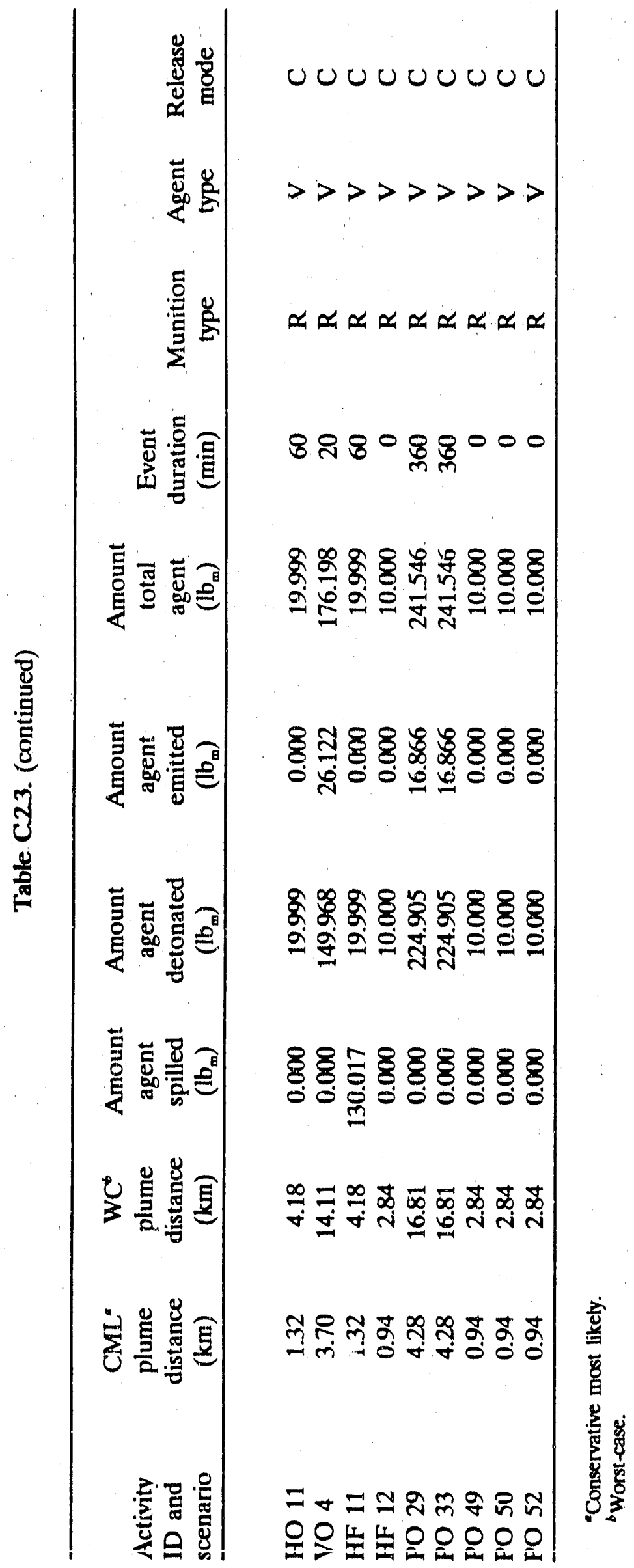




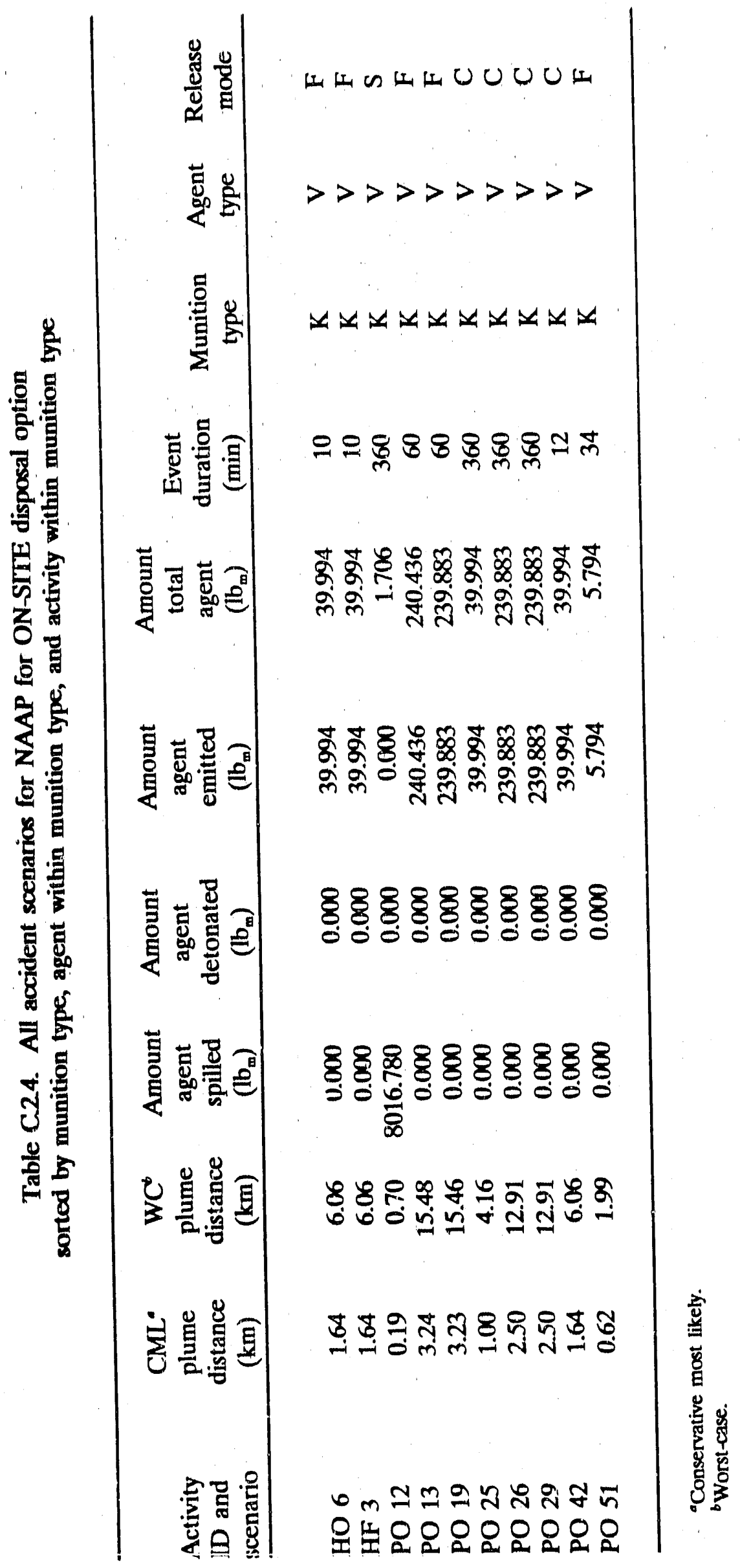




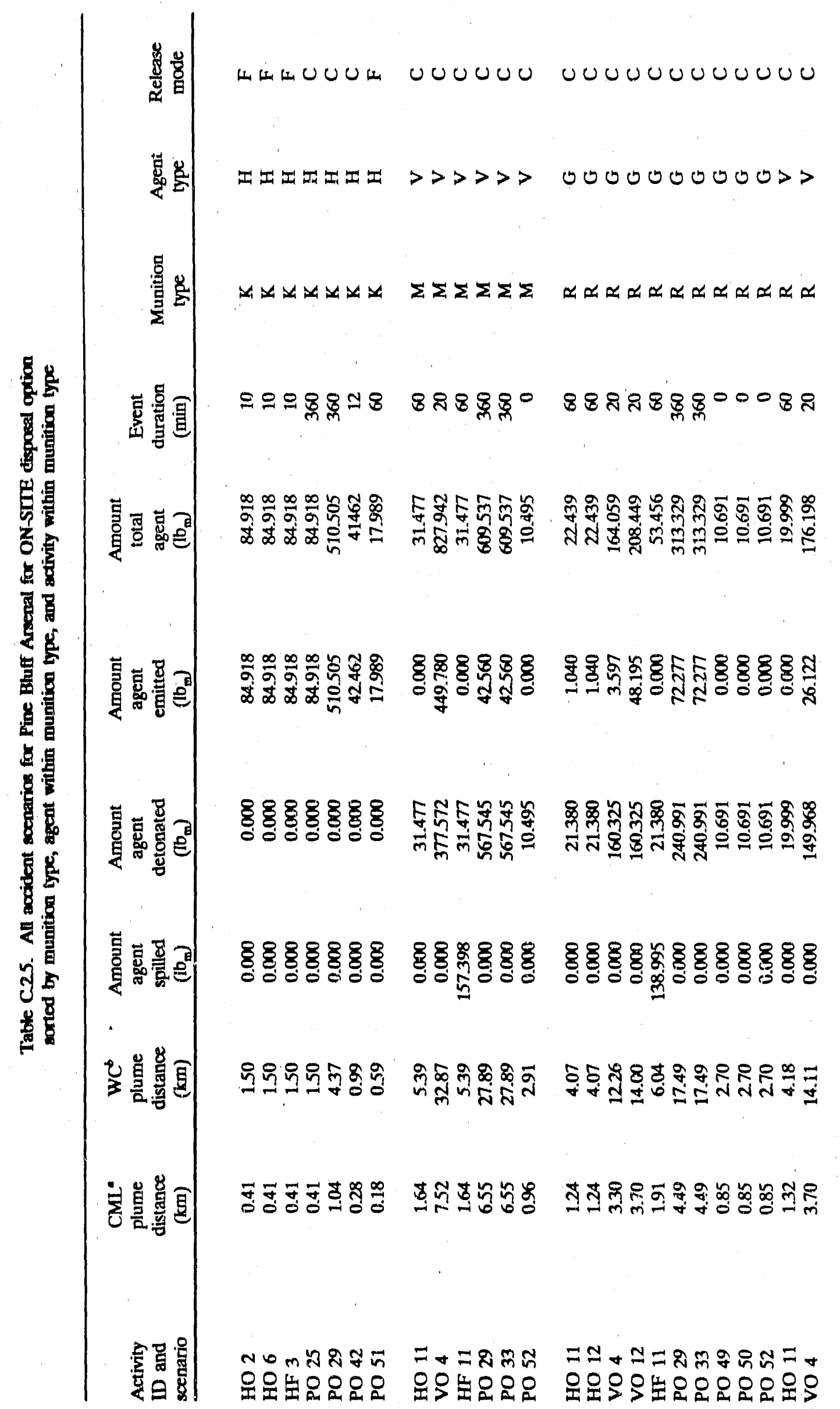




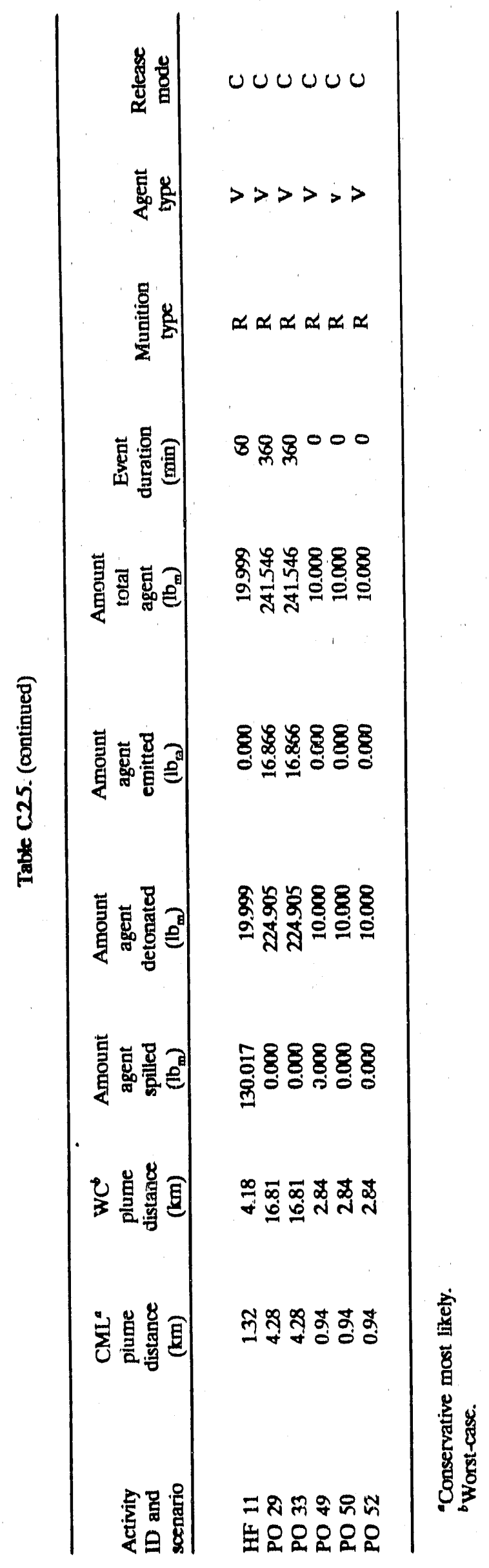




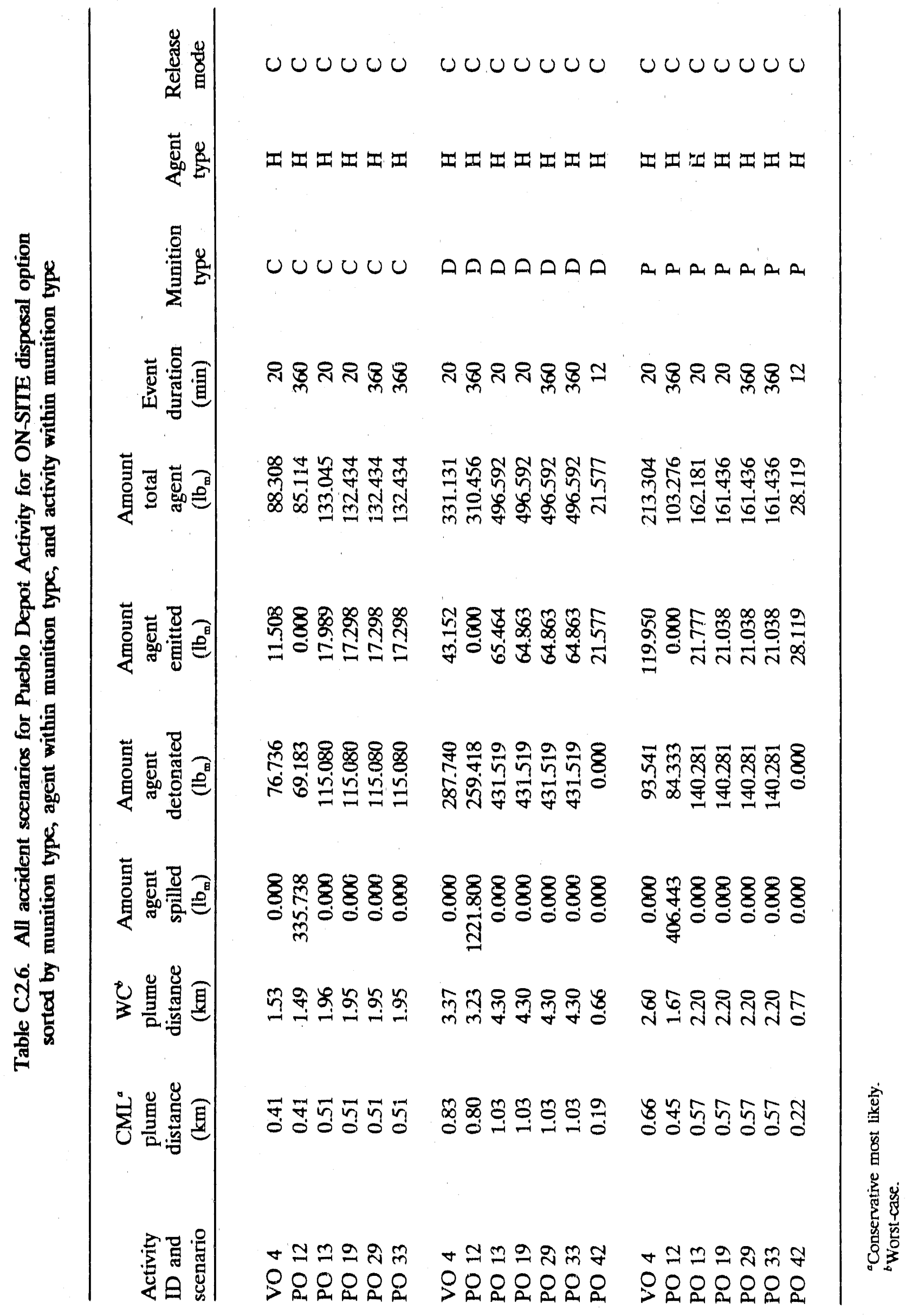




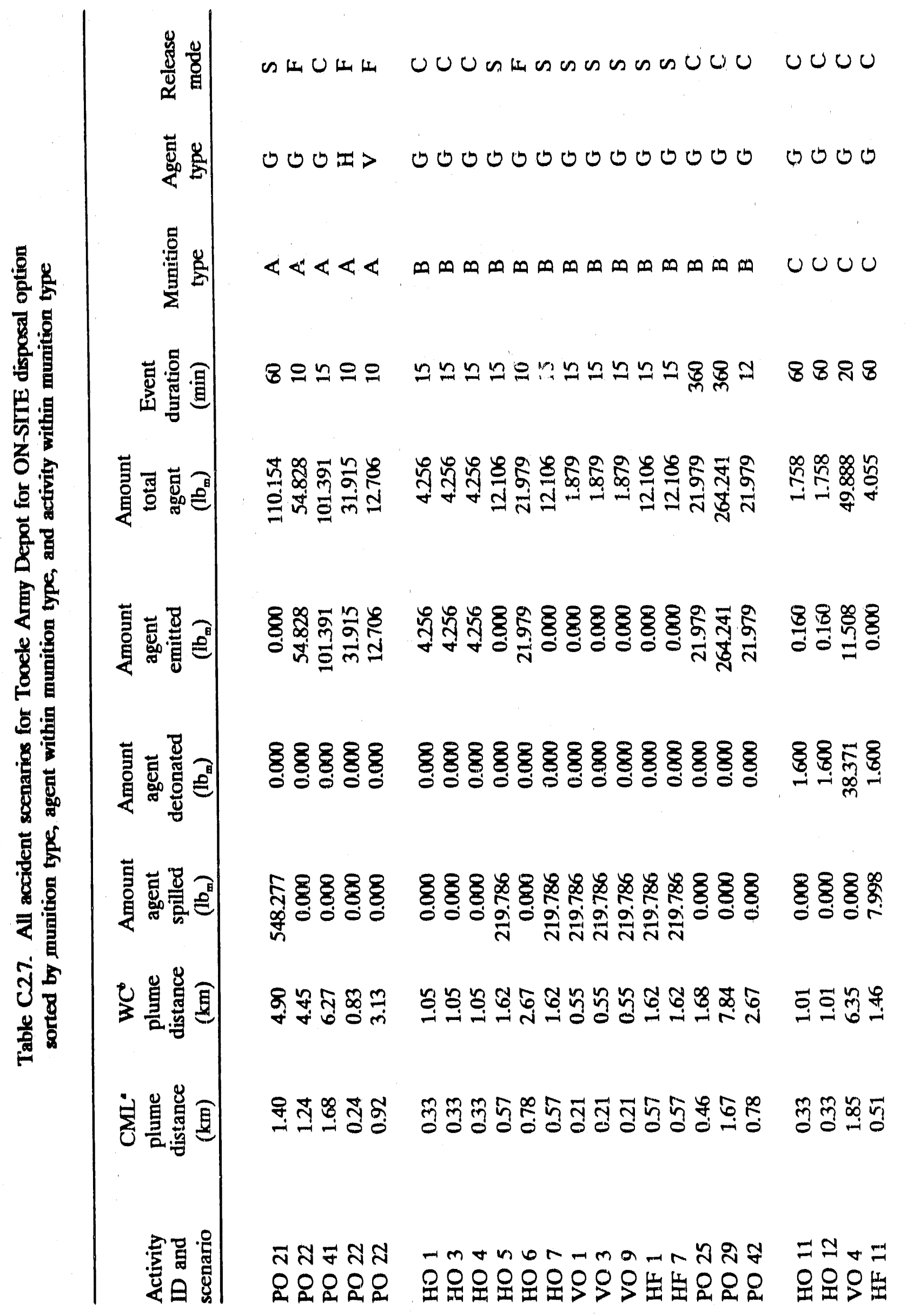




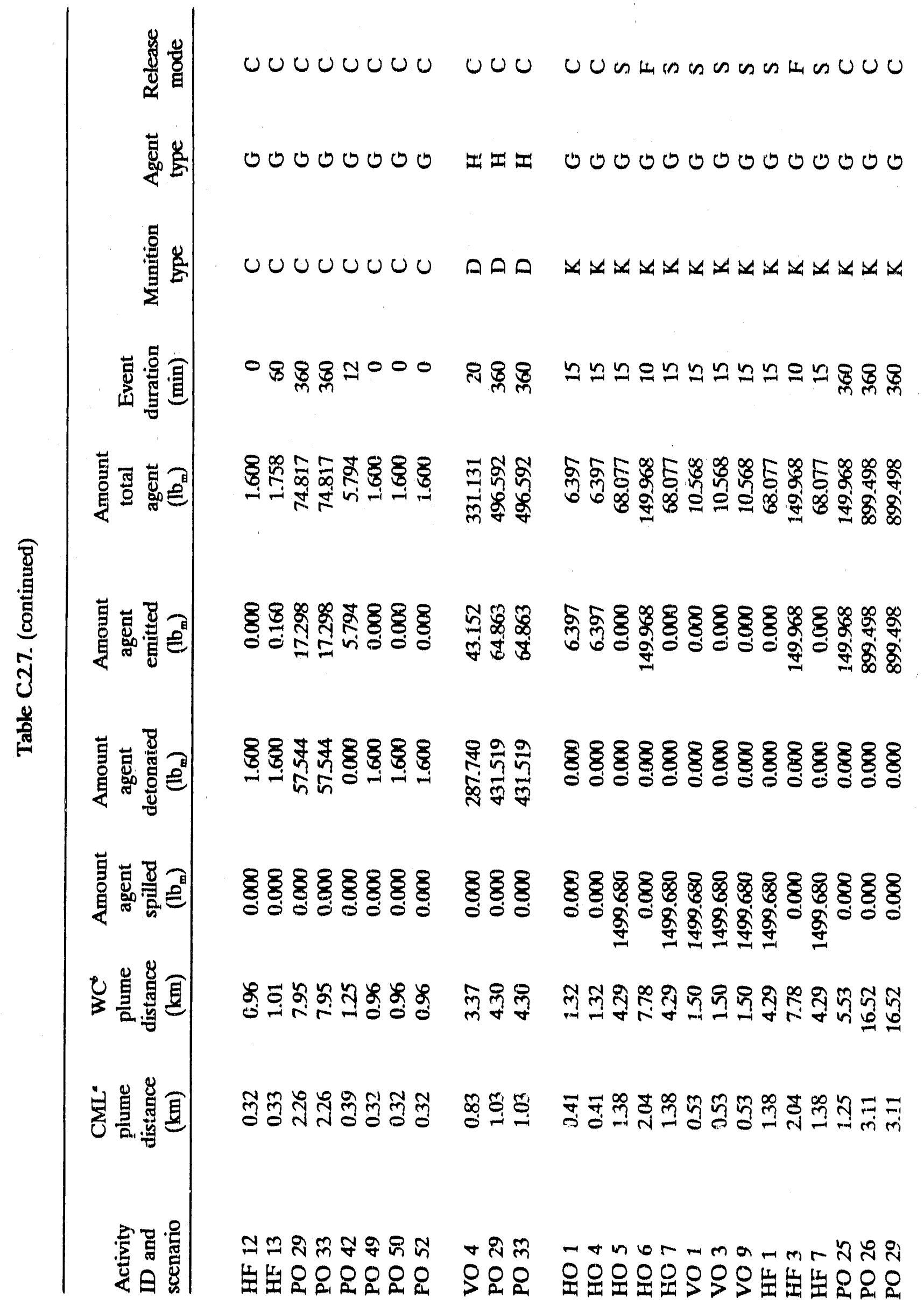




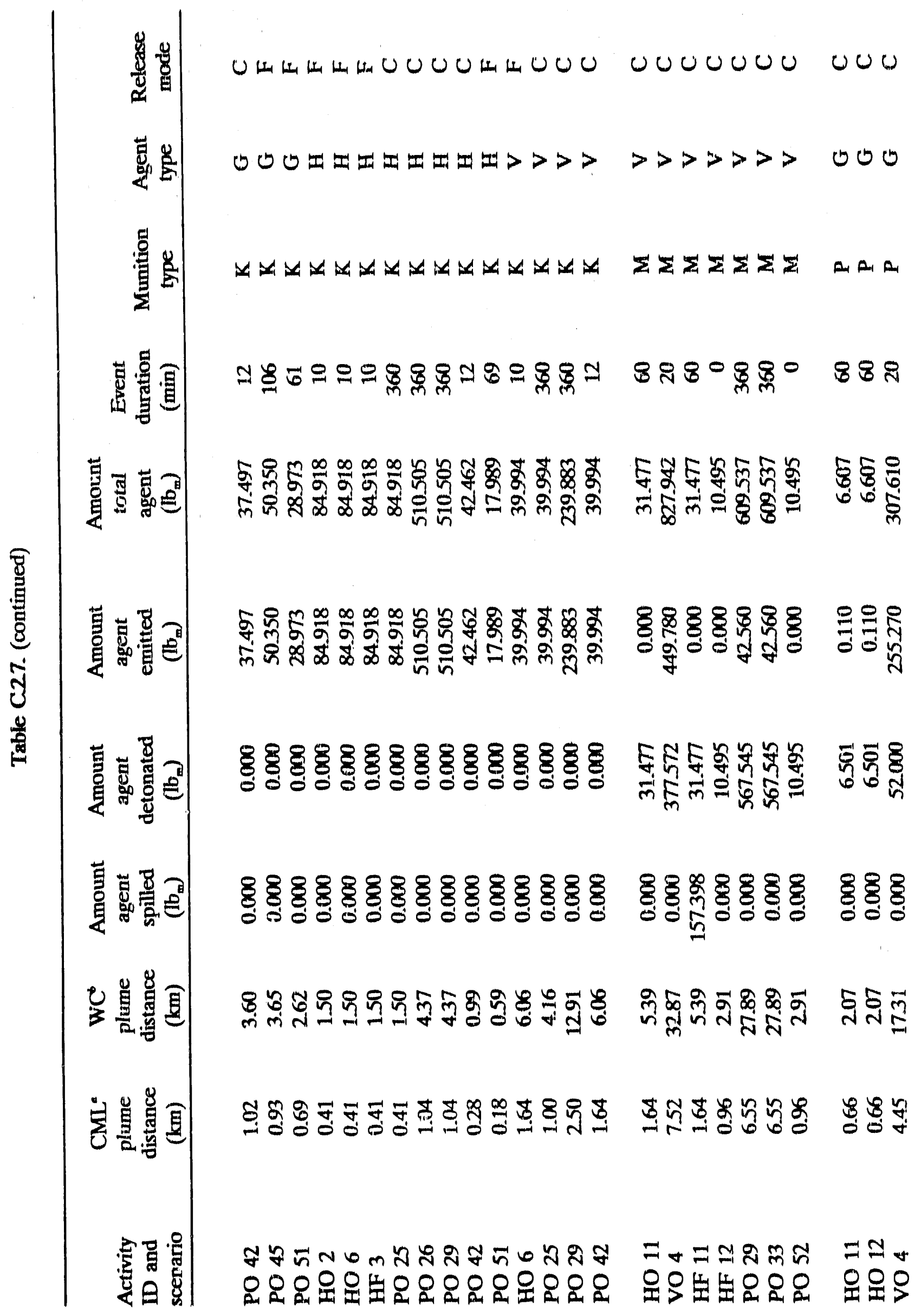




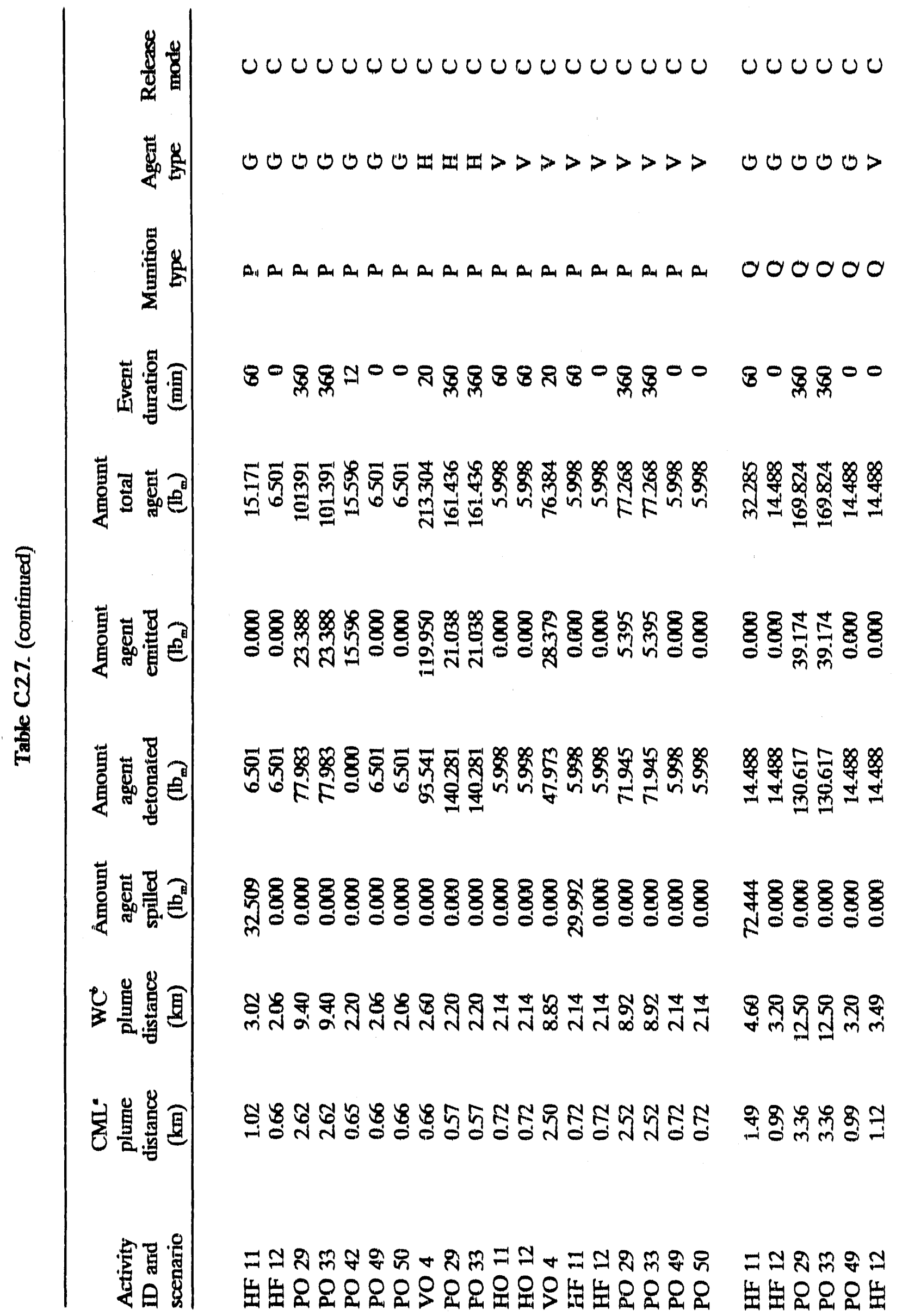




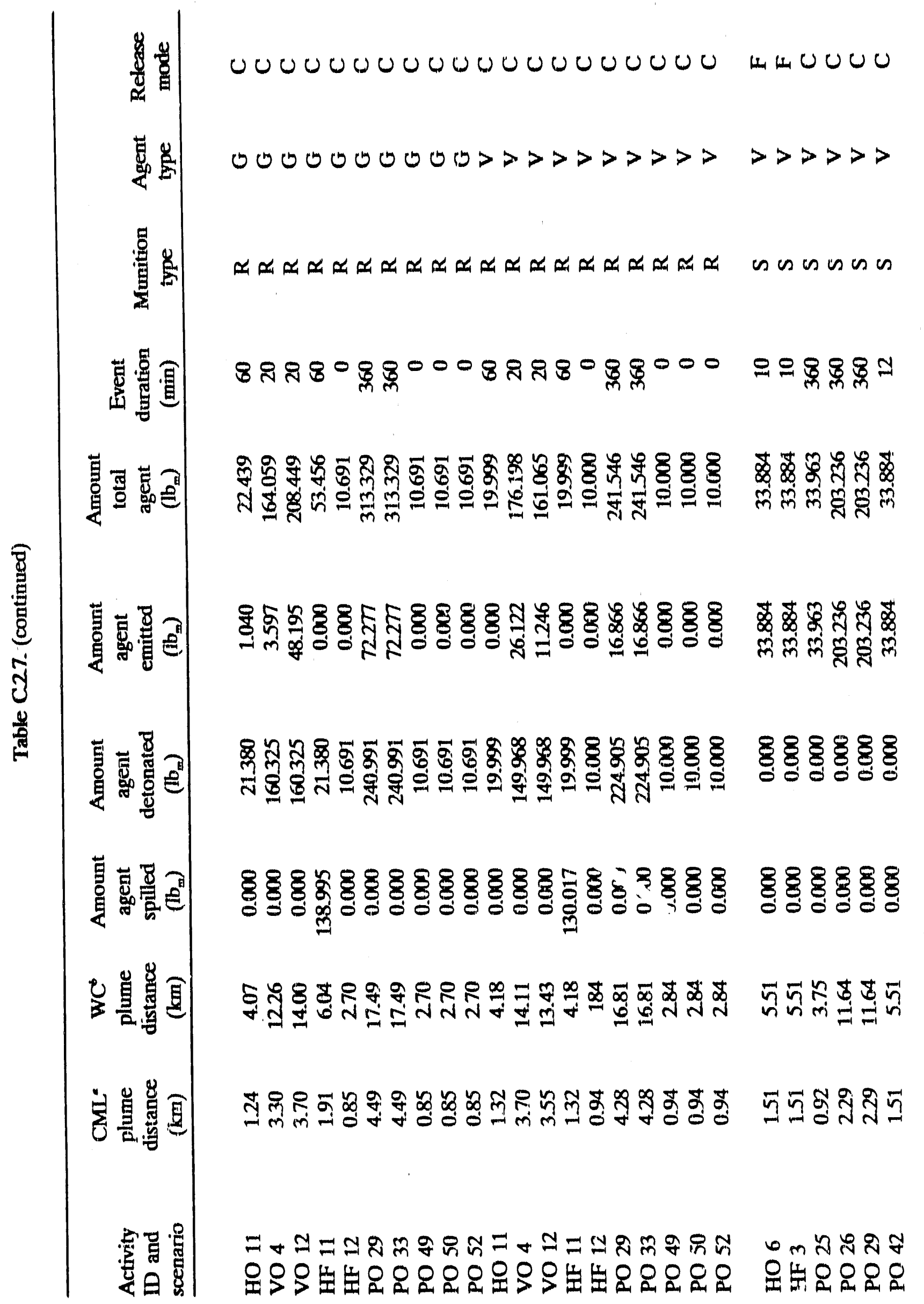




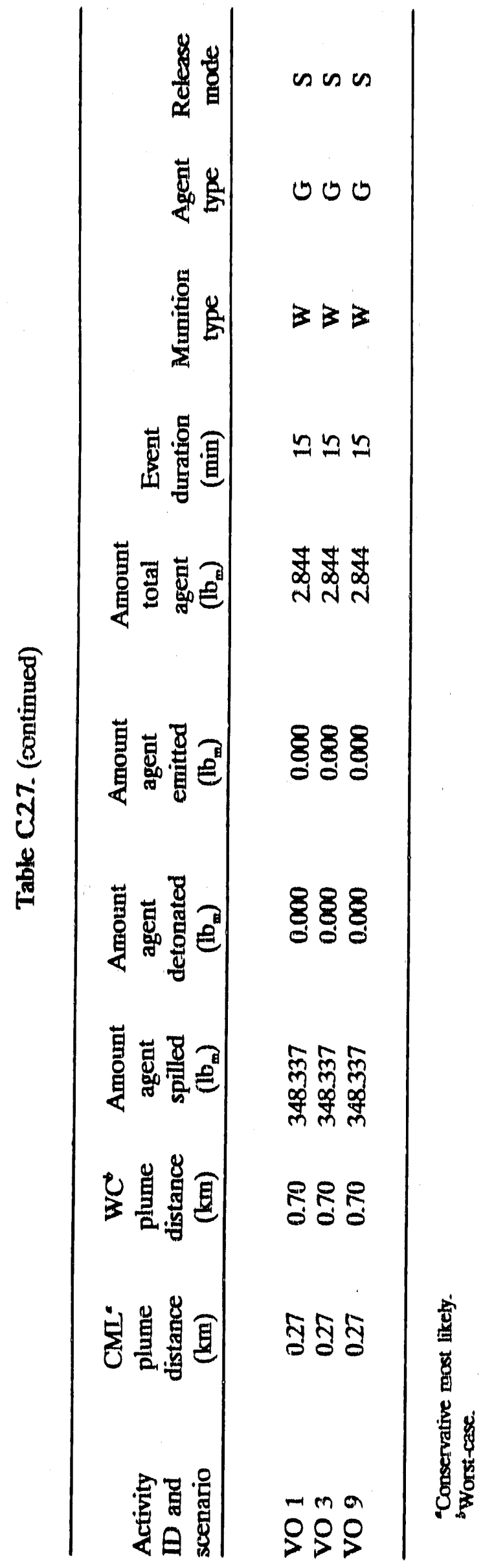




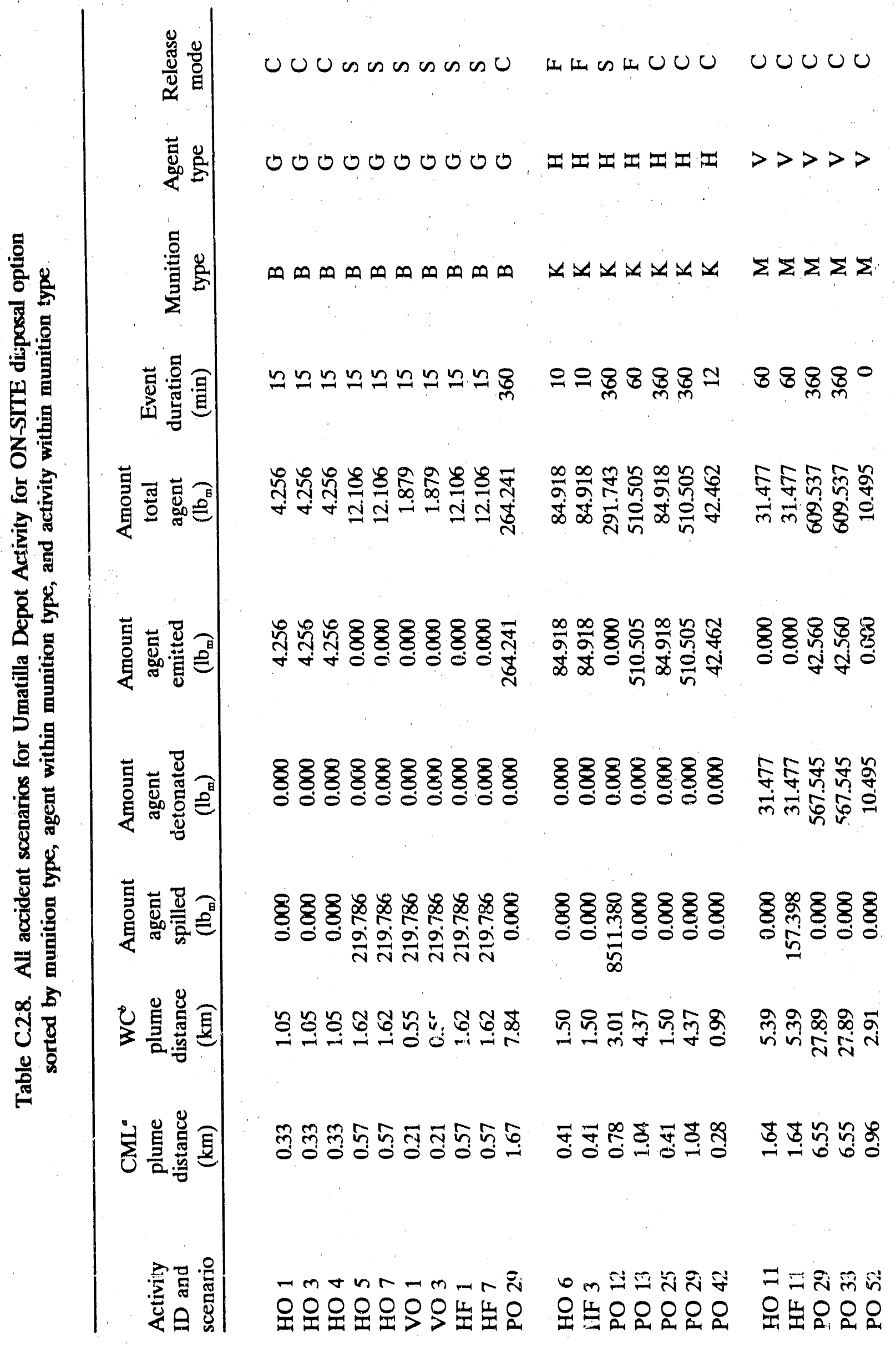




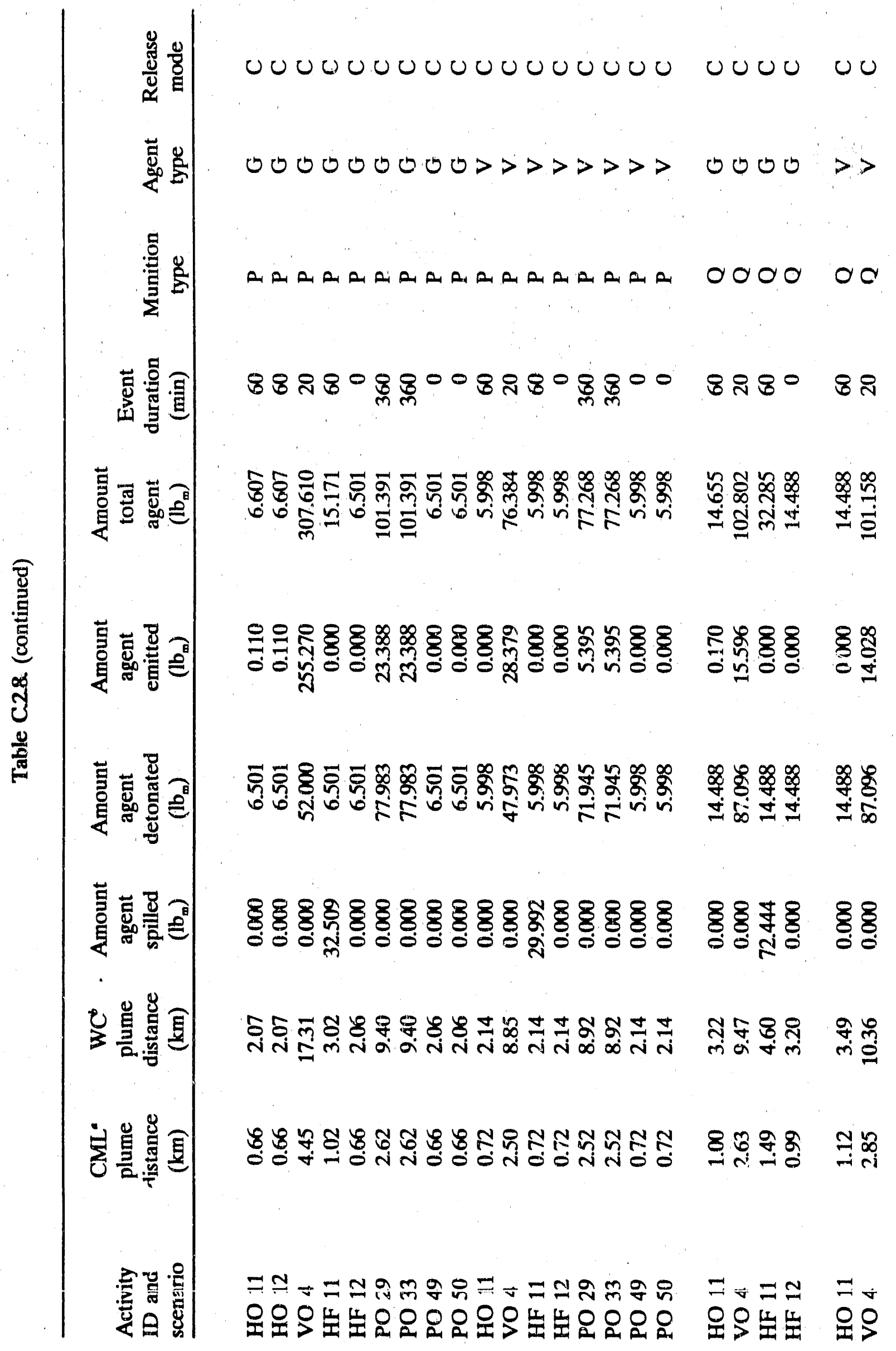




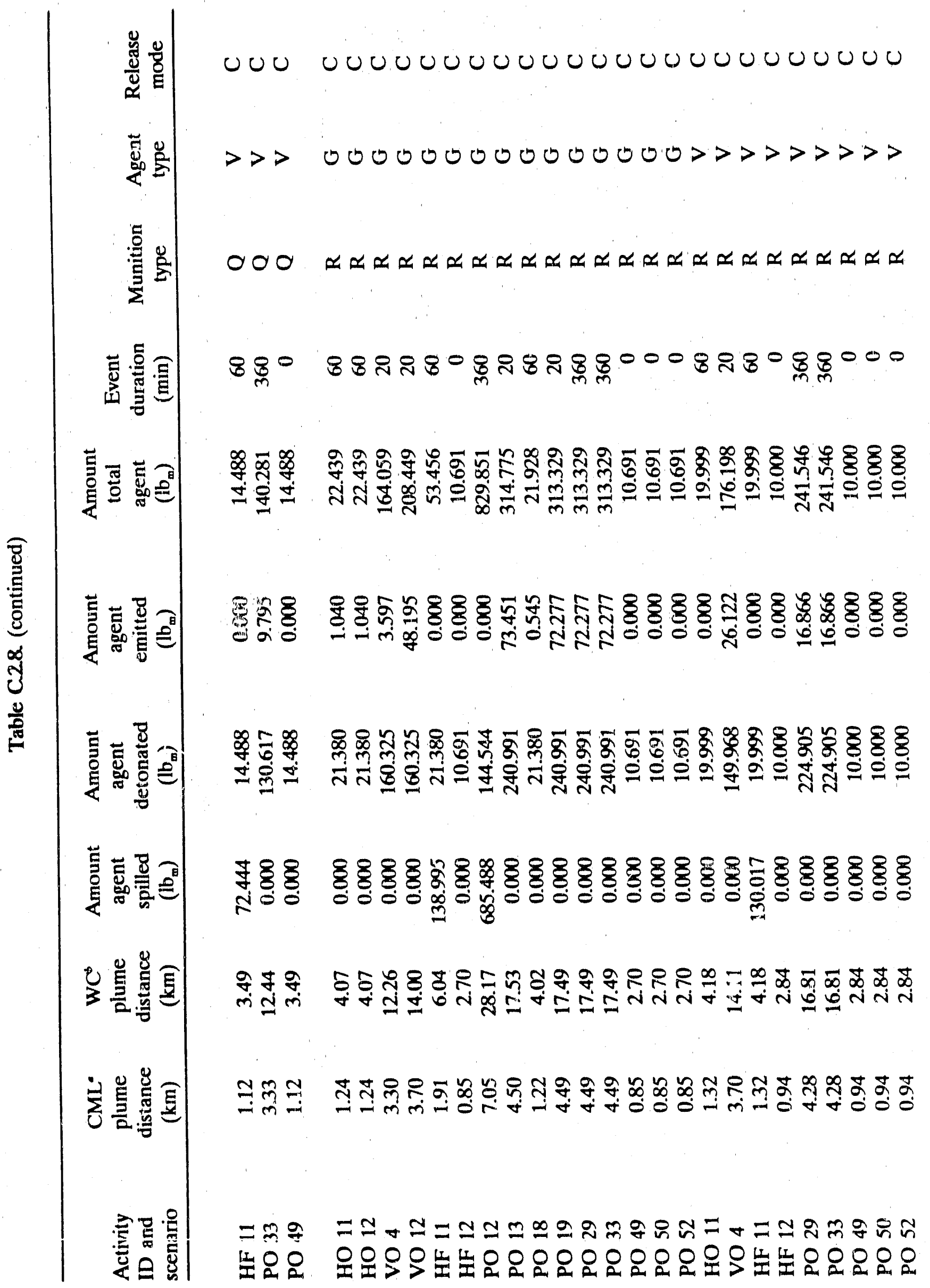




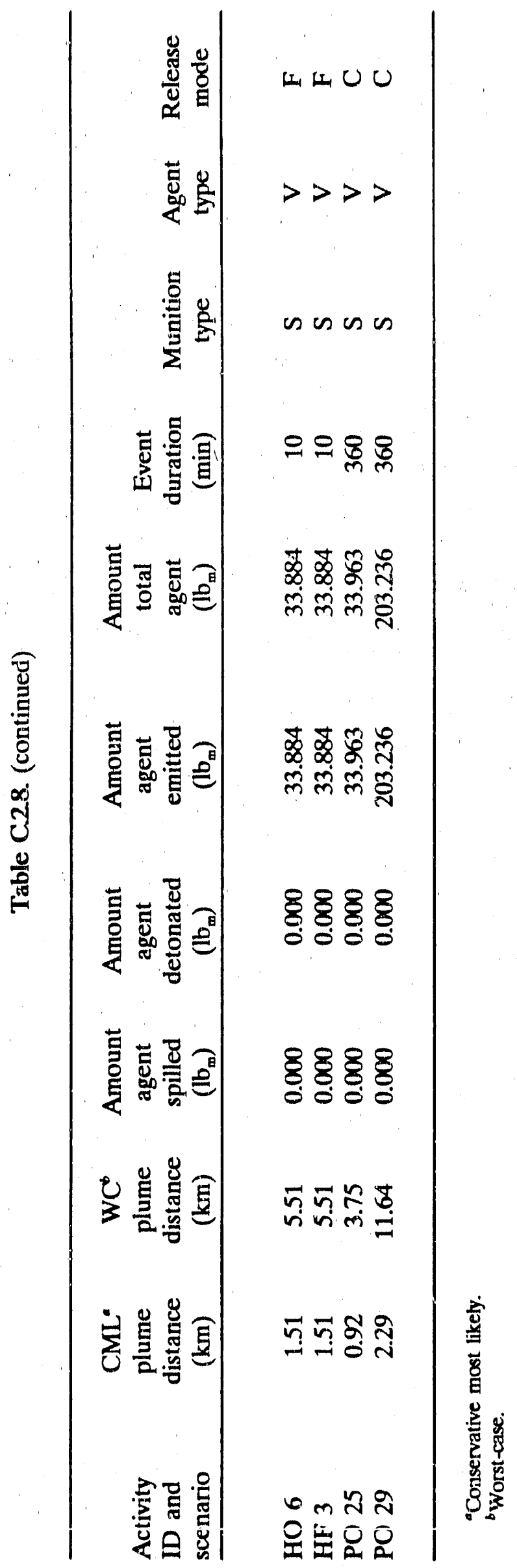




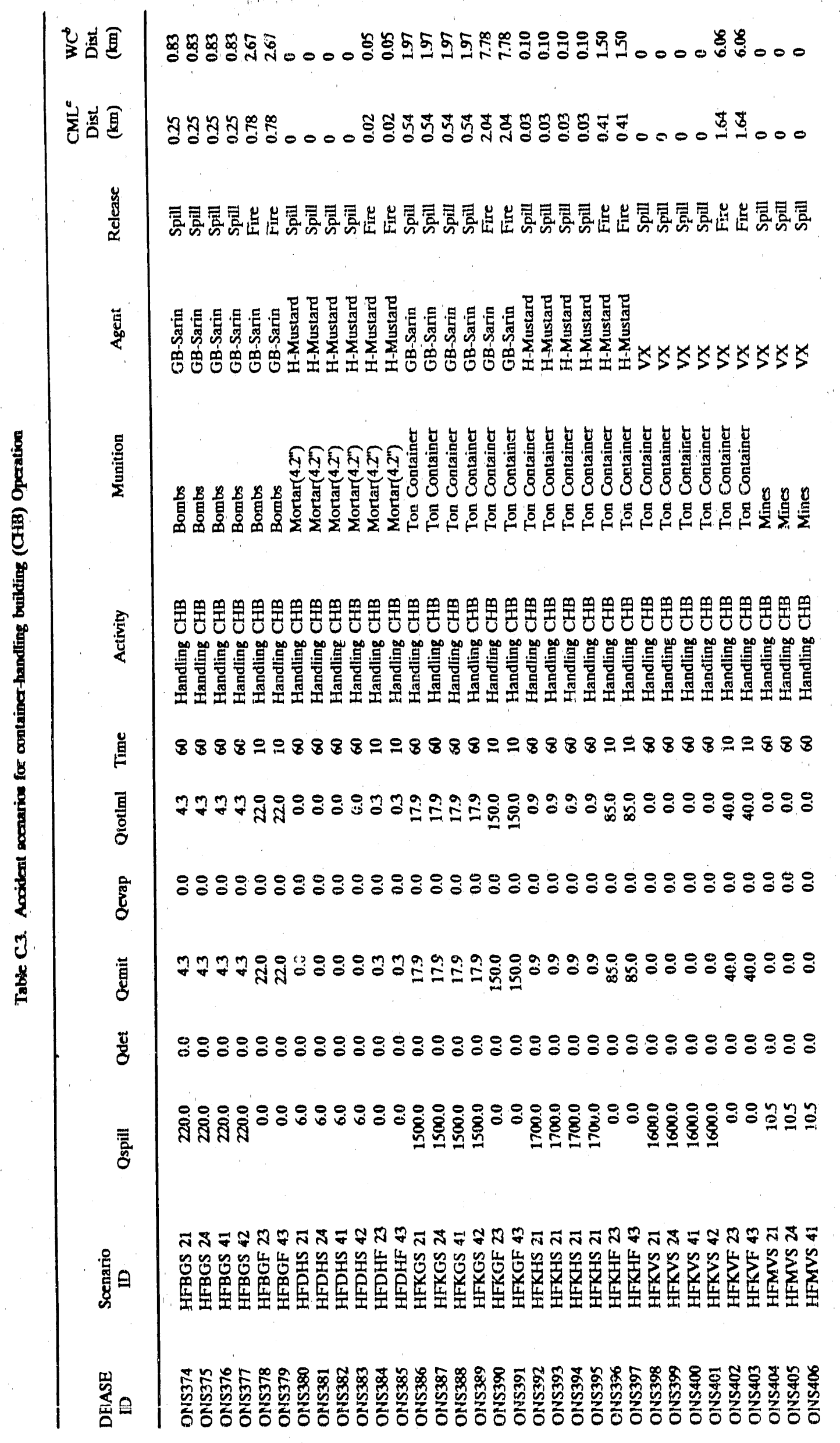




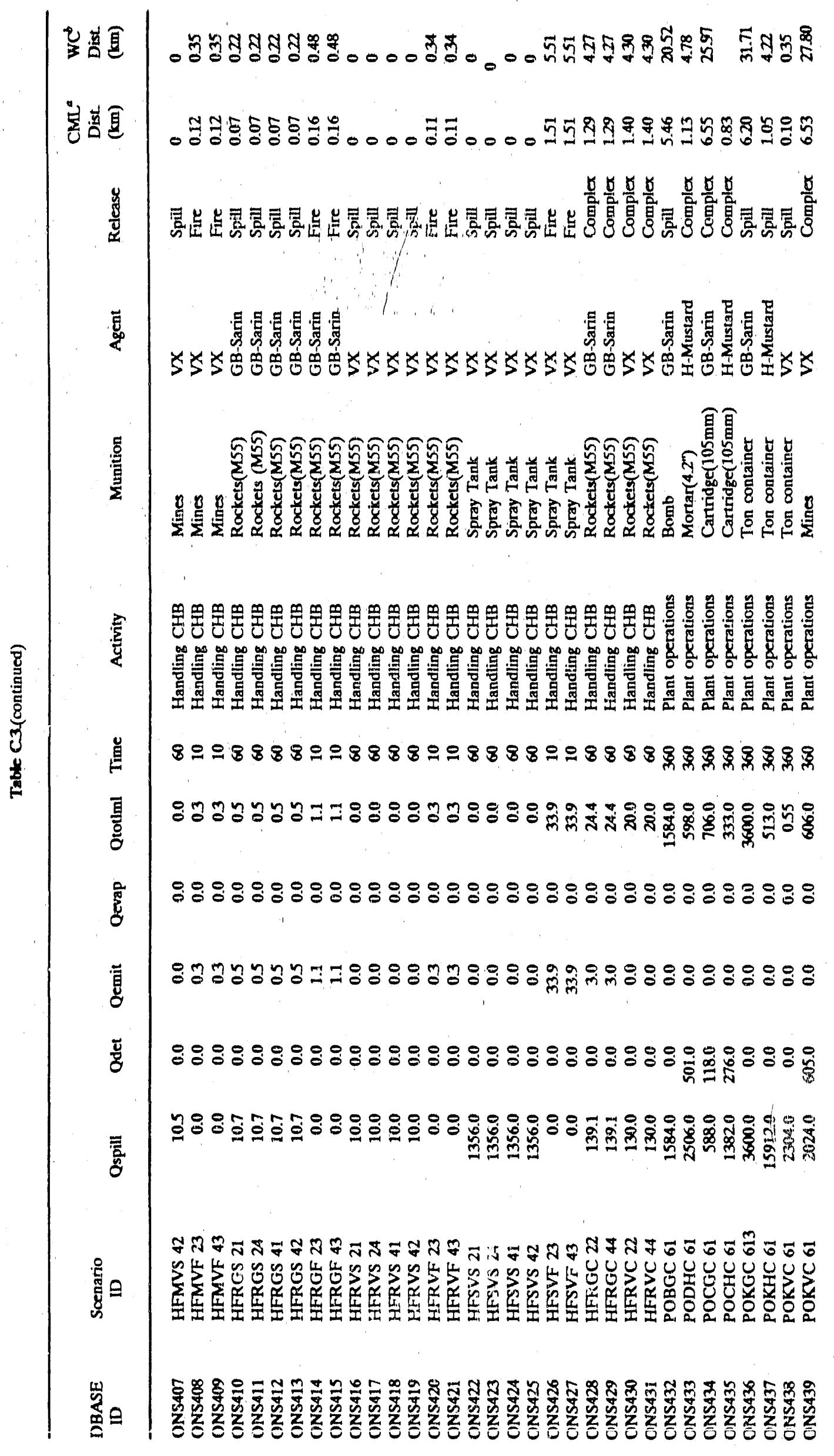




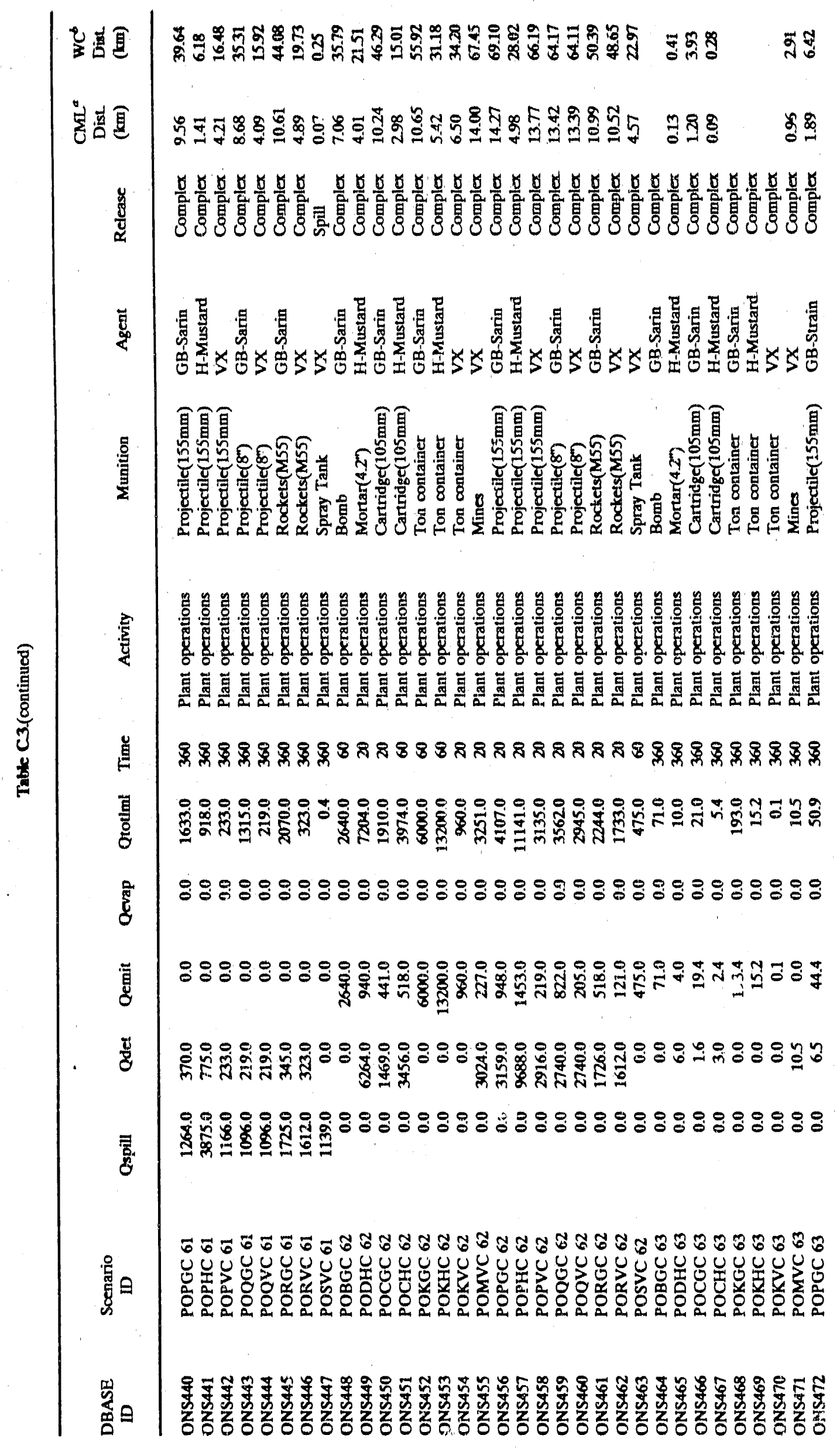




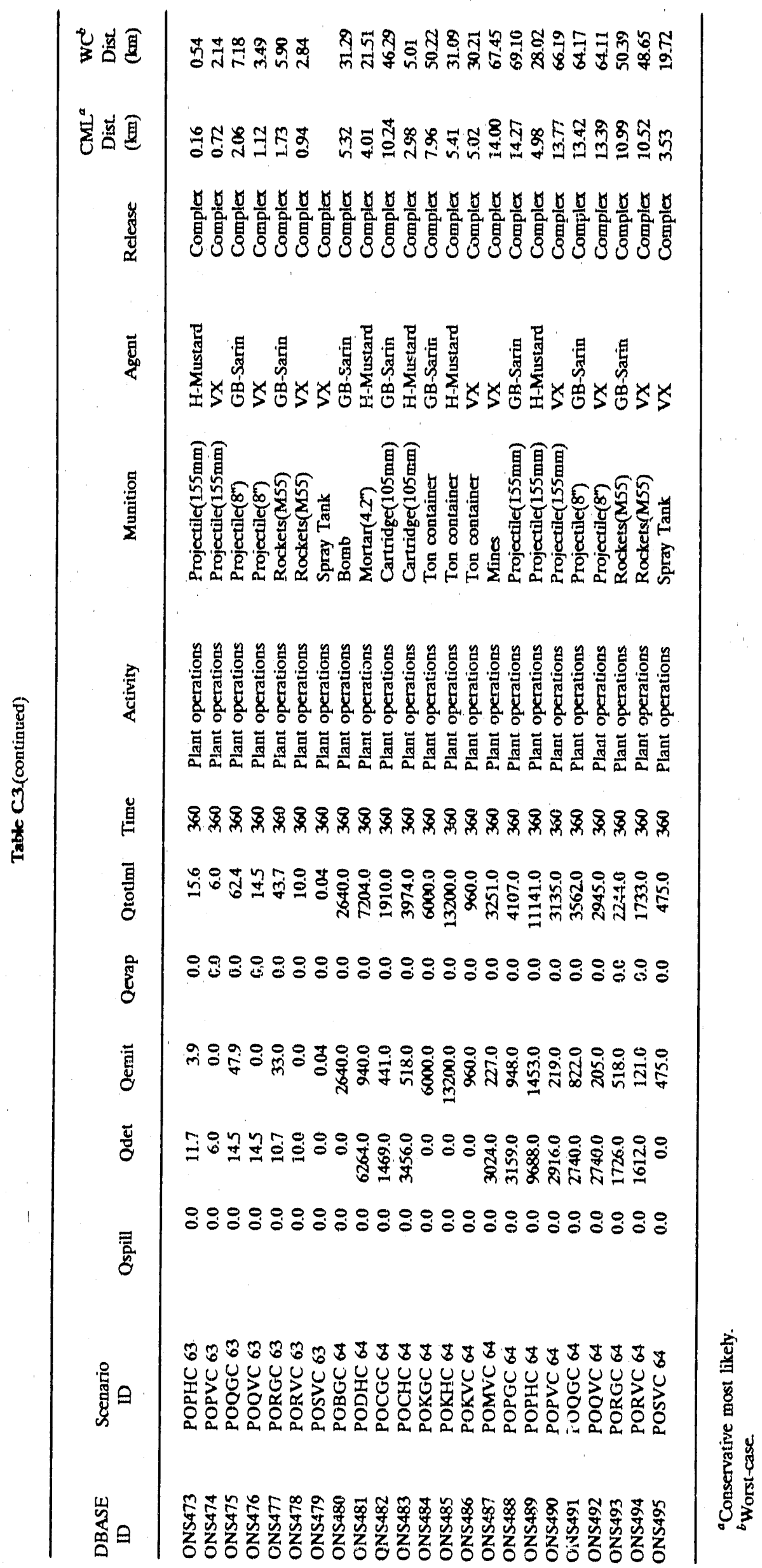



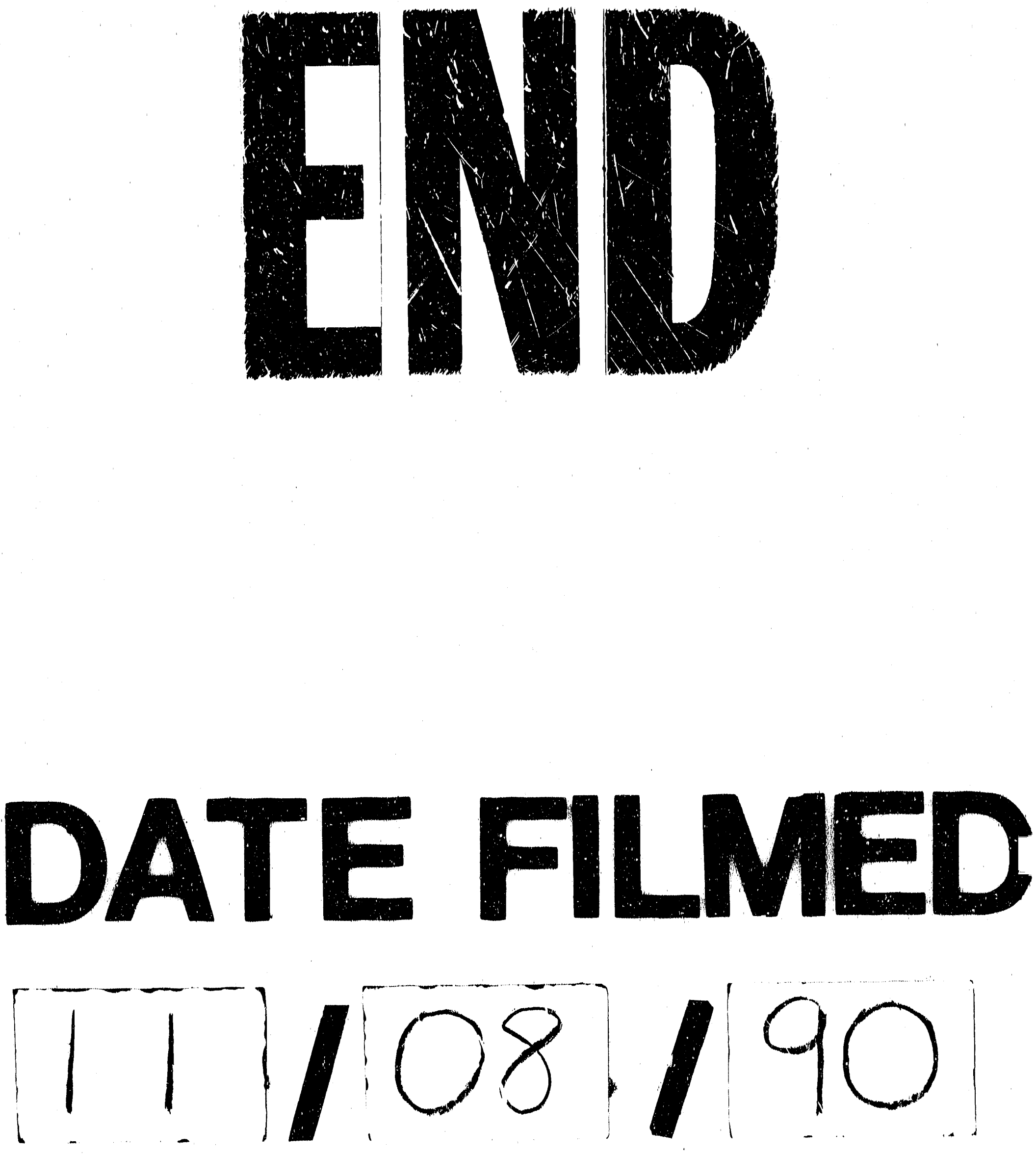
I Im 